\title{
A Chandra/ACIS Study of 30 Doradus II. X-ray Point Sources in the Massive Star Cluster R136 and Beyond
}

\author{
Leisa K. Townsley, Patrick S. Broos, Eric D. Feigelson, Gordon P. Garmire, Konstantin V. \\ Getman \\ Department of Astronomy 83 Astrophysics, 525 Davey Laboratory, Pennsylvania State University, \\ University Park, PA 16802
}

\begin{abstract}
We have studied the X-ray point source population of the 30 Doradus star-forming complex in the Large Magellanic Cloud using high-spatial-resolution X-ray images and spatially-resolved spectra obtained with the Advanced CCD Imaging Spectrometer (ACIS) aboard the Chandra $X$-ray Observatory. Here we describe the X-ray sources in a $17^{\prime} \times 17^{\prime}$ field centered on R136, the massive star cluster at the center of the main 30 Dor nebula. We detect 20 of the 32 Wolf-Rayet stars in the ACIS field. R136 is resolved at the subarcsecond level into almost $100 \mathrm{X}$-ray sources, including many typical O3-O5 stars as well as a few bright X-ray sources previously reported. Over two orders of magnitude of scatter in $L_{X}$ is seen among R136 O stars, suggesting that X-ray emission in the most massive stars depends critically on the details of wind properties and binarity of each system, rather than reflecting the widely-reported characteristic value $L_{X} / L_{b o l} \simeq 10^{-7}$. Such a canonical ratio may exist for single massive stars in R136, but our data are too shallow to confirm this relationship. Through this and future X-ray studies of 30 Doradus, the complete life cycle of a massive stellar cluster can be revealed.
\end{abstract}

Subject headings: HII regions - Magellanic Clouds - open clusters and associations: individual (R 136)

- X-rays: individual (30 Doradus) -stars: Wolf-Rayet - X-rays: stars

\section{INTRODUCTION}

Stars of virtually all masses and stages emit Xrays in their youth, although the mechanisms for X-ray emission vary with stellar mass. T-Tauri and protostars have magnetic flares with $L_{X}$ up to $10^{31-32} \mathrm{ergs} \mathrm{s}^{-1}$ (Feigelson et al. 2005). Individual OB stars emit X-rays at levels $L_{X} \sim$ $10^{-7} \mathrm{~L}_{b o l} \sim 10^{32-34} \mathrm{ergs} \mathrm{s}^{-1}$, probably arising from shocks within their unstable $>1000 \mathrm{~km} \mathrm{~s}^{-1}$ winds (e.g. Berghöfer et al. 1997). Colliding winds of binary $\mathrm{O}$ and Wolf-Rayet (WR) stars can produce shocks with $L_{X}$ up to $10^{35} \mathrm{ergs} \mathrm{s}^{-1}$ variable on timescales of days (e.g. Pollock et al. 1995). For OB stars excavating an HII region within their nascent molecular cloud, diffuse X-rays may be generated as fast winds shock the surrounding media (Weaver et al. 1977); we have recently discovered such parsec-scale diffuse emission with
Chandra observations of the Galactic high-mass star-forming regions M17 and the Rosette Nebula (Townsley et al. 2003).

30 Doradus (30 Dor) is the largest HII region in the Local Group, hosting several young, massive stellar clusters, several well-known supernova remnants (SNRs), and a vast network of superbubbles created by current and past generations of massive stars and their supernovae. At the center of 30 Dor is the massive compact stellar cluster R136 (Feast et al. 1960, called "RMC 136" in SIMBAD), the richest resolved $\mathrm{OB}$ association with dozens of 1-2 Myr-old $>50 \mathrm{M}_{\odot} \mathrm{O}$ and WR stars (Massey \& Hunter 1998), including several examples of the recently-defined earliest spectral type, O2 (Walborn et al. 2002). Including stars down to $0.1 \mathrm{M}_{\odot}$, R136 has a mass of $\sim 6 \times 10^{4} \mathrm{M}_{\odot}$ (Brandl 2005); there are $>3500$ stars within its 10 -pc diameter (Massey \& Hunter 1998). 
30 Dor contains other stellar clusters 1-10 million years old, the $\sim 20$ Myr old stellar cluster Hodge 301 (Grebel \& Chu 2000), and a new generation of deeply embedded high-mass stars just now forming (Walborn et al. 2002, and references therein), making it a prime example of sequential and perhaps triggered star formation. Recent radio observations have revealed water (van Loon \& Zijlstra 2001) and OH (Brogan et al. 2004) masers in 30 Dor, also signifying ongoing star formation. The presence of these young objects as well as a large population of widely-distributed WR stars (Moffat et al. 1987) and evolved supergiants $\sim 25$ Myr old (Walborn \& Blades 1997) shows that 30 Dor is the product of multiple epochs of star formation. The new generation of embedded stars currently forming may be the result of triggered collapse from the effects of R136 (Brandner et al. 2001).

We observed 30 Dor with Chandra's Advanced CCD Imaging Spectrometer (ACIS) camera for $\sim 21 \mathrm{ks}$ in 1999 September; see Figure 1. R136 was positioned at the aimpoint of the $17^{\prime} \times 17^{\prime}$ ACIS Imaging Array (ACIS-I). The reader is referred to the accompanying paper (Townsley et al. 2005, henceforth Paper I) for a review of previous X-ray studies of the 30 Dor complex, a description of our Chandra observations and data analysis, and a detailed treatment of the superbubbles, SNRs, and other diffuse structures in the field. Here we consider the point sources located in the stellar clusters and distributed across the field. Our methods for detecting and extracting sources are described in $\S 2$. The X-ray properties of these sources and counterparts identified from other studies are tabulated in $\S 3$. All luminosities are calculated assuming a distance of $50 \mathrm{kpc}$.

Many of the 180 ACIS-I point sources identified in this observation are early-type stars or stellar systems associated with the very dense, massive stellar cluster R136 (seen as a large concentration of sources at the center of Figure 1). Our efforts to resolve and identify sources in R136 are detailed in $\S 4$. Several point sources are spatially associated with the N157B SNR; some may be clumps in the diffuse emission, but the cospatial OB association LH 99 may account for true point sources in this region. Several dozen faint sources are scattered across the field, notably the well-known WR stars R130, R134, R139, R140a,
R140b, R144, and R145. Most X-ray sources without visual or infrared (IR) counterparts are likely background active galactic nuclei (AGN), but some appear to have unusually hard spectra and may be low-luminosity X-ray binaries associated with the 30 Dor complex. These distributed sources are described in $\S 5$.

\section{SOURCE DETECTION AND CHAR- ACTERIZATION METHODS}

Starting with the three Level 1 event lists that make up this unusual dataset (see Table 1 in Paper I), we performed several custom data processing steps to filter and improve the individual event lists, as described in Paper I. Source detection was then performed on the merged data using wavdetect (Freeman et al. 2002) with a threshold of $1 \times 10^{-5}$ due to the presence of diffuse emission (Townsley et al. 2003). Source searching was performed in three bands $(0.5-2 \mathrm{keV}, 2-8 \mathrm{keV}$, and $0.5-8 \mathrm{keV})$ using images binned at 1,2 , and 4 "sky pixels" ( $0^{\prime \prime} .5,1^{\prime \prime}$, and $2^{\prime \prime}$ respectively) and the resulting 9 sourcelists merged. Considering only sources on the ACIS-I array, this series of wavdetect runs resulted in a list of 167 potential point sources. Inspecting the data showed that several of these potential sources were actually clumps in the diffuse emission and that wavdetect had missed several likely sources in the core of R136.

Due to the high density of point sources in the R136 core, the ACIS data suffer from source confusion in this region. Since this cluster was placed at the aimpoint of the ACIS-I array, R136 sources have sharply-peaked, sub-arcsecond Point Spread Functions (PSFs), so our knowledge of the X-ray emission of those sources might benefit from superresolution techniques. Pursuant to this idea, we applied ACIS sub-pixel resolution software to the photon events (Mori et al. 2001), formed several high-resolution images of the R136 region from those events, reconstructed those images using a simple maximum likelihood algorithm (described below), and used the reconstructions to identify additional X-ray point sources in R136. Similar reconstructions have been performed on ACIS observations of SN1987A (e.g. Park et al. 2005) and gravitational lenses (e.g. Chartas et al. 2004) and revealed subarcsecond spatial features that were confirmed in other wavebands and proved essen- 
tial for understanding the X-ray emission of these targets.

Only the ACIS-I array was considered in our point source searching and characterization; the S3 and S4 chips in the ACIS Spectroscopy Array also show emission consistent with point-like sources (see Figure 2 in Paper I), but the large PSF at these locations ( $>20^{\prime}$ off-axis) and confusion with the extensive diffuse emission there makes quantitative analysis of these sources difficult. As described in Paper I, other Chandra and XMM-Newton observations are better-suited to the analysis of these sources.

\subsection{Image Reconstruction and Source Identification}

To elucidate the source population in R136 and in the subgroup R140 (Moffat et al. 1987), we performed maximum likelihood image reconstructions on these fields using the IDL routine max_liklihood.pro in the IDL Astronomy User's Library maintained by Wayne Landsman ${ }^{1}$. These reconstructions are built into PSB's ACIS Extract software $^{2}$ that performs source extraction and automated spectral fitting (Broos et al. 2002). The user can perform maximum likelihood image reconstruction for every extracted source if desired; the code builds an image of the source "neighborhood" (a region $\sim 50^{\prime \prime} \times 50^{\prime \prime}$ in size for on-axis sources) and uses that source's PSF at an energy specified by the user (1.5 keV in this case) obtained from the CALDB's PSF library in the reconstruction. Since the true Chandra PSF varies substantially with off-axis angle, we chose to reconstruct the neighborhoods around two sources in R136 separated by $\sim 30^{\prime \prime}$ in order to cover the entire region suffering from source confusion using appropriate PSFs. Our goal was to supplement the candidate list of point sources in very crowded parts of the field, where both wavdetect and visual examination fail to provide a good census of sources.

While the R140 reconstruction did not reveal any new point sources in that cluster, the R136 reconstruction separated the unresolved emission in this region into many peaks, hinting that many

\footnotetext{
${ }^{1}$ http://idlastro.gsfc.nasa.gov/homepage.html

${ }^{2}$ The ACIS Extract code is available at http://www.astro.psu.edu/xray/docs/TARA/ae_users_guide.html.
}

more X-ray point sources were present in this region than the $\sim 10$ that wavdetect revealed (see $\S 3)$. We quantified peaks in the reconstructed image using the IDL Astronomy User's Library routine find.pro, an IDL version of the find routine in Peter Stetson's DAOPHOT package (Stetson 1987). This routine gives the centroid position of each peak and a measure of its shape and brightness. Peaks that were clearly associated with single events in the data were filtered out using these shape and brightness criteria. Then using SAOImage $D S 9^{3}$, we overlaid apertures representing the $90 \%$ on-axis PSF contour onto an image of the ACIS data, placed at the locations of reconstruction peaks. Only those peaks that contained at least two ACIS events within the 90\% aperture were kept for further consideration. This list of potential sources from maximum likelihood reconstruction was merged with that from wavdetect, yielding 288 candidate sources on the ACIS-I array.

We then performed a preliminary event extraction for these candidate sources using ACIS Extract, which includes a calculation of the probability that the events contained in a given extraction region are due solely to Poisson variations in the local background (a quantity that we will later call $P_{B}$ in Tables 1 and 2). Note that we did not allow reconstruction peaks that were generated from single isolated X-ray events to be considered X-ray point sources, regardless of their statistical likelihood, due to the presence of diffuse emission in the region. This probability provides an objective estimate of source validity; at this stage of the analysis, we required that each candidate source have no more than a $1 \%$ likelihood of being a background fluctuation in order to be considered valid. This resulted in a final list of 180 acceptable potential sources ${ }^{4}$, ranging in brightness from 1.3 to

\footnotetext{
${ }^{3}$ http://hea-www.harvard.edu/RD/ds9/

${ }^{4}$ Note that the validity of an individual point source $S$ often cannot be judged without consideration of the full catalog of sources. The validity of $S$ depends on the local background estimate for $S$ which must obviously exclude regions thought to contain other point sources. Thus members of the catalog must be chosen before their final source validity is calculated, and source validity estimates are an obvious way to judge membership in the catalog. We have not attempted to define a source identification and local background estimation process that results in a completely unique solution. The initial set of 288 potential sources
} 
6187 net counts. Since this source validity test relies on local background estimates, extremely faint sources can be reliably detected in regions of very low background; such conditions exist in the R136 core. Given the extraordinarily high source density in R136, though, even the reconstructed sources may actually be source blends.

Local background estimates, hence $P_{B}$ used in an absolute sense, are subject to substantial uncertainty in our sparse datasets. In 30 Dor this is complicated by the extensive, highly-structured diffuse emission in the field; to get a reasonable number $(\sim 100)$ of background counts one must travel far $\left(\sim 15^{\prime \prime}\right.$ for our on-axis sources $)$ from the source, making the background estimate not as "local" as one might wish. We use $P_{B}$ as a way to make reasonable distinctions between our primary sourcelist (Table 1, in which we have substantial confidence), our tentative sourcelist (Table 2, containing sources still quite likely to be real), and failed candidate sources.

To test the stability of the primary sourcelist definition criterion $\left(P_{B}<0.003\right)$ to changes in the local background, we deleted the 33 sources in Table 2 with $P_{B}>0.01$ (leaving 30 tentative sources) and re-extracted the remaining 147 sources, recalculating $P_{B}$ for each source. Most of the deleted sources were in R136; when they were removed from the input sourcelist, ACIS Extract treated their photons as background. We wanted to test whether this added background substantially altered the detection significance of the remaining R136 sources, as a way to test the fidelity of using image reconstruction to nominate sources for the ACIS Extract process. After this second extraction, 32 of the 147 sources had $P_{B}>0.003$ and would be considered tentative; of those 32 , 15 had $P_{B}>0.01$. A few sources with $P_{B}$ near the cut-off value of 0.003 changed tables: four primary sources (ACIS \#33, 94, 106, and 116) moved to the tentative table and two tentative sources (ACIS \#97 and 123) moved to the primary table. All other primary sources continued to have $P_{B}<$ 0.003 ; this demonstrates that our method of select-

was extracted and then cut at the threshold of $1 \%$ likelihood of being a background fluctuation. This trimmed list of 180 potential sources was then re-extracted, resulting in different local background estimates and different source validity metrics $P_{B}$. Thus some $P_{B}$ values in Table 2 are $>1 \%\left(\log P_{B}>-2\right)$. ing high-quality point sources using ACIS Extract is stable to changes in the tentative sourcelist and local background. Thus we retained the original 180 potential X-ray point sources for further analysis, divided into primary and tentative sourcelists based on $P_{B}$ from the first extraction. Obviously, users of these data should view tentative sources with appropriate caution based on the value of $P_{B}$ for each source.

\subsection{Source Extraction}

With the caveats of the last section in mind, we extracted a final set of source characteristics for our trimmed list of 180 sources. Positions for the sources derived from reconstructions were unaltered; positions for wavdetect sources were recomputed during the preliminary extractions. Isolated sources were assigned extraction regions corresponding to the $90 \%$ contours of their PSFs. Crowded sources were assigned extraction regions corresponding to smaller (down to 40\%) PSF fractions to ensure that virtually no photons were included in more than one source. Note however that properties of crowded sources may still be affected by the PSF wings of their neighbors. Source spectra, ARFs, and RMFs were constructed by ACIS Extract, which uses standard CIAO tools.

Spatial masking was applied to the event data and exposure map in order to eliminate most point source light prior to extraction of local background spectra for each extracted source. Such masking and background computations necessarily involve a tradeoff between the competing goals of eliminating all the light from the point sources and making the background spectra as "local" as possible. We chose a relatively sophisticated iterative approach which seeks to mask all regions where the expected surface brightness from the point sources is larger than one half the observed background level. An expected surface brightness image is computed using the exposure map and source flux estimates from preliminary extractions. A smooth background image is iteratively computed by smoothing the masked event data and exposure map. The resulting mask always covers all the source extraction regions, and extends beyond them for bright sources.

Local background spectra for each source were extracted from the masked event data and exposure map by searching for a circular aperture cen- 
tered on the source that contained at least 100 counts and included an unmasked area at least 4 times that of the source region. The background spectra were scaled appropriately using the masked exposure map pixels found in the background and source regions. Typically the scaled full-band background level in on-axis spectra is $<1$ count.

\subsection{Source Reliability and Limiting Sen- sitivity}

It is difficult to evaluate rigorously the reliability of this sourcelist. Since this region may contain diffuse emission from the surrounding superbubbles or from R136 itself, some of the reconstructed sources may be spurious or may be source blends. This is undoubtedly true for the X-ray source coincident with the cluster core R136a. We have assessed the validity of these sources by using ACIS Extract to calculate the probability that any of them is a background fluctuation, as described above. The 117 sources with less than a $0.3 \%$ likelihood of being a background fluctuation constitute our primary sourcelist (Table 1), while the 63 sources that have more than a $0.3 \%$ chance of being spurious background fluctuations but otherwise appear legitimate are listed as tentative sources in Table 2 . These tables are described in detail in $\S 3$. We note that 33 of the 63 tentative sources have $P_{B}>1 \%$; those sources in particular should be treated with caution. All images of the ACIS data shown in this paper show primary source extraction regions outlined in red, while tentative sources are outlined in purple.

Given the highly structured diffuse emission present in this field, a few of the sources remaining in our list may be knots in this diffuse emission rather than truly point-like sources. This is much more likely to happen far from the center of the field, where PSFs are large. In a longer observation, sources could be further tested for validity by considering their spectra. ACIS Extract performs a 2-sided Kolmogorov-Smirnov test that could be used to make sure that the spectra extracted from a source and its local background are not identical. For this dataset, however, most sources are too faint to use this test.

We estimate the limiting sensitivity of the source list in the on-axis region around R136 us- ing Koji Mukai's PIMMS ${ }^{5}$ tool. To avoid the X-ray Eddington bias defined by Wang (2004), we consider a full-band countrate limit of 5 counts in $21870 \mathrm{sec}$ (the total for all observations on CCD3). Assuming $N_{H}=5 \times 10^{21} \mathrm{~cm}^{-2}$ (a rough average of the spectral fits in Table 3), the observed X-ray flux for a range of thermal plasmas with $k T=$ $1-3 \mathrm{keV}$ is $F_{X}=1-2 \times 10^{-15} \mathrm{ergs} \mathrm{s}^{-1} \mathrm{~cm}^{-2}$. This gives an intrinsic (absorption-corrected) source flux of $F_{X, \text { corr }} \sim 3.4 \times 10^{-15} \mathrm{ergs} \mathrm{s}^{-1} \mathrm{~cm}^{-2}$, or a limiting full-band luminosity of $\sim 1 \times 10^{33} \mathrm{ergs} \mathrm{s}^{-1}$ in the LMC. The observation is thus not sufficiently sensitive to detect individual low-mass pre-main sequence stars, as their X-ray luminosities rarely exceed $1 \times 10^{32}$ ergs s$^{-1}$ (Feigelson et al. 2005). From a ROSAT survey of early-type stars (Berghöfer et al. 1997), this roughly limits our detection of individual stars on-axis to $\sim \mathrm{O} 5$ and earlier.

\section{RESULTING X-RAY POINT SOURCES}

As described above, we detect 180 pointlike sources in this ACIS observation; their extraction regions are outlined in red (primary sources) and purple (tentative sources) in Figure 1 and the ACIS sequence number from Tables 1 and 2 is shown for sources outside of the crowded R136 region. This binned image of the ACIS-I array also shows some of the counterparts to our Chandra sources: green circles indicate $2 \mathrm{MASS}$ sources and cyan circles show some of the X-ray sources known from previous studies. Counterparts in the dense central cluster have been omitted for clarity; a full list of counterparts is given in Table 5, which is described in detail below. The blue labeled counterparts are a mix of interesting sources: R103f is a foreground M star, Mk 12 is a B supergiant, and the others are WR stars.

Portegies Zwart et al. (2002) also analyzed part of this Chandra observation of 30 Dor. We confirm their detections of X-ray sources except for their sources CX13 and CX16, which did not pass our criteria to be legitimate sources. They note that their CX1 is a blend of the R136a core and that the source they find associated with R140 (CX10) is extended. We confirm these statements and in fact find that all nine of the sources that they identify in R136 have faint neighbors that fall within the

\footnotetext{
${ }^{5}$ http://xte.gsfc.nasa.gov/Tools/w3pimms.html
} 
90\% PSF contour of those sources. Our spectral fitting is in rough agreement with their results for the sources that we have in common.

\subsection{Source Properties}

Basic properties of the 180 pointlike sources are given in Table 1 (for the 117 primary sources) and Table 2 (for the 63 tentative sources). The format of these tables closely follows that of Getman et al. (2005) Tables 2 and 4; details on how certain columns were derived are given there. Column 1 is a running sequence number; Column 2 gives the formal source name based on its J2000 sexagesimal coordinates. The J2000 coordinates in decimal degrees are given in Columns 3 and 4 .

The formal $1 \sigma$ radial positional uncertainty based on source counts is given in Column 5 . It is calculated by ACIS Extract using the following steps: (1) assume the parent distribution of the extracted counts is the observatory PSF within the source's extraction region; (2) compute the standard deviations of that truncated PSF along the sky coordinate axes; (3) divide those standard deviations by the square root of the number of counts extracted; (4) sum the resulting single-axis positional uncertainties in quadrature. The resulting radial positional uncertainties, converted to units of arcseconds, is reported in Column 5.

Positional uncertainties can also be estimated from the Chandra Orion Ultradeep Project (COUP), which provides a large collection of 1400 sources associated with young stars across the full ACIS-I field of view (e.g. Getman et al. 2005). Source positions for COUP are based on the same ACIS Extract algorithms used here and the COUP observations were first registered to the 2MASS astrometric reference frame. We examined $\sim 350$ COUP sources with astrometric near-IR counterparts and fewer than 100 net counts for ACIS-star positional offsets. For sources lying within $5^{\prime}$ of the aimpoint where the Chandra PSF is excellent, we find average offsets of $0^{\prime \prime} .2-0^{\prime \prime} .3$ for sources with $3<$ NetCts $<100$. Some of this is likely due to uncertainties in the IR positions which are estimated to be $0^{\prime \prime} .1-0^{\prime \prime} .2$. For sources lying $5^{\prime}-7^{\prime}$ offaxis, average offsets are $1^{\prime \prime} .0$ for $3<$ NetCts $<10$ and $0^{\prime \prime} .6$ for $11<$ NetCts $<100$. For sources $7^{\prime}-10^{\prime}$ off-axis, average offsets are $2^{\prime \prime}$ for $3<$ NetCts $<20$ and 0 " .8 for $21<$ NetCts $<100$. These COUP positional uncertainties should ap- ply to 30 Dor sources as well and give a sense of the systematic errors that apply in addition to the formal position errors given in Tables 1 and 2 .

Since the Chandra PSF is a strong function of radial distance from the aimpoint, the offaxis angle of each source is given in Column 6 . Columns 7-11 give the source photometry, listing each source's net counts in the full $(0.5-8 \mathrm{keV})$ and hard (2-8 keV) spectral bands, $1 \sigma$ errors on those net counts based on Gehrels (1986, Equation 7 ), the estimated number of background counts in the source extraction region, and the fraction of the PSF used to extract each source. Sources are extracted with a nominal $90 \%$ PSF fraction unless they are crowded; thus a value substantially less than $90 \%$ in Column 11 indicates that the source was crowded and that its properties may be influenced by nearby sources.

Column 12 gives the source's photometric significance, defined as the net counts value (Column 7) divided by the error on that value (Column 8). Column 13 gives the probability that the source is a background fluctuation rather than a true point source. This represents our primary test of source validity. As described in $\S 2.1$, this quantity differentiates the main source catalog in Table 1 (117 sources with final $\left.P_{B} \leq 0.003\right)$ from the list of tentative sources in Table 2 (63 sources with final $\left.P_{B}>0.003\right)$.

Observational anomalies are noted by a set of flags in Column 14. For this field, the only anomalies noted were sources falling in the gap between the CCD chips or on the edges of the field; both effects cause sources to have reduced exposure time and edge sources have poor position estimates due to truncated PSFs. Column 15 is a characterization of each source's likelihood of displaying variability in this observation. It is based on a calculation of the Kolmogorov-Smirnov statistic and was first defined in Feigelson \& Lawson (2004). This quantity is omitted for sources falling in chip gaps or on field edges because satellite dithering can cause such sources to have erroneously variable lightcurves; the test is not performed for very faint sources. Column 16 gives the source's "effective" exposure time, namely the length of time that the source would have to be observed at the Chandra aimpoint in order to collect the same number of counts as were actually obtained in the observation performed. 
Finally, an estimate of the source's backgroundcorrected median energy in the full spectral band completes the table. To compute this statistic we first construct a cumulative energy distribution normalized to unity by integrating the background-corrected spectrum and dividing by net counts. We then search for the lowest and highest energies at which the cumulative distribution crosses $50 \%$ - these energies may be different because the background-corrected cumulative energy distribution may not be monotonic (faint sources may have channels with negative values because that channel contained no source counts but it did contain background counts). The average of these two energies is reported as the median of the background-corrected spectrum.

\subsection{X-ray Spectroscopy}

Spectra, backgrounds, ARFs, and RMFs for all point sources were constructed by ACIS Extract and used for both automated and interactive spectral fitting using Keith Arnaud's XSPEC fitting package (Arnaud 1996) and our XSPEC scripts. Only about a quarter of these sources are bright enough to yield sufficient counts for spectral fitting in this short observation. Sources with photometry significance $>2$ (49 sources in total, all from the primary sourcelist in Table 1) were fit using CSTAT (ungrouped spectra) in XSPEC12 with a single apec thermal plasma model (Smith et al. 2001) with a single solar-abundance absorption component (wabs model, Morrison \& McCammon 1983). If the thermal plasma fit was unacceptable because it gave non-physical parameters or failed to converge and the source was not spatially associated with R136, a power law model was used instead, on the assumption that the source could be an X-ray binary or a background AGN. Sources in R136 were only fit with the thermal plasma model because we assume that these are normal stars, so the thermal plasma model is more appropriate.

We chose to use the simple wabs absorption model to facilitate future comparison with Galactic star-forming regions. The assumption of solar abundance for the absorbing material may be significantly in error, as most of the absorption is thought to be local to the 30 Dor nebula (Norci \& Ögelman 1995). Mignani et al. (2005) note, as part of their spectral fitting to ACIS data of PSR J0537-6910 in N157B, that reducing the abundance of the absorbing material to $0.4 Z_{\odot}$ doubles the resultant $N_{H}$. We caution the reader that this systematic underestimate of $N_{H}$ due to our assumption of solar abundances for the intervening material pertains to all of our fitting results.

Tables 3 and 4 summarize our XSPEC fit results for those sources with photometry significance $>2$. Fits with high absorption $\left(\log N_{H}>\right.$ $22.5)$ omit the soft-band luminosity $L_{S}$ and the absorption-corrected full-band luminosity $L_{t, c}$ because these quantities cannot be determined reliably.

Fits to the fainter sources in this group should be treated with appropriate skepticism. For example, source \#164 in Table 3 (CXOU J053909.46-690429.8) has an acceptable fit, but the soft thermal plasma combined with the large absorbing column yields a very large intrinsic luminosity estimate, suggesting that this 10-count source is the third brightest pointlike object in the field, bested only by the pulsar and cometary nebula source in N157B. Attempts to fit the spectrum with a lower absorbing column and different spectral model (including a power law) were unsuccessful. The nature of CXOU J053909.46-690429.8 is unknown so perhaps it is uniquely luminous, but additional data are needed to establish its X-ray properties with confidence.

Monte Carlo simulations (Feigelson et al. 2002; Gagné et al. 2004) have shown that the formal errors on spectral fit parameters generated by $X S P E C$ for low-significance (faint) sources do not adequately convey the uncertainty in these parameters. Nevertheless, such fits are useful for characterizing the X-ray luminosities of faint sources even though the fit parameters are not well-known; these fits simply spline the data and give an acceptable estimate of model normalization. We thus caution the reader that fit parameters for lowsignificance sources should only be used to reproduce our X-ray luminosities.

Table 3 gives thermal plasma model fits to the stellar sources and others for which that model gave a satisfactory fit; it is based on Tables 6-8 of Getman et al. (2005), which provides details on how certain columns were derived. Columns 1-4 give the running ACIS sequence number, source name, net full-band counts, and photometric significance from Tables 1 and 2. Columns 5-7 give 
the spectral fit parameters and their $90 \%$ confidence intervals for the absorbed thermal plasma model. Missing confidence intervals mean that $X S P E C$ detected some abnormality in the error calculation from at least one of the fit parameters; fits without uncertainties should be treated with caution. Columns 8-12 give apparent and absorption-corrected luminosities in various wavebands. Column 13 completes the table with notes about the nature of the source or the fit.

Table 4 gives power law fits to those sources outside of R136 for which a thermal plasma model gave no acceptable fit or gave a plasma temperature that was implausibly high. It has the same overall structure as Table 3 but of course the spectral fit parameters are those relevant to the absorbed power law model and we report apparent and absorption-corrected fluxes rather than luminosities, since the distances of many of these sources (at least the ones that are background AGN) are unknown.

\subsection{Counterparts}

We searched for counterparts to our ACIS sources, using SIMBAD and VizieR for sources outside R136 (off-axis angle $\theta>30^{\prime \prime}$ ). We used a progressively larger search radius $R$, with $R=2^{\prime \prime}$ for sources with $0^{\prime} .5<\theta<2^{\prime}, R=5^{\prime \prime}$ for $2^{\prime}<\theta<5^{\prime}$, and $R=10^{\prime \prime}$ for $\theta>5^{\prime}$. When matching ACIS sources near the field center with other catalogs of this region, counterpart searches started by registering the ACIS astrometric reference frame and that of the catalog under study to remove systematic offsets. For the confused region close to R136, we required potential counterparts to fall within $0^{\prime \prime} .5$ of the ACIS source position in order to be considered a match.

Table 5 lists counterparts to ACIS sources from several catalogs. Columns 1 and 2 give the usual ACIS sequence number and source name. Column 3 gives the separation between the ACIS source and its counterpart using a hierarchy of matched catalogs: if a match from Malumuth \& Heap (1994) (hereafter MH94) was available then that separation is noted; if there was no MH94 match then the 2MASS separation is noted; if neither of these matches exists, the separation between the ACIS source and its match from SIM$\mathrm{BAD}$ or VizieR is given. Column 4 gives the spectral type of the star or multiple stellar sys- tem if known, taken from Breysacher et al. (1999), Crowther \& Dessart (1998) (hereafter CD98), or SIMBAD. Column 5 gives the Breysacher et al. (1999) catalog number (a catalog of LMC WR stars). Column 6 gives the Parker (1993) catalog number (a ground-based UBV photometric study of 30 Dor). Column 7 gives the MH94 catalog number (a UBV photometric study of 30 Dor performed with the Hubble Space Telescope). Column 8 gives the $\mathrm{X}$-ray source identification from Portegies Zwart et al. (2002). Columns 9 and 10 give the 2MASS match coordinates in decimal degrees (J2000). Column 11 completes the table with matches from other catalogs, common names for well-known sources, and other notes.

About one third of the ACIS sources have counterparts. Several of these are known very earlytype (WR-WR or WR-O) binaries, where the primary source of X-rays is probably collisions between the powerful stellar winds (Portegies Zwart et al. 2002). In R136, there are at least as many individual (not known to be binary) early O stars with detectable $\mathrm{X}$-ray emission in this observation, though, contrary to the conclusions of Portegies Zwart et al. (2002). This will be discussed below.

\section{THE MASSIVE CLUSTER R136}

The X-ray point source population of 30 Dor is dominated by the central star cluster R136. Figure 2 shows the environs of R136, with ACIS source extraction regions shown in red (primary sources) or purple (tentative sources) and some of the 2MASS counterparts shown with large gold circles (these have been omitted in very confused regions). Sources from the MH94 catalog that are close spatial matches to the ACIS sources $\left(<0^{\prime \prime} .5\right.$ separation) are indicated with small blue circles (brighter MH94 sources listed in CD98) or small cyan circles (fainter MH94 sources). MH94 catalog numbers are given in unconfused regions; all MH94 numbers for matched sources are given in Table 5. Since we expect to detect only the early-type members of R136 (see $§ 2.3$ ), only MH94 sources brighter than 16th magnitude were considered to be possible matches to ACIS sources. The 2MASS catalog is confused in this region; often two or more ACIS and MH94 sources fall within the $2^{\prime \prime}$ 2MASS PSF.

One notable feature of the X-ray point source 
distribution seen in Figure 2 is the apparent clustering of faint sources around the brightest X-ray source in the field (CXOU J053844.25-690605.9, ACIS \#132), the WR star Melnick 34 (Mk 34), located about $10^{\prime \prime}$ east and slightly south of the R136 core and coincident with MH94 source \#880. None of these faint Chandra sources has a counterpart in another waveband using our matching criteria (although there are faint MH94 sources that are spatially coincident with these sources) so they could be artifacts from the reconstruction (shown in Figure 3). Since this shallow ACIS observation is unlikely to detect lower-mass pre-main sequence stars in R136, the X-ray companions that we see around Mk 34 are most likely individual $\mathrm{O}$ stars. If these sources are confirmed in a longer X-ray observation, their presence may indicate that Mk 34 hosts a young subcluster of massive stars distinct from the main R136 cluster.

Figure 3 gives the reconstructed image of the field shown in Figure 2. From this reconstruction, we identify $109 \mathrm{X}$-ray sources within a $30^{\prime \prime}$ radius of the core of R136, compared to 37 sources found by a combination of wavdetect and visual inspection of the binned image. Figure 3 shows the red (primary source) and purple (tentative source) extraction regions for these $\mathrm{X}$-ray sources along with their ACIS sequence numbers.

Peaks in the reconstruction that lack ACIS extraction regions did not pass our source validity criteria. In some cases (e.g. ACIS \#125, the source corresponding to MH94 \#815) the reconstruction generated two peaks within the $90 \%$ PSF extraction region but one of those peaks did not pass our source validity checks, so it was included in the extraction region of the primary peak. A longer observation may show two X-ray sources present in this region.

Figure 4 shows the inner $\sim 10^{\prime \prime} \times 10^{\prime \prime}$ region around R136, displayed with $0^{\prime \prime} .25$ pixels, before and after image reconstruction. X-ray point sources are marked in both images with their red or purple PSF extraction regions from ACIS Extract. The bright patch near field center coincides with the dense cluster core R136a and undoubtedly represents emission from many cluster stars. The brightest X-ray source $4^{\prime \prime}$ to the southeast is the WR star R136c. Counterparts to ACIS sources from MH94 are shown with blue and cyan circles as in Figure 2; green circles show the brightest members of R136 in the MH94 catalog (taken from CD98) that lack individual X-ray counterparts.

As evidenced by the swarm of green circles near $\mathrm{R} 136 \mathrm{a}$, in the densest part of the cluster even image reconstruction is not sufficient to pinpoint exactly which high-mass cluster members are X-ray emitters above our flux limit. There is an intriguing ring of X-ray emission roughly $3^{\prime \prime}$ in diameter to the northeast of R136a that largely condenses into pointlike emission in the reconstruction, although a small ridge of emission $1^{\prime \prime}$ east of R136a remains and all the condensations in this ring appear more extended than other point sources in the reconstruction. It is unclear whether this is a physical structure or a statistical aberration due to small number counts in these data. Our referee suggests that it may be due to a dense molecular cloud in this region.

Spectral properties of the brighter sources in R136 are given in Table 3 . They show a wide range of values, with $N_{H}=1-10 \times 10^{21} \mathrm{~cm}^{-2}$ and $k T=0.5-4 \mathrm{keV}$, although the small number of counts in most of these spectra leaves their fit parameters not well-constrained. These absorbing columns are typical of massive star-forming complexes on the edges of molecular clouds. The plasma temperatures for some sources are consistent with those seen in single Galactic $\mathrm{O}$ stars $(<1 \mathrm{keV}$, Chlebowski et al. 1989), although a hotter component is sometimes present (Stelzer et al. 2005). Other R136 sources are dominated by much hotter values more typical of colliding-wind binaries (Portegies Zwart et al. 2002). This is expected given the number of known high-mass binaries in the field (Breysacher et al. 1999).

We also examined the average spectrum of Xray sources in or near R136 that are individually too faint for analysis by integrating or "stacking" their counts. Figure 5a shows the average spectrum of 101 sources (using 358 combined ACIS events) within $1^{\prime}$ off-axis having a photometric significance $<2$. This spectrum is adequately fit by a single absorbed thermal plasma with $0.3 Z_{\odot}$ abundances, $N_{H} \sim 0.2 \times 10^{22} \mathrm{~cm}^{-2}$, and $k T \sim 2 \mathrm{keV}$.

This gives a coarse estimate of the average spectral characteristics of the highest end of the Xray luminosity function in R136. As with the brighter sources that we detect in this observation, the fainter sources should be composed of early $\mathrm{O}$ stars, WR stars, and colliding-wind bi- 
naries. The spectral parameters from the stacked spectrum are consistent with the fits to individual sources in R136 given in Table 3, as we would expect from a similar population.

\subsection{Melnick 34 and Other WN5h Stars}

Massey \& Hunter (1998) interpreted the WN5h sources in R136 as "O3 stars in Wolf-Rayet clothing," still burning hydrogen in their cores but so luminous and with such prodigious mass loss that their spectra let them masquerade as WR stars. The brightest ACIS source in R136 is CXOU J053844.25-690605.9 (ACIS \#132), spatially coincident with Mk 34, a $130 \mathrm{M}_{\odot}$ WN5h star located $2.62 \mathrm{pc}$ from the R136 core and not known to be binary (Massey \& Hunter 1998; Crowther \& Dessart 1998). It was observed $\sim 22^{\prime \prime}$ off-axis in these ACIS data. No variability was detected in the X-ray lightcurve. There are $\sim 950$ ACIS counts in the $0.5-8 \mathrm{keV}$ band, or a countrate of $\sim 0.14$ counts per CCD frame. From the simulation in Townsley et al. (2002), this countrate should not cause substantial spectral distortion due to photon pile-up. The extraction region contained only $75 \%$ of the PSF due to the presence of several fainter sources nearby.

The spectrum and plasma modeling of Mk 34 derived using an $X S P E C$ fit to grouped data are shown in Figure 5b. This fit is somewhat different than that from the automated spectral fitting using ungrouped data presented in Table 3 (source \#132) but the results are consistent to within the errors. The model shown in Figure 5b is an absorbed apec plasma with $N_{H}=0.34_{0.26}^{0.43} \times$ $10^{22} \mathrm{~cm}^{-2}$ and $k T=4.3_{3.6}^{4.9} \mathrm{keV}$, with permitted elemental abundances ranging from LMC to solar levels. The absorption-corrected $0.5-8 \mathrm{keV}$ luminosity of Mk 34 is $L_{X, c o r r}=2.2 \times 10^{35} \mathrm{ergs} \mathrm{s}^{-1}$; this agrees well with the results of Portegies Zwart et al. (2002), although our spectral fits give a hotter, less-absorbed thermal plasma than theirs.

HST observations of Mk 34 show photometric variability of a few tenths of a magnitude over a period of 20 days (Massey et al. 2002). Mk 34 was known to be X-ray-bright from ROSAT data (Wang 1995). Portegies Zwart et al. (2002) find that its X-ray luminosity has not changed in the nine years between the original Einstein observation (Wang \& Helfand 1991) and this Chandra observation. We agree with the conclusion of these authors, that Mk 34 is probably binary and the source of its hard X-rays is most likely the collision of the high-velocity winds of the binary components.

The second-brightest ACIS source in R136 is CXOU J053842.89-690604.9, with 247 net fullband counts. It is coincident with another WN5h star, R136c. It exhibits a hard spectrum similar to Mk 34 (Figure 5c); the best-fit model is an absorbed apec plasma with $N_{H}=0.4_{0.2}^{0.6} \times 10^{22} \mathrm{~cm}^{-2}$ and $k T=3.1_{2.0}^{5.6} \mathrm{keV}$. The absorption-corrected $0.5-8 \mathrm{keV}$ luminosity is $L_{X, \text { corr }}=9 \times 10^{34} \mathrm{ergs} \mathrm{s}^{-1}$, almost a factor of 3 fainter than Mk 34. As with Mk 34, we detect no X-ray variability.

Other WN5h stars in the field are R136a1, R136a2, and R136a3 (Crowther \& Dessart 1998). We detect a blend of the R136a core sources (CXOU J053842.35-690602.8) which includes components a1 and a2. The composite spectrum is comparatively soft $(k T=1.3 \mathrm{keV})$ and faint, with just 53 net counts $\left(L_{X, \text { corr }}=2 \times 10^{34} \mathrm{ergs} \mathrm{s}^{-1}\right)$. $\mathrm{R} 136 \mathrm{a} 3$ is blended with the O3V star R136a6 and other sources yielding the composite ACIS source CXOU J053842.29-690603.4; this composite is faint ( 22 net counts, $L_{X, c o r r}=0.9 \times 10^{34} \mathrm{ergs} \mathrm{s}^{-1}$ ) but with a hard spectrum $(k T=4 \mathrm{keV})$.

\subsection{Other R136 Stars Seen and Not Seen}

The O3If/WN6-A "transition" object Mk 39 (Breysacher et al. 1999) is detected with 66 net counts $\left(L_{X, c o r r}=2 \times 10^{34} \operatorname{ergs~s}^{-1}\right)$ and $k T=$ $2 \mathrm{keV}$. The WN6h star R134 is very faint with just 2 net counts; due to the X-ray Eddington bias (Wang 2004) its X-ray luminosity is poorly constrained. According to Massey \& Hunter (1998), Mk 39 and R134 could be similar to the WN5h sources. While all of these sources are visually bright and have consistently large mass loss rates (Crowther \& Dessart 1998), they range over a factor of $\sim 500$ in intrinsic X-ray luminosity!

The $\mathrm{O}$ stars in R136 show similar behavior. We detect O3 stars across a range of luminosity classes (O3I, O3III, and O3V). Cooler stars are also seen: several O5 stars, an O7V star, and the $\mathrm{B}$ supergiant Mk 12. They exhibit a wide range of X-ray luminosities; while most of these sources are quite faint, the O3III(f) star Mk 33Sa is detected with 51 net counts and fit with a soft spec- 
trum $(k T=0.6 \mathrm{keV})$ and a large absorbing column $\left(N_{H}=1 \times 10^{22} \mathrm{~cm}^{-2}\right)$. This combination of spectral fit parameters leads to a large intrinsic luminosity, $L_{X, c o r r}=4 \times 10^{34} \mathrm{ergs} \mathrm{s}^{-1}$.

While we detect many early-type stars in R136, there are many O3 stars in the list of Crowther \& Dessart (1998) that have no X-ray counterpart at our limiting sensitivity of $L_{X \text {, corr }} \sim 1 \times$ $10^{33}$ ergs s $^{-1}$. Notably, we do not detect 30 Dor MH36, the O2-3 If star that helped to define the new spectral type O2 (Walborn et al. 2002). Also absent in X-rays is Mk 33Sb, the WC5 star that Massey \& Hunter (1998) call the only bona fide WR star in their sample; this is not surprising, since single WC stars are typically X-ray-faint (Oskinova et al. 2003). None of the deeply embedded new generation of massive stars (Walborn et al. 2002) is detected.

If X-ray spectral hardness and high luminosity are indicators of close binarity because shocks from colliding fast winds are necessary to generate hard X-rays, we infer that Mk 34, R136c, and R136a3 are likely close binaries, while the faint source R134 and the soft source Mk 33Sa are not. This contradicts somewhat the conclusions of Portegies Zwart et al. (2002), who surmised that all of their Chandra sources in R136 (CX 1 through CX 9) were colliding-wind binaries. We find that all nine of those source locations show multiple Xray sources within a $90 \%$ PSF extraction region; this is the primary source of our disagreement.

R136 provides the largest sample of such earlytype stars currently available to us. Ideally, accurate $L_{X}$ 's for its stars would allow us to generate a high-mass X-ray luminosity function and extend the $L_{X} / L_{\text {bol }}$ correlation (Berghöfer et al. 1997) to the earliest spectral types, but it appears that any such correlation will be masked by the wide scatter in $L_{X}$ caused by details of the wind properties and binarity in R136 stars.

\section{OTHER SOURCES IN THE FIELD}

\subsection{Wolf-Rayet Stars}

We detect two sources associated with the cluster R140, imaged 24" off-axis. These were found during the first stage of source detection; image reconstruction reveals no more. The brighter source (CXOU J053841.59-690513.4) is coincident with the grouping of high-mass stars R140a1/a2 (Mof- fat et al. 1987). It has 378 net full-band counts $\left(L_{X, \text { corr }}=1.7 \times 10^{35} \mathrm{ergs} \mathrm{s}^{-1}\right)$, making it the second brightest $\mathrm{X}$-ray source in the field outside of N157B. It is well-fit by a thermal plasma with $k T=0.9 \mathrm{keV}$ (see Figure 6a). This is surprisingly soft, given the combined spectral types of the system: WC5+O(?) for R140a1 and WN6+O for R140a2 (Breysacher et al. 1999). The WN6 star $\mathrm{R} 140 \mathrm{~b}$ is much fainter, with just 15 net counts, but it has a much hotter (although not wellconstrained) spectrum with $k T \sim 2.5 \mathrm{keV}$.

We also find X-ray emission associated with several other WR stars or stellar systems spread around the field (Figure 1): R130 (WN6+B1Ia), R139 (O6Iaf/WN), R144 (WN6h), and R145 (WN6(h)) (spectral types from Breysacher et al. 1999). All of these sources are detected with $<20$ net counts $\left(L_{X, \text { corr }} \sim 2-8 \times 10^{33}\right.$ ergs s$\left.^{-1}\right)$ and $k T \sim 1.6-2.5 \mathrm{keV}$. Twelve of the $32 \mathrm{WR}$ stars in the field from the catalog of Breysacher et al. (1999), most of them single WR stars, remain undetected in this observation.

\subsection{Other Clusters}

Several X-ray sources, some with 2MASS matches, are found near the massive stellar cluster LH 99 associated with N157B. CXOU J053742.64-690958.2 is a 54-count ACIS source that falls at the edge of N157B's cometary tail; although it has no 2MASS match, it coincides with UV source \#30689 from Parker et al. (1998). Although some of the ACIS sources are clearly associated with the SNR, some may be massive members of LH 99.

Absent from the ACIS sourcelist are any members of the $\sim 20$ Myr old cluster Hodge 301 (Grebel \& Chu 2000), located 3' northwest of R136. The lack of X-ray sources in this cluster is consistent with its age; Grebel \& Chu (2000) note that the most massive remaining members are early B stars and that the $\sim 40$ more massive original cluster members may have exploded as supernovae. Given our shallow limiting X-ray sensitivity and the absence of $\mathrm{O}$ stars in this cluster, we would not expect to detect stars in Hodge 301 .

\subsection{Field 2MASS Sources}

There are several X-ray sources with 2MASS matches scattered across the ACIS-I field that are not associated with known stars or clusters. Many 
of these matches are listed as tentative in Table 5 due to separations between the ACIS source and its proposed 2MASS counterpart that exceed $3^{\prime \prime}$. These are still possible matches because the ACIS sources are at large off-axis angles (hence have large PSFs) and they are faint, so their positions could be more uncertain than the simple error calculation in Table 1 implies. Nevertheless, we will not speculate about the nature of these sources due to the uncertainty in the matching.

Three ACIS sources (\#27, \#43, and \#171) with close 2MASS matches are also close to UCAC2 or USNO-B sources with proper motions greater than \pm 10 mas $\mathrm{yr}^{-1}$, implying that they could be foreground stars (Momany \& Zaggia 2005). Only \#27 is bright enough in X-rays to merit a spectral fit; we find that it is best fit by a power law with $\Gamma=1.7$ and high absorption, but these values are highly uncertain and the source has only 24.1 net full-band counts.

Another four ACIS sources (\#8, \#16, \#23, and \#32) have visual as well as 2MASS counterparts and exhibit small or unmeasured proper motions. They are all too faint to merit spectral fits, but \#8 has an unusually large fraction of hard counts (see Table 1). They are more likely to be LMC stars than background sources because their $J-K$ colors are more typical of ROSAT-selected cataclysmic variables (white dwarf X-ray binaries) and white dwarfs than background AGN (see Figure 1 of Gänsicke et al. 2005).

If we assume that all seven described in the last two paragraphs are foreground Galactic disk stars that serendipitously lie along the line of sight and are coronal X-ray emitters (Güdel 2004), we can use their visual and IR photometric properties to speculate on their spectral types. Sources \#32 and \#171 have colors consistent with mid-M stars. Assuming that they lie on the main sequence, their distances are $\sim 500 \mathrm{pc}$ and $\sim 250 \mathrm{pc}$ respectively with X-ray luminosities $L_{t} \sim 10^{28.5} \mathrm{ergs} \mathrm{s}^{-1}$, near the upper end of the normal stellar X-ray luminosity function (Schmitt et al. 1995). Considering that they lie $3^{\prime \prime}-4^{\prime \prime}$ from their 2MASS counterparts, it is possible that one or both may be spurious identifications.

Sources \#16, \#23, and \#27 have photometric colors consistent with mid-A stars. If they lie on the main sequence, their distances would be $\sim 100, \sim 40$, and $\sim 35 \mathrm{pc}$, respectively. Their presence in the field is also difficult to understand, as the Galactic disk population of A stars in this direction is sufficiently sparse that not even a single such star should be present in the field, irrespective of X-ray properties. We therefore suggest that they may be LMC members, perhaps A supergiants. ACIS sources \#8 and \#43 have extraordinary visual and IR colors inconsistent with any normal star. We suggest that these stars are highly variable and/or exhibit strong emission lines. They might be cataclysmic variables in the LMC. Visual spectroscopy of these five sources is warranted.

\subsection{X-ray Binaries}

Shtykovskiy \& Gilfanov (2005) surveyed several square degrees of the LMC using XMMNewton and found few high-mass X-ray binary systems in the luminosity range $10^{33.5}<L_{X}<$ $10^{35.5} \mathrm{ergs} \mathrm{s}^{-1}$. They expect even fewer lowmass X-ray binaries. Scaling their results to our small Chandra field, we expect no bright $\left(L_{X}>\right.$ $10^{35}$ ergs s$^{-1}$ ) X-ray binaries in our field, and indeed find none. We can also exclude any high-mass X-ray binaries because no ACIS sources outside of R136 have bright visual counterparts (see Haberl 2002). Some of our sources, especially those with very flat power law spectra $(\Gamma<1)$, could be cataclysmic variables, such as the intermediate polars seen in profusion in the Galactic Center (Muno et al. 2004).

\subsection{Extragalactic Background Sources}

The $\log \mathrm{N}-\log \mathrm{S}$ distribution of cosmic X-ray background sources from Moretti et al. (2003) shows that over 100 sources in our field could be from this background population, if we were not looking through the plane of the LMC. Due to this additional absorption and the elevated X-ray background due to diffuse emission in 30 Dor, we expect to see fewer extragalactic sources. These sources should be spread uniformly around the field and tend to have hard spectra that are well-fit by a power law model with photon index $\Gamma \sim 1.8$ (Haberl et al. 2001), usually consistent (to within our large errors) with our sources. Thus we conclude that most of the ACIS sources not associated with N157B or R136 and lacking counterparts in other wavebands are likely to be background AGN. There are 41 such X-ray sources in the field, plus 
an additional 8 sources with only tentative 2MASS or Parker et al. (1998) matches that could be spurious.

A few of these sources can be further characterized. The bright source CXOU J053809.92-685658.3 near the northern edge of the ACIS field, also seen by ROSAT, has a spectrum that is well-fit by a power law with $\Gamma=1.8$ and absorption-corrected $0.5-8 \mathrm{keV}$ flux $F_{t, c}=1.5 \times 10^{-13} \mathrm{ergs} \mathrm{s}^{-1} \mathrm{~cm}^{-2}$ (Figure 6b). This is similar to other AGN nearby seen by XMM (Haberl et al. 2001). Our source CXOU J0503707.64-691243.4 matches source \#4 in Haberl et al. (2001), which they also determine to be a background AGN. One Chandra source (CXOU J054001.87-690618.7) has a counterpart in a radio catalog (Marx et al. 1997) and is thus likely to be an AGN, although we find a thermal plasma spectral fit for this source to be preferable to a power law fit.

\section{CONCLUDING COMMENTS}

We have analyzed early Chandra/ACIS observations of 30 Doradus and catalog here a wide variety of X-ray-emitting point sources: individual high-mass stars, colliding-wind binaries, possibly evolved X-ray binaries, foreground stars, and background AGN. Using publicly-available tools, we describe both the spatial and spectral characteristics of these X-ray sources.

In this $\sim 21 \mathrm{ks}$ observation of 30 Dor, 180 $\mathrm{X}$-ray point sources are found in the $17^{\prime} \times 17^{\prime}$ Chandra/ACIS-I field. Most (85\%) of these sources are associated with high-mass stellar systems. While many of the remaining sources are likely background AGN, a handful of white dwarf $\mathrm{X}$-ray binaries may be present and one known foreground star is seen. Nearly 100 of the sources lie in the R136 massive star cluster; several of these may form a small subcluster around the WR star Mk 34. A few sources are collected in the LH 99 cluster around the supernova remnant N157B.

Individual $\mathrm{O}$ stars emit $\mathrm{X}$-rays at levels typical of their Galactic counterparts; we detect a number of early-type (O3-O7) stars by using image reconstruction to reduce the confusion in the R136 core. The X-ray luminosity of R136, however, is dominated by a few sources known to be WR-WR or WR-O star binaries. Their spectra show higher plasma temperatures than are typ- ical for single early-type stars; as first noted by Portegies Zwart et al. (2002), these are most likely colliding-wind binaries. None of them show variable lightcurves in this short observation. The individual systems display a wide variety of X-ray luminosities, ranging from Mk 34 with absorptioncorrected $L_{X}=2.2 \times 10^{35} \mathrm{ergs} \mathrm{s}^{-1}$ to many with $L_{X}<4 \times 10^{32} \mathrm{ergs} \mathrm{s}^{-1}$ (assuming a typical stellar spectral model).

Thus we find no evidence for a characteristic $L_{X} / L_{b o l}$ ratio for the massive members of R136, such as the widely reported relation $L_{X} / L_{b o l} \simeq$ $10^{-7}$ (e.g. Harnden et al. 1979; Pallavicini et al. 1981; Berghöfer et al. 1997) that holds for latertype stars. Rather, the X-ray emission seems to depend critically on the details of the wind properties and binarity for high-luminosity WR and O stars. For example, we infer that Mk 34, R136c, and R136a3 are likely close binaries due to their high X-ray luminosities and/or spectral hardness, while R134 and Mk 33Sa probably are not.

Although our Chandra exposure is too short to penetrate deeply into the stellar X-ray luminosity function of the region, this is still the richest field of very-high-mass stellar sources ever characterized in the X-ray band. The high stellar density in R136 makes this field a showcase for Chandra's excellent spatial resolution. This study marks the beginning of our attempts to understand the highenergy processes at work in the massive stars of 30 Dor; partnered with Paper I, we are beginning to see how the life cycle of high-mass stars shapes the overall view of giant HII regions and their surroundings through their powerful winds and supernovae. These results from early Chandra observations lay the groundwork for more sensitive Chandra studies planned for the near future.

Support for this work was provided to Gordon Garmire, the ACIS Principal Investigator, by the National Aeronautics and Space Administration (NASA) through NASA Contract NAS8-38252 and Chandra Contract SV4-74018 issued by the Chandra X-ray Observatory Center, which is operated by the Smithsonian Astrophysical Observatory for and on behalf of NASA under Contract NAS8-03060. We are grateful to our referee for a thorough review of this paper and many helpful suggestions. LKT appreciates helpful conversations with Mike Eracleous regarding binary pop- 
ulations. This publication makes use of data products from the Two Micron All Sky Survey, which is a joint project of the University of Massachusetts and the Infrared Processing and Analysis Center/California Institute of Technology, funded by NASA and the National Science Foundation. This research made use of the SIMBAD database and VizieR catalogue access tool, operated at CDS, Strasbourg, France. We would have been lost without the invaluable tools of NASA's Astrophysics Data System.

\section{REFERENCES}

Arnaud, K. A. 1996, in ASP Conf. Ser. 101, Astronomical Data Analysis Software and Systems V, ed. G. H. Jacoby \& J. Barnes (San Francisco: ASP), 17

Berghöfer, T. W., Schmitt, J. H. M. M., Danner, R., \& Cassinelli, J. P. 1997, A\&A, 322, 167

Brandl, B. R. 2005, in ASSL Vol. 329, Starbursts: From 30 Doradus to Lyman Break Galaxies, ed. R. de Grijs \& R. M. González Delgado (Dordrecht: Springer), 49

Brandner, W., Grebel, E. K., Barbá, R. H., Walborn, N. R., \& Moneti, A. 2001, AJ, 122, 858

Breysacher, J., Azzopardi, M., \& Testor, G. 1999, A\&AS, 137, 117

Brogan, C. L., Goss, W. M., Lazendic, J. S., \& Green, A. J. 2004, AJ, 128, 700

Broos, P. S., Townsley, L. K., Getman, K. V., \& Bauer, F. E. 2002, ACIS Extract, An ACIS Point Source Extraction Package (University Park: Pennsylvania State Univ.)

Chartas, G., Eracleous, M., Agol, E., \& Gallagher, S. C. 2004, ApJ, 606, 78

Chlebowski, T., Harnden, F. R., \& Sciortino, S. 1989, ApJ, 341, 427

Crowther, P. A., \& Dessart, L. 1998, MNRAS, 296,622

Feast, M. W., Thackeray, A. D., \& Wesselink, A. J. 1960, MNRAS, 121, 337

Feigelson, E. D., Broos, P., Gaffney, J. A., Garmire, G., Hillenbrand, L. A., Pravdo, S. H., Townsley, L., \& Tsuboi, Y. 2002, ApJ, 574, 258

Feigelson, E. D., \& Lawson, W. A. 2004, ApJ, 614, 267

Feigelson, E. D., et al. 2005, ApJS, 160, 379

Freeman, P. E., Kashyap, V., Rosner, R., \& Lamb, D. Q. 2002, ApJS, 138, 185

Gagné, M., Skinner, S. L., \& Daniel, K. J. 2004, ApJ, 613, 393

Gänsicke, B. T., et al. 2005, MNRAS, 361, 141 
Gehrels, N. 1986, ApJ, 303, 336

Getman, K. V., et al. 2005, ApJS, 160, 319

Grebel, E. K., \& Chu, Y. 2000, AJ, 119, 787

Güdel, M. 2004, A\&A Rev., 12, 71

Haberl, F., Dennerl, K., Filipović, M. D., Aschenbach, B., Pietsch, W., \& Trümper, J. 2001, A\&A, 365, L208

Haberl, F. 2002, in Proc. Symposium "New Visions of the X-ray Universe in the $X M M$ Newton and Chandra Era," ESA SP-488, ed. F. Jansen (astro-ph/0203233)

Harnden, F. R., et al. 1979, ApJ, 234, L51

Malumuth, E. M., \& Heap, S. R. 1994, AJ, 107, 1054

Marx, M., Dickey, J. M., \& Mebold, U. 1997, A\&AS, 126, 325

Massey, P., \& Hunter, D. A. 1998, ApJ, 493, 180

Massey, P., Penny, L. R., \& Vukovich, J. 2002, ApJ, 565, 982

Mignani, R. P., Pulone, L., Iannicola, G., Pavlov, G. G., Townsley, L., \& Kargaltsev, O. Y. 2005, A\&A, 431, 659

Moffat, A. F. J., Niemela, V. S., Phillips, M. M., Chu, Y., \& Seggewiss, W. 1987, ApJ, 312, 612

Momany, Y., \& Zaggia, S. 2005, A\&A, 437, 339

Moretti, A., Campana, S., Lazzati, D., \& Tagliaferri, G. 2003, ApJ, 588, 696

Mori, K., Tsunemi, H., Miyata, E., Baluta, C. J., Burrows, D. N., Garmire, G. P., \& Chartas, G. 2001, in ASP Conf. Ser. 251, New Century of X-ray Astronomy, ed. H. Inoue \& H. Kunieda (San Francisco: ASP), 576

Morrison, R. \& McCammon, D. 1983, ApJ, 270, 119

Muno, M. P., et al. 2004, ApJ, 613, 1179

Norci, L., \& Ögelman, H. 1995, A\&A, 302, 879

Oskinova, L. M., Ignace, R., Hamann, W.-R., Pollock, A. M. T., \& Brown, J. C. 2003, A\&A, 402, 755
Pallavicini, R., Golub, L., Rosner, R., Vaiana, G. S., Ayres, T., \& Linsky, J. L. 1981, ApJ, 248,279

Park, S., Zhekov, S. A., Burrows, D. N., Garmire, G. P., \& McCray, D. 2005, Advances in Space Research, 35, 991

Parker, J. W. 1992, PASP, 104, 1107

Parker, J. W. 1993, AJ, 106, 560

Parker, J. W., et al. 1998, AJ, 116, 180

Pollock, A. M. T., Haberl, F., \& Corcoran, M. F. 1995, in IAU Symp. 163, Wolf-Rayet Stars: Binaries; Colliding Winds; Evolution, ed. K. A. van der Hucht \& P. M. Williams (Dordrecht: Kluwer), 512

Portegies Zwart, S. F., Pooley, D., \& Lewin, W. H. G. 2002, ApJ, 574, 762

Sasaki, M., Haberl, F., \& Pietsch, W. 2000, A\&AS, 143, 391

Schmitt, J. H. M. M., Fleming, T. A., \& Giampapa, M. S. 1995, ApJ, 450, 392

Shtykovskiy, P., \& Gilfanov, M. 2005, A\&A, 431, 597

Smith, R. K., Brickhouse, N. S., Liedahl, D. A., \& Raymond, J. C. 2001, ApJ, 556, L91

Stelzer, B., Flaccomio, E., Montmerle, T., Micela, G., Sciortino, S., Favata, F., Preibisch, T., \& Feigelson, E. D. 2005, ApJS, 160, 557

Stetson, P. B. 1987, PASP, 99, 191

Townsley, L. K., Broos, P. S., Chartas, G., Moskalenko, E., Nousek, J. A., \& Pavlov, G. G. 2001, Nuclear Instr. \& Methods, 486, 716

Townsley, L. K., Feigelson, E. D., Montmerle, T., Broos, P. S., Chu, Y., \& Garmire, G. P. 2003, ApJ, 593, 874

Townsley, L. K., Broos, P. S., Feigelson, E. D., Brandl, B. R., Chu, Y.-H., Garmire, G. P., \& Pavlov, G. G. 2005, AJ, submitted

van Loon, J. T., \& Zijlstra, A. A. 2001, ApJ, 547, L61

Voges, W., et al. 1999, A\&A, 349, 389 
Walborn, N. R., \& Blades, J. C. 1997, ApJS, 112, 457

Walborn, N. R., et al. 2002, AJ, 123, 2754

Walborn, N. R., Maíz-Apellániz, J., \& Barbá, R. H. 2002, AJ, 124, 1601

Wang, Q., \& Helfand, D. J. 1991a, ApJ, 370, 541

Wang, Q. D. 1995, ApJ, 453, 783

Wang, Q. D. 2004, ApJ, 612, 159

Weaver, R., McCray, R., Castor, J., Shapiro, P., \& Moore, R. 1977, ApJ, 218, 377

This 2-column preprint was prepared with the AAS IATEX macros v5.2. 


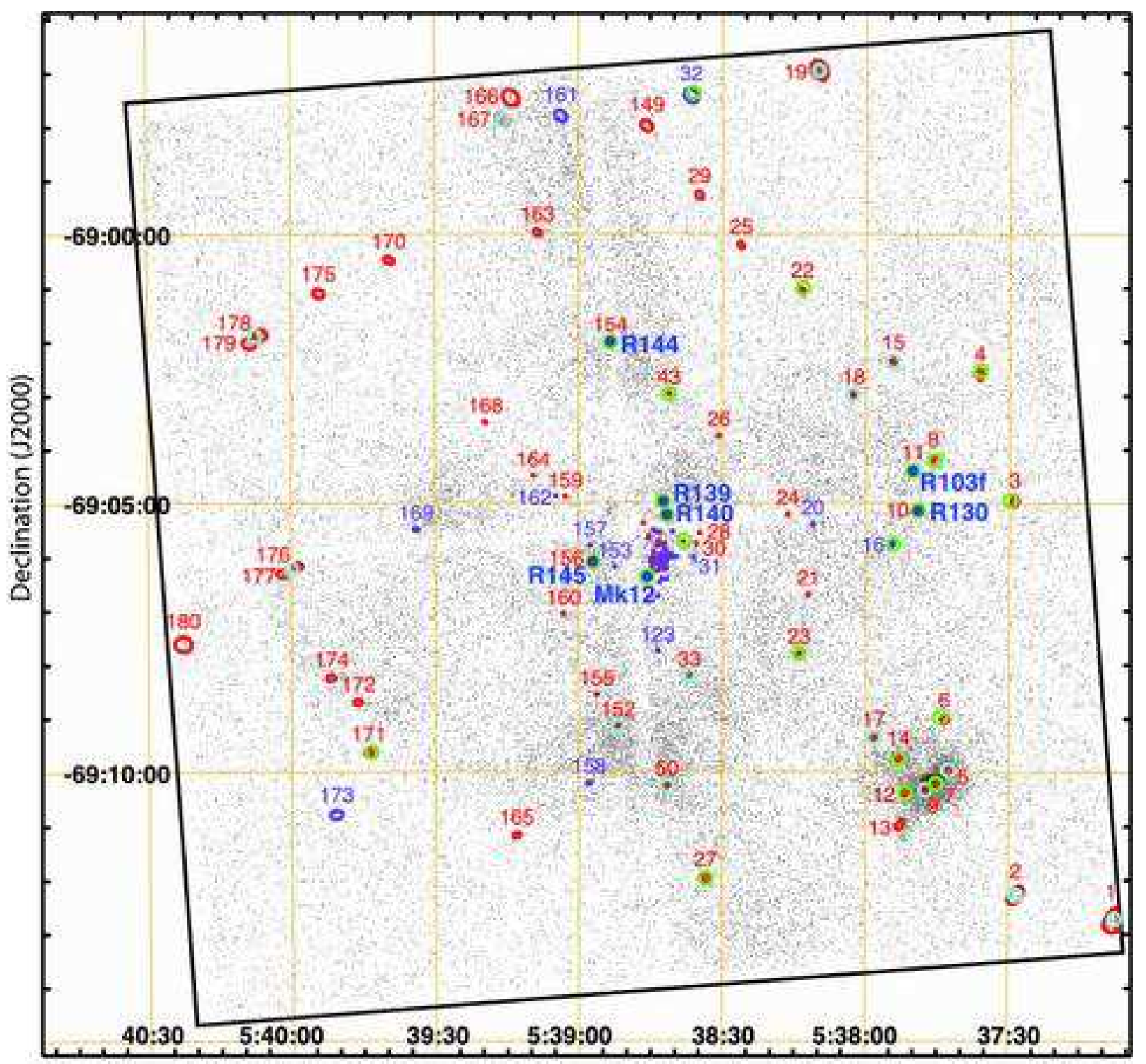

Right Ascension (J2000)

Fig. 1.- A binned image showing the Chandra observation of 30 Dor on the $17^{\prime} \times 17^{\prime}$ ACIS-I array. The aimpoint was on R136. Data were binned by four sky pixels $\left(2^{\prime \prime} \times 2^{\prime \prime}\right)$; events with energies between $0.5 \mathrm{keV}$ and $7 \mathrm{keV}$ were included. Chandra point sources are outlined with red polygons (primary sources from Table 1) and purple polygons (tentative sources from Table 2) and are labeled with their sequence numbers from those tables. These polygons define the event extraction regions for each source and were generated by ACIS Extract using the point spread function (PSF) appropriate for each source location. Their shapes reflect the shape of the PSF at each source location. Some counterparts from other studies are shown with colored circles: 2MASS in green, previously known X-ray sources in cyan, WR stars and a few other notable sources in blue (see §3). Counterparts in R136 (field center) have been omitted for clarity. 


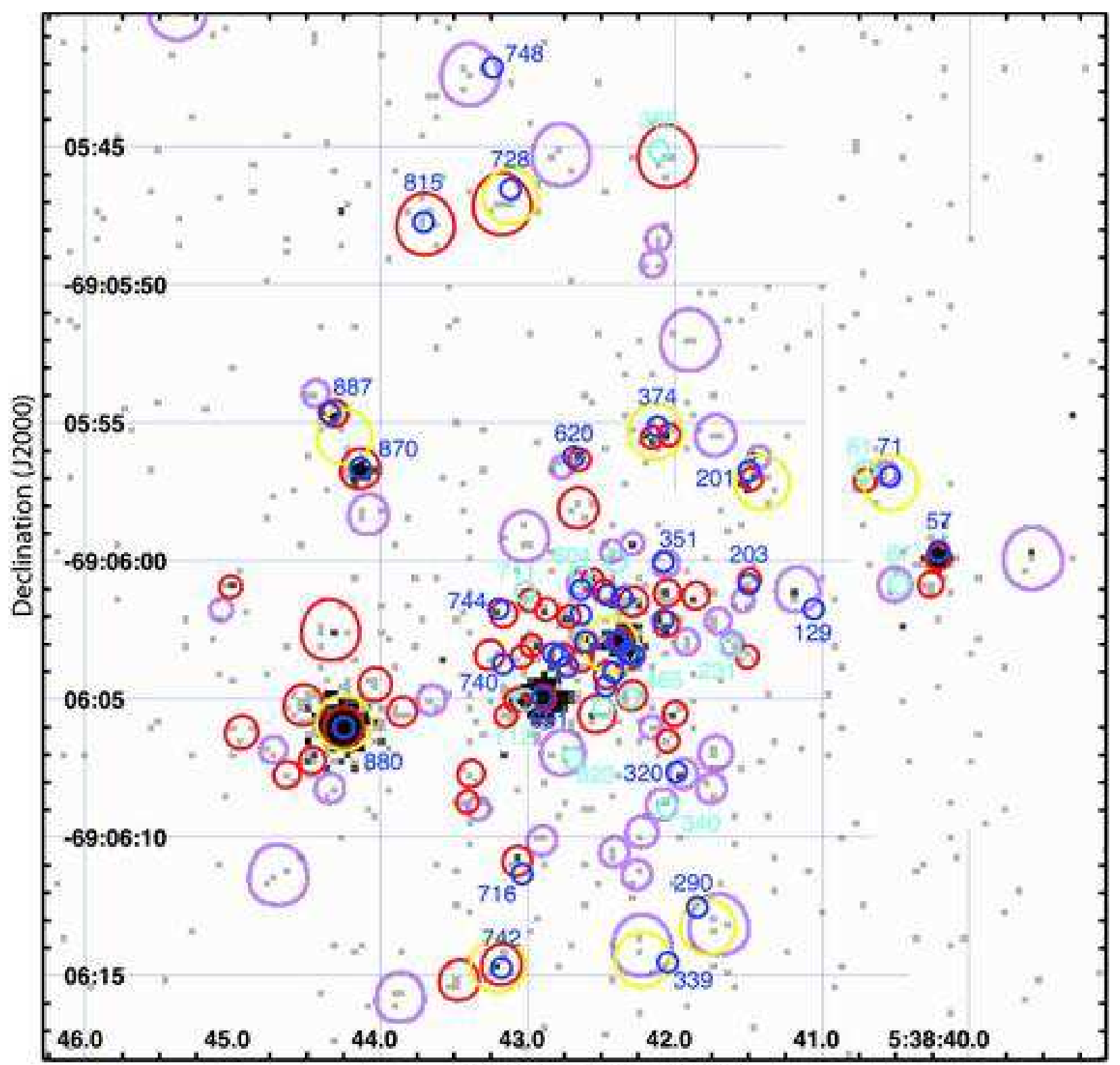

Right Ascension (J2000)

Fig. 2.- An image of the central part of the ACIS observation $\left(\sim 38^{\prime \prime} \times 38^{\prime \prime}\right)$, binned by $0^{\prime \prime} .25$ and centered on the massive stellar cluster R136. Extraction polygons (as in Figure 1) for the ACIS point sources are shown in red (primary sources) and purple (tentative sources) and are based on the 90\% PSF contour in uncrowded regions; smaller extraction polygons were used in crowded regions to minimize cross-contamination of source properties. Some counterparts from 2MASS (those not suffering confusion) are shown as large gold circles. Counterparts from MH94 are shown with small blue circles (brighter MH94 sources listed in CD98) and small cyan circles (fainter sources from the MH94 catalog); their MH94 catalog numbers are given in the outer parts of the field but omitted in the crowded central region around R136a for clarity. All counterparts are given in Table 5 . 


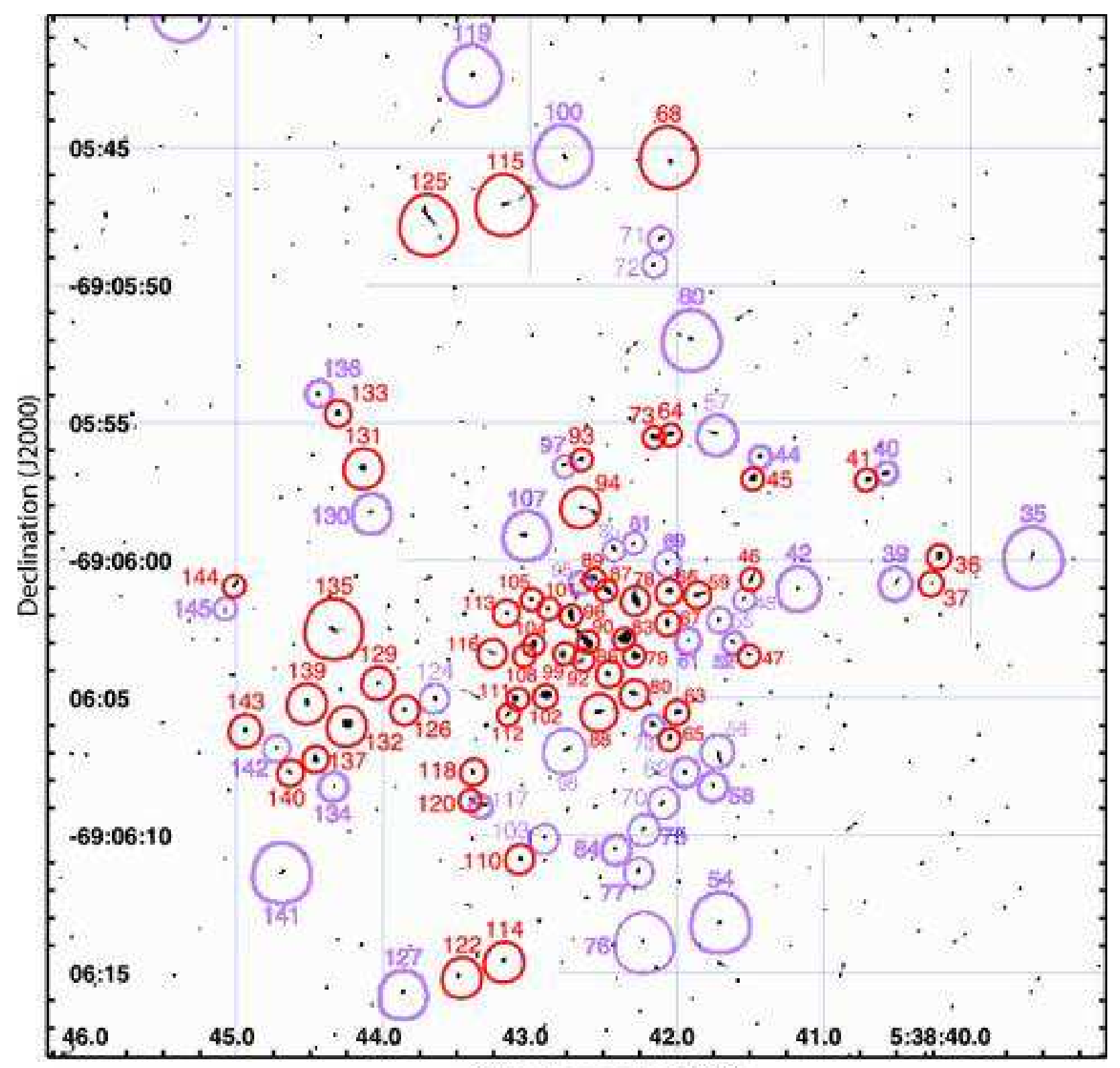

Right Ascension (12000)

Fig. 3.- A maximum likelihood reconstruction (200 iterations) of the field around R136 shown in Figure 2. Extraction polygons for the ACIS point sources that passed all validity criteria are shown as in Figure 2, with primary sources in red and tentative sources in purple. Here counterparts have been omitted; now ACIS sequence numbers are shown for all sources. 

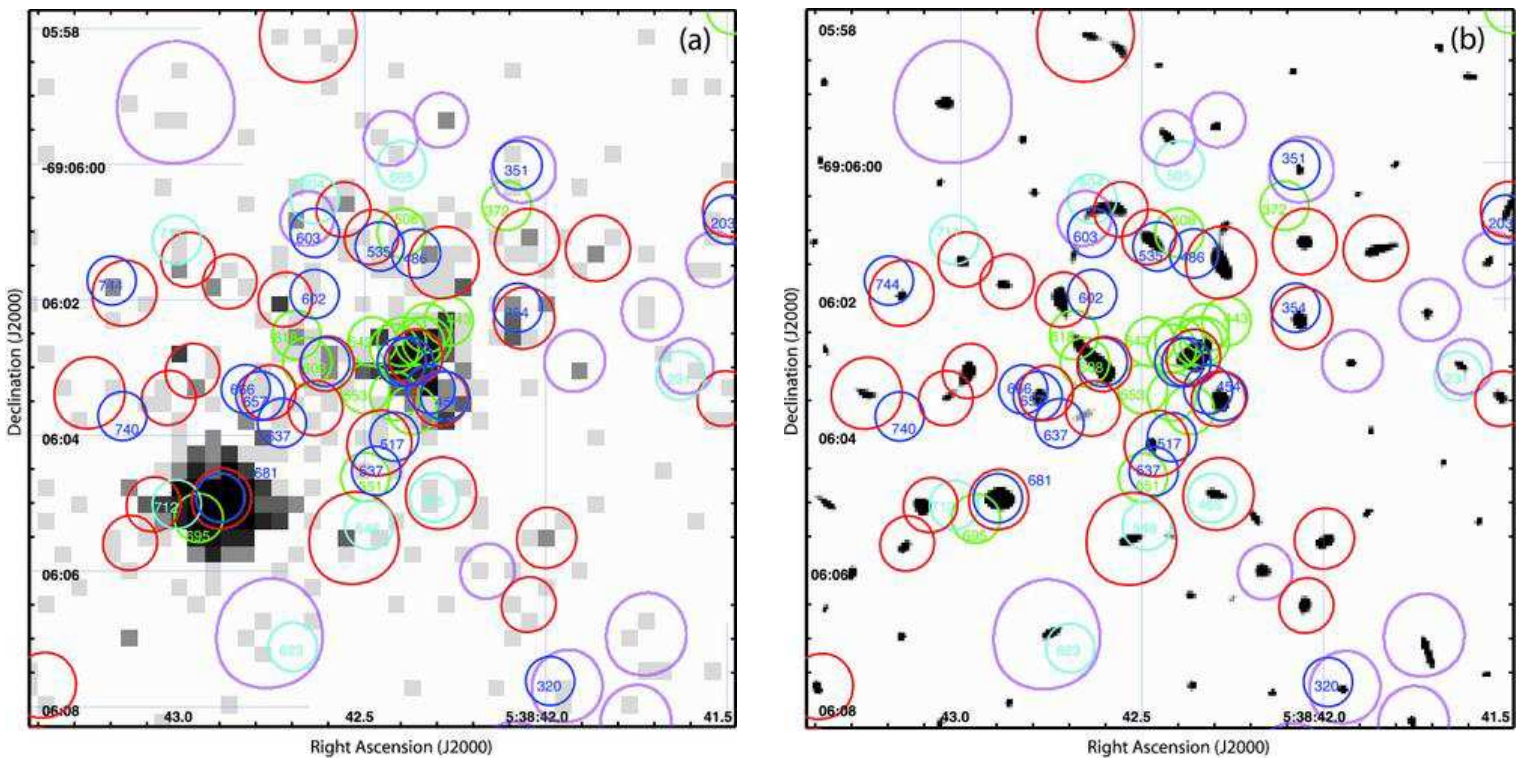

Fig. 4.- (a) A zoom of Figure 2, showing the R136 core $\left(\sim 10^{\prime \prime} \times 10^{\prime \prime}\right)$. As in Figure 2, extraction polygons for ACIS sources are shown in red (primary sources) and purple (tentative sources) and matches to the visual catalog of MH94 are marked with circles of blue (brighter MH94 sources listed in CD98) and cyan (fainter sources from the MH94 catalog). Green circles now show brighter MH94 sources (from the CD98 list) that lack Chandra counterparts. MH94 source names are included for all but the most crowded region around R136a. (b) The reconstructed image of the R136 core, sized to match (a) and showing the same ACIS source regions and MH94 catalog members.
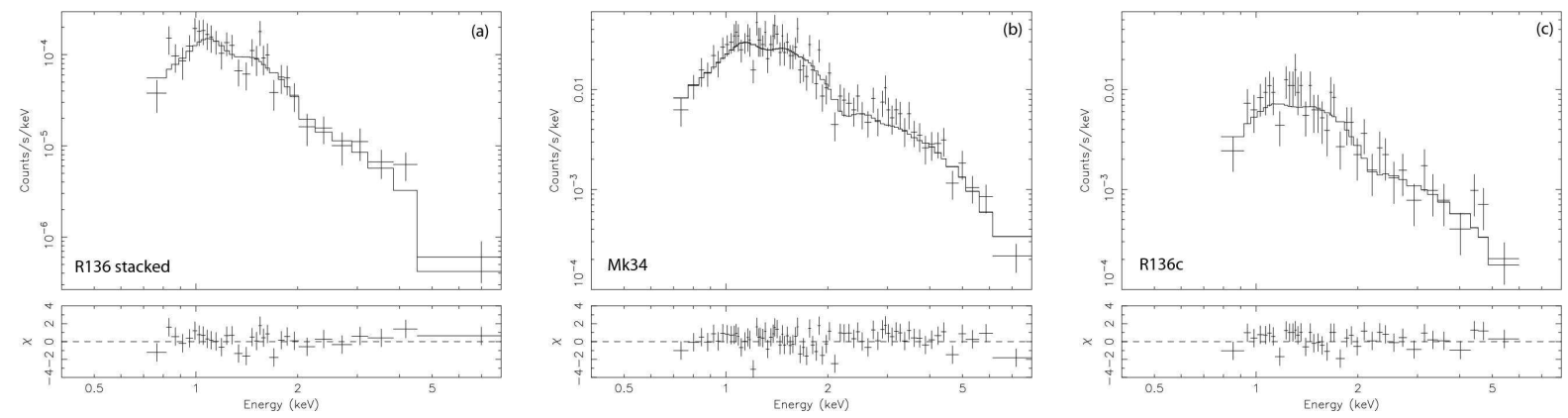

Fig. 5. - ACIS spectra of sources in R136 fit with absorbed thermal plasma models. The top panels show the data and best-fit models; the bottom panels give the (data - model) residuals. Note that the first panel has a different y-axis range than the other two. (a) Average spectrum of all sources within 1' off-axis with photometric significance $<2$ (generally those sources close to R136 with fewer than 10 counts). (b) The WN5h star Mk34. (c) The WN5h star R136c. 

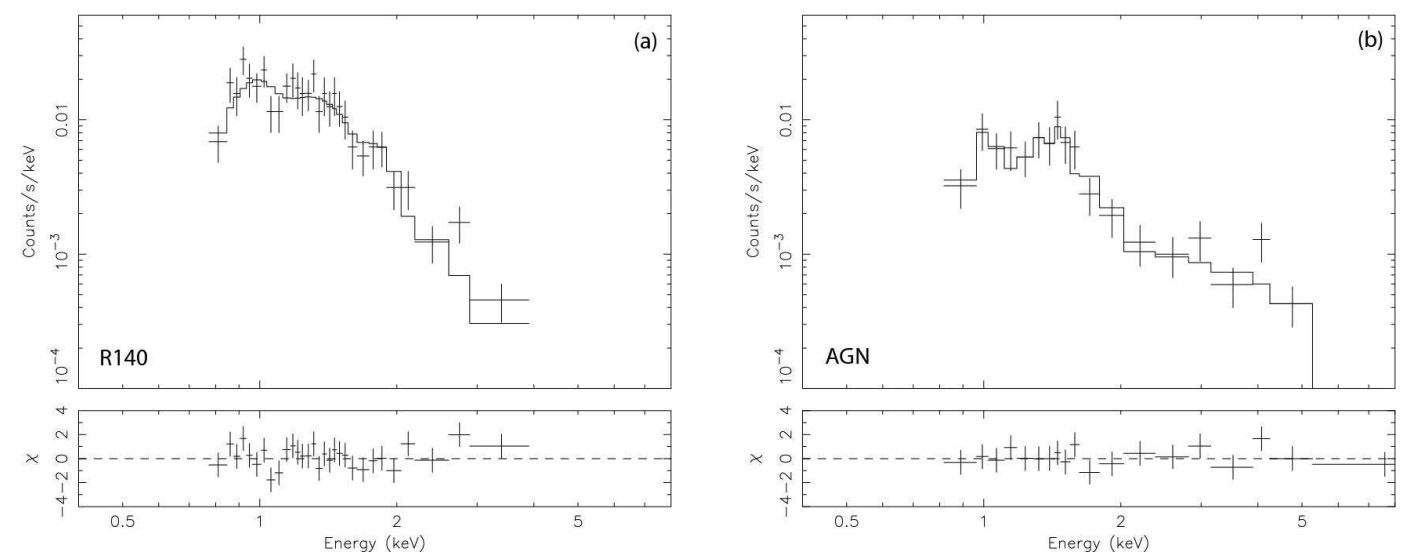

Fig. 6. - Spectral fits of other 30 Dor X-ray sources. Axis ranges match those in Figure 5b and c. (a) The blend of massive stars R 140 a1/a2 fit by a thermal plasma model. (b) A probable background AGN, CXOU J053809.92-685658.3, fit by a power law. 
TABle 1

Main Chandra Catalog: Basic Source Properties

\begin{tabular}{|c|c|c|c|c|c|c|c|c|c|c|c|c|c|c|c|c|}
\hline \multicolumn{2}{|r|}{ Source } & \multicolumn{4}{|c|}{ Position } & \multicolumn{5}{|c|}{ Extracted Counts $\mathrm{a}$} & \multicolumn{6}{|c|}{$\begin{array}{l}\text { Characteristics } \\
\end{array}$} \\
\hline $\begin{array}{c}\text { Seq } \\
\# \\
(1) \\
\end{array}$ & $\begin{array}{c}\text { CXOU J } \\
(2) \\
\end{array}$ & 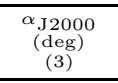 & 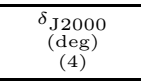 & $\begin{array}{l}\text { Err } \\
\left({ }^{\prime \prime}\right) \\
(5) \\
\end{array}$ & $\begin{array}{c}\theta^{\mathbf{b}} \\
(1) \\
(6) \\
\end{array}$ & $\begin{array}{l}\text { Net } \\
\text { Full } \\
(7) \\
\end{array}$ & $\begin{array}{c}\mathrm{Net} \\
\text { Full } \\
(8) \\
\end{array}$ & $\begin{array}{c}\text { Bkgd } \\
\text { Full } \\
(9) \\
\end{array}$ & $\begin{array}{c}\text { Net } \\
\text { Hard } \\
(10) \\
\end{array}$ & $\begin{array}{l}\text { PSF } \\
\text { Frac } \\
(11) \\
\end{array}$ & $\begin{array}{l}\text { Signif } \\
(12) \\
\end{array}$ & $\begin{array}{c}\log P_{B}{ }^{\mathrm{C}} \\
(13)\end{array}$ & $\begin{array}{l}\text { Anom }^{\mathrm{d}} \\
(14)\end{array}$ & $\begin{array}{l}\operatorname{Var}^{\mathrm{e}} \\
(15) \\
\end{array}$ & $\begin{array}{c}\text { EffExp } \\
(\mathrm{ks}) \\
(16) \\
\end{array}$ & $\begin{array}{c}\begin{array}{c}\text { Med E } \\
(\mathrm{keV}) \\
(17)\end{array} \\
\end{array}$ \\
\hline 1 & $053707.64-691243.4$ & 84.281870 & -69.212077 & 1.2 & 11.1 & 20.3 & 5.9 & 8.7 & 12.1 & 0.76 & 3.1 & $<-5$ & ge.. & & 12.1 & 2.2 \\
\hline 2 & $053728.39-691217.0$ & 84.368330 & -69.204740 & 1.1 & & 11.2 & 5.1 & 9.8 & 6.7 & 0.91 & 2.0 & -2.9 & & $\mathrm{~b}$ & 18.8 & 2.2 \\
\hline 3 & $053728.90-690457.9$ & 84.370428 & -69.082760 & 0.7 & 6.8 & 11.2 & 4.4 & 3.8 & 4.0 & 0.90 & 2.3 & -5.0 & $\mathrm{~g} \ldots$ & 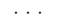 & 12.0 & 1.4 \\
\hline 4 & $053736.30-690236.8$ & $\begin{array}{l}84.401267 \\
84.427678\end{array}$ & -69.043579 & 0.4 & 6.9 & 54.7 & 8.2 & 4.3 & 28.7 & 0.89 & 6.3 & $<-5$ & & a & 19.8 & 2.2 \\
\hline $\begin{array}{l}5 \\
6\end{array}$ & $\begin{array}{l}535742.64-6980988.2 \\
053743.45-690901.8\end{array}$ & $\begin{array}{l}84.427678 \\
84.431083\end{array}$ & $\begin{array}{l}-69.166169 \\
-69.150519\end{array}$ & $\begin{array}{l}0.3 \\
0.7\end{array}$ & $\begin{array}{l}7.0 \\
6.4\end{array}$ & $\begin{array}{l}53.8 \\
11.8\end{array}$ & $\begin{array}{r}14.6 \\
4.9\end{array}$ & $\begin{array}{r}133.2 \\
7.2\end{array}$ & $\begin{array}{l}0.0 \\
0.0\end{array}$ & $\begin{array}{l}0.89 \\
0.90\end{array}$ & $\begin{array}{l}3.6 \\
2.2\end{array}$ & $\begin{array}{l}<-5 \\
-3.7 \\
-3\end{array}$ & $\cdots$. & a & $\begin{array}{l}19.8 \\
19.9\end{array}$ & $\begin{array}{l}1.2 \\
1.5\end{array}$ \\
\hline 7 & $053745.61-691011.1$ & 84.440045 & $\begin{array}{l}-6.150519 \\
-69.169776\end{array}$ & 0.1 & 6.9 & 1574.3 & & $\begin{array}{r}. .2 \\
755.7\end{array}$ & $\begin{array}{r}0.0 \\
535.1\end{array}$ & 0.89 & 31.5 & $<-5$ & $\cdots$ & a & $\begin{array}{l}19.9 \\
19.8\end{array}$ & $\begin{array}{l}1.5 \\
1.6\end{array}$ \\
\hline 8 & & & -69.069622 & 0.6 & 5.5 & & 4.3 & 4.9 & -1 & 0.91 & 0 & 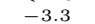 & $\cdots$ & $a_{a}$ & $\begin{array}{l}20.6 \\
202\end{array}$ & $\begin{array}{l}1.6 \\
2.3\end{array}$ \\
\hline 9 & $053747.41-691019.8$ & 84.447567 & -69.172188 & 0.0 & 6.9 & 6186.8 & 83.3 & 611.2 & 2435.3 & 0.89 & 73.9 & $<-5$ & ...p. & a & 19.8 & 1.7 \\
\hline 10 & $053749.11-690508.7$ & 84.454626 & -69.085765 & 0.5 & 5.0 & 9.4 & 4.0 & 2.6 & 3.6 & 0.90 & 2.1 & & g... & & 13.0 & 1.3 \\
\hline 11 & $053750.21-690424.0$ & 84.459225 & -69.073359 & 0.4 & 5.1 & 10.7 & 4.4 & 4.3 & 0.0 & 0.90 & 2.1 & -4.3 & $\therefore .$. & $\mathrm{a}$ & 20.4 & 0.8 \\
\hline 12 & $053751.63-691021.4$ & 84.465160 & -69.172629 & 0.2 & 6.6 & 99.4 & 13.0 & 51.6 & 0.0 & 0.90 & 7.4 & $<-5$ & & $\mathrm{a}$ & 19.9 & 1.0 \\
\hline 13 & $053752.81-691058.5$ & 84.470059 & -69.182923 & 0.5 & 7.0 & 16.2 & 7.2 & 26.8 & 0.6 & 0.89 & 2.1 & -2.6 & & $\mathrm{a}$ & 19.8 & 1.0 \\
\hline $\begin{array}{l}14 \\
15\end{array}$ & 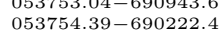 & $\begin{array}{l}84.471006 \\
84.476648\end{array}$ & $\begin{array}{l}-69.162138 \\
-69.039568\end{array}$ & $\begin{array}{l}0.4 \\
0.2\end{array}-1$ & $\begin{array}{l}6.1 \\
5.6\end{array}$ & $\begin{array}{l}15.7 \\
106.5\end{array}$ & $\begin{array}{r}7.1 \\
11.0\end{array}$ & $\begin{array}{r}26.3 \\
2.5\end{array}$ & $\begin{array}{r}1.1 \\
54.2\end{array}$ & $\begin{array}{l}0.90 \\
0.91\end{array}$ & $\begin{array}{l}2.0 \\
9.3 \\
9.3\end{array}-10$ & $<-5$ & $\ldots$ & a & $\begin{array}{l}20.1 \\
20.3\end{array}$ & 1.1 \\
\hline 17 & $053758.24-690921.5$ & 84.492675 & -69.155984 & 0.5 & $\begin{array}{l}5.0 \\
5.5\end{array}$ & 9.1 & $\begin{array}{r}11.0 \\
4.1\end{array}$ & $\begin{array}{l}2.0 \\
3.9\end{array}$ & $\begin{array}{r}0.2 \\
0.6\end{array}$ & $\begin{array}{l}0.91 \\
0.89\end{array}$ & $\begin{array}{l}9.3 \\
1.9\end{array}$ & $\begin{array}{l}<-5 \\
-3.6\end{array}$ & $\ldots$ & $\mathrm{a}$ & 19.5 & $\begin{array}{l}2.1 \\
1.1\end{array}$ \\
\hline 18 & $053802.71-690259.2$ & 84.511320 & -69.049803 & 0.2 & 4.7 & 20.3 & 5.2 & 1.7 & 8.7 & 0.90 & 3.5 & $<-5$ & $\ldots$ & $a$ & 19.4 & 1.1 \\
\hline 19 & $053809.92-685658.3$ & 84.541354 & -68.949539 & 0.3 & 9.3 & 198.8 & 14.9 & 9.2 & 64.2 & 0.90 & 12.9 & $<-5$ & & b & 17.7 & 1.5 \\
\hline 21 & $053812.07-690642.3$ & 84.550295 & -69.111755 & 0.4 & 3.1 & 4.2 & 2.8 & 0.8 & 0.8 & 0.90 & 1.2 & & & & 21.0 & 0.9 \\
\hline 22 & $053813.35-690104.3$ & 84.555643 & -69.017866 & 0.5 & 5.4 & 5.5 & 3.2 & 1.5 & 0.4 & 0.90 & 1.5 & -3.1 & & $\mathrm{a}$ & 20.4 & 1.5 \\
\hline 23 & $053813.97-690747.8$ & 84.558234 & -69.129948 & 0.3 & 3.4 & 6.8 & 3.4 & 1.2 & 0.0 & 0.89 & 1.7 & -4.5 & & $\mathrm{a}$ & 21.0 & 1.1 \\
\hline 24 & $053816.33-690512.6$ & 84.568055 & -69.086850 & 0.3 & 2.6 & 4.6 & 2.8 & 0.4 & 0.9 & 0.89 & 1.3 & -4.1 & $g \cdots$ & & 10.0 & 1.3 \\
\hline $\begin{array}{l}25 \\
26 \\
26\end{array}$ & $\begin{array}{l}03826.14-690013.1 \\
053830-73-690345\end{array}$ & $\begin{array}{l}84.608948 \\
84.628062\end{array}$ & $\begin{array}{l}-69.003654 \\
-69.062559\end{array}$ & $\begin{array}{l}0.2 \\
0.3\end{array}$ & $\begin{array}{l}5.8 \\
2.3\end{array}$ & $\begin{array}{c}58.1 \\
6.4\end{array}$ & $\begin{array}{l}8.3 \\
3.2\end{array}$ & $\begin{array}{l}1.9 \\
0.6\end{array}$ & $\begin{array}{r}18.2 \\
4.9\end{array}$ & $\begin{array}{l}0.90 \\
0.89\end{array}$ & $\begin{array}{l}6.0 \\
1.7\end{array}$ & $<-5$ & $\cdots$ & $\mathrm{a}$ & 20.3 & 1.5 \\
\hline 27 & $053833.46-691158.7$ & $\begin{array}{l}84.020002 \\
84.639422\end{array}$ & $\begin{array}{l}-00.002009 \\
-69.199664\end{array}$ & 0.4 & $\begin{array}{l}2.5 \\
6.3\end{array}$ & 24.1 & $\begin{array}{l}.22 \\
6.2\end{array}$ & $\begin{array}{l}0.0 \\
7.9\end{array}$ & $\begin{array}{r}4.9 \\
15.6\end{array}$ & $\begin{array}{l}0.89 \\
0.90\end{array}$ & 3.6 & $<-5$ & $\cdots$ & a & 20.5 & 2.3 \\
\hline 28 & $053834.73-690533.5$ & 84.644711 & $\begin{array}{l}-69.092656 \\
-696\end{array}$ & 0.3 & 0.9 & 4.6 & 2.8 & 0.4 & ${ }_{1.0}^{0}$ & 0.90 & 1.4 & & g.... $>$ & & 17.7 & 年. \\
\hline 29 & $053834.79-685917.4$ & $\begin{array}{l}84.644711 \\
84.644975\end{array}$ & $\begin{array}{l}-6.092656 \\
-68.988187\end{array}$ & 0.5 & $\begin{array}{l}0.9 \\
6.5\end{array}$ & $\begin{array}{r}4.6 \\
11.4\end{array}$ & $\begin{array}{l}2.8 \\
4.4\end{array}$ & $\begin{array}{l}0.4 \\
3.6\end{array}$ & 1.0 & 0.90 & 1.4 & -5 & g. & $a^{2}$ & 10.6 & 0.9 \\
\hline 30 & $053835.46-690545.4$ & 84.647769 & -69.095971 & 0.3 & 0.8 & 3.5 & $\begin{array}{l}.45 \\
2.5\end{array}$ & $\begin{array}{l}.0 \\
0.5\end{array}$ & $\begin{array}{l}.0 \\
1.0\end{array}$ & 0.90 & 1.1 & -2.7 & $\ldots$ & a & 21.5 & 0.7 \\
\hline 33 & $053836.85-690812.2$ & 84.653559 & -69.136748 & 0.4 & 2.6 & 4.7 & 3.0 & 1.3 & 0.8 & 0.89 & 1.3 & -2.6 & & $\mathrm{a}$ & 21.5 & 1.3 \\
\hline 34 & $053838.07-690543.2$ & 84.658629 & -69.095354 & & 0.6 & 4.5 & 2.8 & 0.5 & 0.0 & 0.90 & 1.3 & & & a & 21.5 & 1.1 \\
\hline 36 & $053840.21-690559.8$ & 84.667548 & -69.099955 & 0.0 & 0.5 & 65.9 & 8.6 & 0.1 & 10.0 & 0.45 & 7.2 & $<-5$ & & $\mathrm{a}$ & 21.6 & 1.2 \\
\hline $\begin{array}{l}37 \\
41\end{array}$ & $\begin{array}{l}053840.26-690600.8 \\
053840.78-690557.8\end{array}$ & $\begin{array}{l}84.667774 \\
84.669622\end{array}$ & $\begin{array}{l}-69.100227 \\
-69099181\end{array}$ & $\begin{array}{l}0.2 \\
0.2\end{array}$ & $\begin{array}{l}0.5 \\
0.4\end{array}$ & $\begin{array}{l}3.9 \\
5.9\end{array}$ & $\begin{array}{l}2.5 \\
30\end{array}$ & 0.1 & $\begin{array}{l}1.0 \\
0.0\end{array}$ & $\begin{array}{l}0.45 \\
0.39\end{array}$ & 1.2 & $<-5$ & & a & $\begin{array}{l}21.6 \\
21.6\end{array}$ & 1.5 \\
\hline $\begin{array}{l}41 \\
43\end{array}$ & $\begin{array}{l}538840.70-69057.0 \\
053841.19-690258.5\end{array}$ & $\begin{array}{l}84.669622 \\
84.671626\end{array}$ & $\begin{array}{l}-69.099181 \\
-69.049587\end{array}$ & $\begin{array}{l}0.2 \\
0.3\end{array}-1$ & $\begin{array}{l}0.4 \\
2.8\end{array}$ & $\begin{array}{l}5.9 \\
5.2\end{array}$ & $\begin{array}{l}3.0 \\
3.0\end{array}$ & $\begin{array}{l}0.1 \\
0.8\end{array}$ & $\begin{array}{l}0.0 \\
0.9\end{array}$ & $\begin{array}{l}0.39 \\
0.89\end{array}$ & 1.6 & $\begin{array}{l}<-5 \\
-37\end{array}$ & & $\mathrm{a}$ & 21.6 & 1.1 \\
\hline 45 & $053841.48-690557.0$ & $\begin{array}{l}84.671020 \\
84.672845\end{array}$ & $\begin{array}{l}-69.049581 \\
-69.099170\end{array}$ & 0.1 & $\begin{array}{l}2.8 \\
0.4\end{array}$ & $\begin{array}{l}.2 \\
8.9\end{array}$ & $\begin{array}{l}3.0 \\
3.5\end{array}$ & $\begin{array}{l}0.8 \\
0.1\end{array}$ & $\begin{array}{l}.9 \\
1.0\end{array}$ & $\begin{array}{l}0.89 \\
0.39\end{array}$ & $\begin{array}{l}1.4 \\
2.2\end{array}$ & $<-5$ & $\ldots$ & $\begin{array}{c}\mathrm{a} \\
\mathrm{a}\end{array}$ & $\begin{array}{l}21.5 \\
21.6\end{array}$ & $\begin{array}{l}1.1 \\
1.1\end{array}$ \\
\hline 46 & $053841.49-690600.6$ & 84.672893 & $\begin{array}{l}-69.100183 \\
-101\end{array}$ & 0.2 & 0.4 & $\begin{array}{l}8.9 \\
2.9\end{array}$ & $\begin{array}{l}3.5 \\
2.3\end{array}$ & 0.1 & $\begin{array}{l}1.0 \\
0.0\end{array}$ & $\begin{array}{l}0.39 \\
0.39\end{array}$ & $\begin{array}{l}2.2 \\
1.0\end{array}$ & $\begin{array}{l}<-5 \\
-3.4\end{array}$ & $\ldots$. & & $\begin{array}{l}21.6 \\
21.6\end{array}$ & $\begin{array}{l}1.1 \\
1.2\end{array}$ \\
\hline 47 & $053841.50-690603.4$ & 84.672956 & -69.100957 & 0.2 & 0.4 & 2.9 & 2.3 & 0.1 & 0.0 & 0.39 & 1.0 & -3.4 &.. & & 21.6 & 1.7 \\
\hline 49 & $053841.56-690515.4$ & 84.673188 & -69.087633 & 0.1 & 0.6 & 14.6 & 4.4 & 0.4 & 4.0 & 0.85 & 2.9 & $<-5$ & $\mathrm{~g} \ldots$ & & 12.9 & 1.3 \\
\hline 50 & $053841.56-691015.4$ & 84.673197 & -69.170950 & 0.4 & 4.5 & 10.2 & 4.9 & 8.8 & 0.0 & 0.90 & 1.9 & -2.7 & & $\mathrm{a}$ & 21.0 & 1.0 \\
\hline 51 & $053841.59-690513.4$ & 84.673312 & -69.087061 & 0.0 & 0.6 & 377.6 & 19.9 & 0.4 & 57.0 & 0.85 & 18.5 & $<-5$ & $\mathrm{~g} \ldots$ & & 14.9 & 1.3 \\
\hline $\begin{array}{l}59 \\
63\end{array}$ & $\begin{array}{l}053841.85-690601.2 \\
053841.99-690005.4\end{array}$ & $\begin{array}{l}84.674408 \\
84.674998\end{array}$ & $\begin{array}{l}-69.100342 \\
-69.101526\end{array}$ & $\begin{array}{l}0.2 \\
0.2\end{array}$ & $\begin{array}{l}0.4 \\
0.4\end{array}$ & $\begin{array}{l}3.8 \\
3.8\end{array}$ & $\begin{array}{l}2.5 \\
2.5\end{array}$ & $\begin{array}{l}0.2 \\
0.2\end{array}$ & $\begin{array}{l}0.0 \\
0.0\end{array}$ & $\begin{array}{l}0.50 \\
0.45\end{array}$ & 1.2 & -4.4 & & $\mathrm{a}$ & 21.6 & 1.2 \\
\hline 63 & $\begin{array}{l}038841.99-69065.4 \\
05384204-6905554\end{array}$ & $\begin{array}{l}84.674998 \\
84.675175\end{array}$ & $\begin{array}{l}-69.101526 \\
-69098726\end{array}$ & 0.2 & 0.4 & 3.8 & $\begin{array}{l}2.5 \\
30\end{array}$ & 0.2 & 0.0 & $\begin{array}{l}0.45 \\
0.39\end{array}$ & 1.2 & -4.5 & & $\mathrm{a}$ & 21.6 & \\
\hline $\begin{array}{l}64 \\
65\end{array}$ & 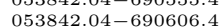 & 84.675205 & $\begin{array}{l}-69.098720 \\
-69.101800\end{array}$ & $\begin{array}{l}0.1 \\
0.2\end{array}$ & $\begin{array}{l}0.3 \\
0.5\end{array}$ & $\begin{array}{l}5.9 \\
2.9\end{array}$ & $\begin{array}{l}3.0 \\
2.3\end{array}$ & $\begin{array}{l}0.1 \\
0.1\end{array}$ & $\begin{array}{l}2.0 \\
1.0\end{array}$ & $\begin{array}{l}0.39 \\
0.39\end{array}$ & $\begin{array}{l}1.6 \\
1.0\end{array}$ & $\begin{array}{l}<-5 \\
-3.4\end{array}$ & $\ldots$ & a & $\begin{array}{l}21.6 \\
21.6\end{array}$ & 1.1 \\
\hline 66 & $053842.05-690601.1$ & 84.675222 & -69.100314 & 0.1 & 0.4 & 5.8 & 3.0 & 0.2 & 1.9 & 0.50 & 1.6 & $<-5$ & $\ldots$ & $\mathrm{a}$ & 21.6 & 1.2 \\
\hline 67 & $053842.06-690602.2$ & 84.675254 & -69.100627 & 0.1 & 0.4 & 10.8 & 3.8 & 0.2 & 0.0 & 0.46 & 2.4 & $<-5$ & $\ldots$. & a & 21.6 & 1.4 \\
\hline 68 & $053842.06-690545.3$ & 84.675256 & -69.095925 & 0.3 & 0.3 & 5.0 & 3.0 & 1.0 & 0.0 & 0.90 & 1.4 & -3.3 & & $\mathrm{a}$ & 21.6 & 1.4 \\
\hline 73 & $053842.15-690555.4$ & 84.675654 & -69.098749 & 0.1 & 0.3 & 5.9 & 3.0 & 0.1 & 0.0 & 0.39 & 1.6 & & $\ldots$. & b & & 1.0 \\
\hline 78 & $053842.28-690601.4$ & 84.676180 & -69.100399 & 0.1 & 0.4 & 9.8 & 3.7 & 0.2 & 0.0 & 0.55 & 2.3 & $<-5$ & & $\mathrm{a}$ & 21.6 & 1.3 \\
\hline $\begin{array}{r}79 \\
80\end{array}$ & $053842.29-690603.4$ & 84.676211 & -69.100957 & 0.1 & 0.4 & 21.9 & 5.22 & 0.1 & 5.0 & 0.39 & 3.8 & $<-5$ & & $\mathrm{a}$ & 21.6 & 1.4 \\
\hline $\begin{array}{l}80 \\
82\end{array}$ & $\begin{array}{l}053842.29-69064.8 \\
053842.34-690458\end{array}$ & $\begin{array}{l}84.676211 \\
84.676433\end{array}$ & $\begin{array}{l}-69.101344 \\
-69082831\end{array}$ & 0.2 & $\begin{array}{l}0.4 \\
0.8\end{array}$ & $\begin{array}{r}2.7 \\
15.1\end{array}$ & $\begin{array}{l}2.3 \\
4.5\end{array}$ & $\begin{array}{l}0.3 \\
0.9\end{array}$ & $\begin{array}{l}0.0 \\
1.9\end{array}$ & $\begin{array}{l}0.55 \\
0.90\end{array}$ & $\begin{array}{l}0.9 \\
3.0\end{array}$ & -2.6 & & $\cdots$ & $\begin{array}{l}21.6 \\
21.8\end{array}$ & 1.2 \\
\hline 83 & $053842.35-690602.8$ & 84.676498 & $\begin{array}{l}-69.082031 \\
-69.100786\end{array}$ & $\begin{array}{l}0.1 \\
0.0\end{array}$ & $\begin{array}{l}0.8 \\
0.4\end{array}$ & $\begin{array}{l}10.1 \\
52.8\end{array}$ & $\begin{array}{l}.5 \\
7.8\end{array}$ & 0.2 & $\begin{array}{l}1.9 \\
5.9\end{array}$ & $\begin{array}{l}0.90 \\
0.39\end{array}$ & $\begin{array}{l}3.0 \\
6.3\end{array}$ & $<-5$ & & $\mathrm{a}$ & 21.6 & 1.4 \\
\hline 86 & $053842.46-690604.0$ & 84.676920 & -69.101138 & 0.2 & 0.4 & $\begin{array}{r}0.8 \\
3.8\end{array}$ & 2.5 & 0.2 & 0.9 & 0.50 & 1.2 & -4.0 & $\ldots$ & $a_{a}$ & 21.6 & 0.9 \\
\hline 87 & $053842.48-690601.0$ & 84.677009 & -69.100297 & 0.2 & 0.4 & $\begin{array}{l}4.9 \\
4.9\end{array}$ & 2.8 & 0.1 & 0.0 & 0.39 & 1.4 & $<-5$ & $\cdots$ & $\begin{array}{c}a \\
a\end{array}$ & 21.6 & 1.0 \\
\hline 88 & $053842.53-690605.4$ & 84.677216 & -69.101526 & 0.1 & 0.4 & 5.6 & 3.0 & 0.4 & 2.9 & 0.71 & 1.5 & $<-5$ & $\ldots$ & $\mathrm{a}$ & 21.6 & 3.4 \\
\hline 89 & $053842.55-690600.6$ & 84.677329 & -69.100183 & 0.1 & 0.3 & 3.9 & 2.5 & 0.1 & 1.0 & 0.39 & 1.2 & -4.8 & & & 21.6 & 1.4 \\
\hline 90 & $053842.60-690602.9$ & 84.677520 & -69.100815 & 0.1 & 0.4 & 10.8 & 3.8 & 0.2 & 2.9 & 0.39 & 2.4 & $<-5$ & & $\mathrm{a}$ & 21.6 & 1.2 \\
\hline 92 & $053842.63-690603.5$ & 84.677650 & -69.100997 & 0.2 & 0.4 & 4.8 & 2.8 & 0.2 & 0.0 & 0.39 & 1.4 & $<-5$ & & $\mathrm{a}$ & 21.6 & 1.2 \\
\hline $\begin{array}{l}93 \\
94\end{array}$ & 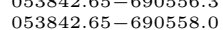 & $\begin{array}{l}84.677712 \\
84.677744\end{array}$ & $\begin{array}{l}-69.098976 \\
-69.099455\end{array}$ & $\begin{array}{l}0.1 \\
0.3\end{array}$ & $\begin{array}{l}0.3 \\
0.3\end{array}$ & $\begin{array}{l}3.9 \\
3.6\end{array}$ & $\begin{array}{l}2.5 \\
2.5\end{array}$ & $\begin{array}{l}0.1 \\
0.4\end{array}$ & $\begin{array}{l}0.0 \\
1.9\end{array}$ & $\begin{array}{l}0.39 \\
0.75\end{array}$ & $\begin{array}{l}1.2 \\
1.1\end{array}$ & $\begin{array}{l}<-5 \\
-3.0\end{array}$ & $\ldots$. & $\mathrm{a}$ & $\begin{array}{l}21.6 \\
21.6\end{array}$ & $\begin{array}{l}1.3 \\
2.1\end{array}$ \\
\hline 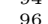 & $05384271-6900619$ & 84677999 & 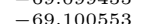 & 01 & 0.5 & 4.9 & 28 & 01 & $\begin{array}{ll}0.5 \\
0\end{array}$ & 0.39 & 1.1 & $<-5$ & $\cdots$ & $a$ & 21.6 & 1.14 \\
\hline
\end{tabular}


TABLE $1-$ Continued

\begin{tabular}{|c|c|c|c|c|c|c|c|c|c|c|c|c|c|c|c|c|}
\hline \multirow{2}{*}{\multicolumn{2}{|c|}{$\begin{array}{c}\text { Source } \\
\text { CXOU J } \\
\text { (2) }\end{array}$}} & \multicolumn{4}{|c|}{ Position } & \multicolumn{5}{|c|}{ Extracted Counts $\mathrm{a}$} & \multicolumn{6}{|c|}{ Characteristics } \\
\hline & & $\begin{array}{c}\alpha_{\text {J2000 }} \\
\text { (deg) } \\
\text { (3) }\end{array}$ & $\begin{array}{c}\delta_{\text {J2000 }} \\
\text { (deg) } \\
(4)\end{array}$ & $\begin{array}{l}\text { Err } \\
\left({ }^{\prime \prime}\right) \\
(5)\end{array}$ & $\begin{array}{c}\theta^{\mathrm{D}} \\
\left({ }^{\prime}\right) \\
(6)\end{array}$ & $\begin{array}{c}\text { Net } \\
\text { Full } \\
(7)\end{array}$ & $\begin{array}{c}\Delta \text { Net } \\
\text { Full } \\
(8)\end{array}$ & $\begin{array}{l}\text { Bkgd } \\
\text { Full } \\
(9)\end{array}$ & $\begin{array}{c}\text { Net } \\
\text { Hard } \\
(10)\end{array}$ & $\begin{array}{l}\text { PSF } \\
\text { Frac } \\
(11)\end{array}$ & $\begin{array}{c}\text { Signif } \\
(12)\end{array}$ & $\begin{array}{c}\log P_{B}{ }^{\mathrm{c}} \\
\text { (13) }\end{array}$ & $\begin{array}{l}\text { Anom }^{\mathrm{d}} \\
(14)\end{array}$ & $\begin{array}{l}\operatorname{Var}^{\mathrm{e}} \\
(15)\end{array}$ & $\begin{array}{c}\text { EffExp } \\
(\mathrm{ks}) \\
(16)\end{array}$ & $\begin{array}{c}\text { Med E } \\
(\mathrm{keV}) \\
(17)\end{array}$ \\
\hline 99 & $053842.76-690603.3$ & 84.678189 & -69.100933 & 0.2 & 0.4 & 5.9 & 3.0 & 0.1 & 1.0 & 0.39 & 1.6 & $<<-5$ & $\ldots$ & $\mathrm{a}$ & 21.6 & 1.0 \\
\hline 101 & $053842.87-690601.7$ & 84.678637 & -69.100479 & 0.2 & 0.3 & 3.9 & 2.5 & 0.1 & 2.0 & 0.39 & $\begin{array}{l}1.2 \\
1.2\end{array}$ & -4.9 & $\ldots$ & $\mathrm{a}$ & 21.6 & 2.3 \\
\hline 102 & $053842.89-690604.9$ & 84.678732 & -69.101367 & 0.0 & 0.4 & 246.8 & 16.2 & 0.2 & 80.0 & 0.45 & 14.7 & $<-5$ & $\ldots$. & $\mathrm{a}$ & 21.6 & 1.5 \\
\hline 104 & $053842.97-690603.0$ & $\begin{array}{l}84.679067 \\
84679116\end{array}$ & -69.100843 & 0.1 & 0.4 & 7.9 & 3.4 & 0.1 & 2.0 & 0.39 & 2.0 & $<-5$ & $\ldots$ & $\mathrm{a}$ & 21.6 & 1.8 \\
\hline $\begin{array}{l}105 \\
106\end{array}$ & $\begin{array}{l}053842.98-690601.3 \\
05384302-690533 .\end{array}$ & $\begin{array}{l}84.679116 \\
84.679269\end{array}$ & $\begin{array}{l}-69.100388 \\
-69.092512\end{array}$ & $\begin{array}{l}0.1 \\
0.6\end{array}-1$ & $\begin{array}{l}0.3 \\
0.2\end{array}$ & $\begin{array}{l}3.9 \\
3.5\end{array}$ & $\begin{array}{l}2.5 \\
2.5\end{array}$ & $\begin{array}{l}0.1 \\
0.5\end{array}$ & $\begin{array}{l}1.0 \\
0.9\end{array}$ & $\begin{array}{l}0.39 \\
0.90\end{array}$ & $\begin{array}{l}1.2 \\
1.1\end{array}$ & $\begin{array}{l}-4.8 \\
-2.6\end{array}$ & $\ldots$. & $\ldots$ & $\begin{array}{l}21.6 \\
13.1\end{array}$ & 1.6 \\
\hline 108 & $053843.04-690603.4$ & $\begin{array}{l}84.679269 \\
84.679338\end{array}$ & $\begin{array}{l}-69.092512 \\
-69.100954\end{array}$ & $\begin{array}{l}0.6 \\
0.2\end{array}-1$ & $\begin{array}{l}0.2 \\
0.4\end{array}$ & $\begin{array}{l}3.5 \\
4.9\end{array}$ & $\begin{array}{l}2.5 \\
2.8\end{array}$ & $\begin{array}{l}0.5 \\
0.1\end{array}$ & $\begin{array}{l}0.9 \\
1.0\end{array}$ & $\begin{array}{l}0.90 \\
0.39\end{array}$ & $\begin{array}{l}1.1 \\
1.4\end{array}$ & $<-5$ & $\mathrm{~g} \cdots$ & $\cdots$ & $\begin{array}{l}13.1 \\
21.6\end{array}$ & 1.2 \\
\hline 110 & $053843.07-690610.8$ & 84.679466 & -69.103007 & 0.1 & 0.5 & $\begin{array}{l}4.9 \\
3.8\end{array}$ & 2.5 & 0.2 & 0.9 & 0.56 & 1.2 & -3.9 & $\ldots$ & a & 21.6 & 1.4 \\
\hline 111 & $053843.08-690605.0$ & 84.679514 & -69.101390 & 0.1 & 0.4 & 13.9 & $\begin{array}{l}.0 \\
4.3\end{array}$ & $\begin{array}{l}0.1 \\
0.1\end{array}$ & 3.0 & $\begin{array}{l}0.30 \\
0.39\end{array}$ & 2.9 & $<-5$ & & a & 21.6 & $\begin{array}{l}1.4 \\
1.3\end{array}$ \\
\hline 112 & $053843.14-690605.5$ & 84.679781 & -69.101548 & 0.2 & 0.4 & 4.9 & 2.8 & 0.1 & 1.0 & 0.39 & 1.4 & $<-5$ & & $\mathrm{a}$ & 21.6 & 1.6 \\
\hline 113 & $053843.16-690601.8$ & 84.679849 & -69.100525 & 0.2 & 0.3 & 3.8 & 2.5 & 0.2 & 1.9 & 0.50 & 1.2 & -4.2 & & $\mathrm{a}$ & 21.6 & 1.7 \\
\hline 114 & $053843.17-690614.5$ & 84.679912 & -69.104043 & 0.1 & 0.5 & 5.6 & 3.0 & 0.4 & 1.9 & 0.75 & 1.6 & $<-5$ & $\ldots$. & a & 21.6 & 1.3 \\
\hline 115 & $053843.17-690547.0$ & 84.679916 & -69.096404 & 0.2 & 0.2 & 5.0 & 3.0 & 1.0 & & 0.90 & 1.4 & -3.2 & $\cdots$ & $\mathrm{a}$ & 21.6 & 1.3 \\
\hline $\begin{array}{l}116 \\
118\end{array}$ & $\begin{array}{l}053843.26-690003.3 \\
053843.38-690607.6\end{array}$ & $\begin{array}{l}84.680250 \\
84.680775\end{array}$ & $\begin{array}{l}-69.100932 \\
-69.102130\end{array}$ & $\begin{array}{l}0.3 \\
0.2\end{array}-1$ & $\begin{array}{l}0.4 \\
0.4\end{array}$ & $\begin{array}{l}2.8 \\
2.8\end{array}$ & $\begin{array}{l}2.3 \\
2.3\end{array}$ & $\begin{array}{l}0.2 \\
0.2\end{array}$ & $\begin{array}{l}0.0 \\
0.9\end{array}$ & $\begin{array}{l}0.55 \\
0.50\end{array}$ & $\begin{array}{l}0.9 \\
1.0\end{array}$ & -2.8 & $\cdots$ & $\therefore$ & 21.6 & 1.3 \\
\hline $\begin{array}{l}118 \\
120\end{array}$ & $053843.40-690608.6$ & $\begin{array}{l}84.680775 \\
84.680870\end{array}$ & $\begin{array}{l}-69.102130 \\
-69.102415\end{array}$ & $\begin{array}{l}0.2 \\
0.2\end{array}-1$ & $\begin{array}{l}0.4 \\
0.4\end{array}$ & $\begin{array}{l}2.8 \\
2.9\end{array}$ & $\begin{array}{l}2.3 \\
2.3\end{array}$ & $\begin{array}{l}0.2 \\
0.1\end{array}$ & $\begin{array}{l}0.9 \\
1.0\end{array}$ & $\begin{array}{l}0.50 \\
0.39\end{array}$ & $\begin{array}{l}1.0 \\
1.0\end{array}$ & $\begin{array}{l}-3.1 \\
-3.5\end{array}$ & $\cdots$ & $\cdots$ & $\begin{array}{l}21.6 \\
21.6\end{array}$ & $\begin{array}{l}1.6 \\
1.4\end{array}$ \\
\hline 122 & 0 & 84681109 & $\begin{array}{l}-69104202 \\
-69102\end{array}$ & 022 & 0,4 & 46 & 28 & 04 & 09 & 0.75 & 1.0 & -41 & $\cdots$ & a & 21.6 & 1.4 \\
\hline 125 & $053843.69-690547.7$ & 84.682080 & -69.096607 & 0.2 & $\begin{array}{l}0.0 \\
0.1\end{array}$ & $\begin{array}{l}4.0 \\
7.0\end{array}$ & $\begin{array}{l}.8 \\
3.4\end{array}$ & $\begin{array}{l}.4 \\
1.0\end{array}$ & 0.0 & 0.90 & 1.8 & $\begin{array}{l}-4.1 \\
-5.0\end{array}$ & & $\mathrm{a}$ & 21.6 & $\begin{array}{l}1.4 \\
1.0\end{array}$ \\
\hline 126 & $053843.85-690605.4$ & 84.682721 & -69.101504 & 0.2 & 0.4 & 3.8 & 2.5 & 0.2 & 0.0 & 0.55 & 1.2 & -4.0 & & $\mathrm{a}$ & 21.6 & 1.8 \\
\hline 129 & $053844.03-690604.4$ & 84.683487 & -69.101230 & 0.2 & 0.4 & 4.7 & 2.8 & 0.3 & 2.9 & 0.64 & 1.4 & $<-5$ & & $\mathrm{a}$ & 21.6 & 2.7 \\
\hline 131 & $053844.13-690556.6$ & 84.683903 & -69.099062 & 0.0 & 0.2 & 50.6 & 7.7 & 0.4 & 3.9 & 0.75 & 6.2 & $<-5$ & & a & 21.7 & 1.2 \\
\hline 132 & $\begin{array}{l}053844.25-690605.9 \\
053844.30-690554\end{array}$ & $\begin{array}{l}84.684381 \\
84684621\end{array}$ & -69.101663 & 0.0 & 0.4 & $\begin{array}{r}948.6 \\
14.8\end{array}$ & $\begin{array}{r}31.3 \\
44\end{array}$ & 0.4 & 325.9 & 0.75 & 29.8 & $<-5$ & & a & 21.6 & 1.6 \\
\hline $\begin{array}{l}133 \\
135\end{array}$ & $\begin{array}{l}0338444.30-690554.6 \\
05384434-690602.4\end{array}$ & $\begin{array}{l}84.684621 \\
84.684760\end{array}$ & $\begin{array}{l}-69.098510 \\
-69.100684\end{array}$ & $\begin{array}{l}0.1 \\
0.3\end{array}$ & $\begin{array}{l}0.2 \\
0.3\end{array}$ & $\begin{array}{r}14.8 \\
7.2\end{array}$ & $\begin{array}{l}4.4 \\
3.4\end{array}$ & $\begin{array}{l}0.2 \\
0.8\end{array}$ & $\begin{array}{l}3.0 \\
1.8\end{array}$ & $\begin{array}{l}0.50 \\
0.90\end{array}$ & $\begin{array}{l}3.0 \\
1.8\end{array}$ & $\begin{array}{l}<-5 \\
<-5\end{array}$ & $\cdots$ & $\begin{array}{l}\mathrm{a} \\
\mathrm{a}\end{array}$ & $\begin{array}{l}21.7 \\
21.6\end{array}$ & 1.7 \\
\hline 列 & 0 & $\begin{array}{l}84.084700 \\
8465259\end{array}$ & $\begin{array}{l}-69.10084 \\
-6910199\end{array}$ & 0.3 & 0.3 & $\because .2$ & $\begin{array}{l}3.4 \\
3.4\end{array}$ & 0.8 & 1.8 & 0.90 & 1.8 & $\begin{array}{l}-5 \\
<-5\end{array}$ & $\cdots$ & $a_{a}$ & 21.6 & 1.0 \\
\hline 139 & $053844.52-690605.1$ & 84.685514 & -69.101436 & 0.1 & $\begin{array}{l}0.4 \\
0.4\end{array}$ & $\begin{array}{l}1.0 \\
13.6\end{array}$ & $\begin{array}{l}.4 \\
4.3\end{array}$ & 0.4 & $\begin{array}{l}0.0 \\
3.9\end{array}$ & 0.75 & $\begin{array}{l}2.0 \\
2.8\end{array}$ & $<-5$ & $\ldots$ & $a_{a}$ & 21.6 & $\begin{array}{l}1.1 \\
1.4\end{array}$ \\
\hline 140 & $053844.63-690607.7$ & 84.685973 & -69.102140 & 0.3 & 0.4 & $\begin{array}{r}2.8 \\
2.8\end{array}$ & 2.3 & $\begin{array}{l}0.4 \\
0.2\end{array}$ & $\begin{array}{l}.5 \\
2.0\end{array}$ & 0.50 & $\begin{array}{l}2.0 \\
1.0\end{array}$ & -3.3 & $\ldots$. & & 21.6 & $\begin{array}{l}2.4 \\
2.7\end{array}$ \\
\hline 143 & $053844.94-690606.1$ & 84.687262 & -69.101713 & 0.3 & 0.4 & 2.8 & 2.3 & 0.2 & 0.9 & 0.64 & 0.9 & -2.8 & $\ldots$. & .. & 21.7 & 1.6 \\
\hline 144 & $053845.01-690600.9$ & 84.687572 & -69.100252 & 0.1 & 0.3 & 2.9 & 2.3 & 0.1 & 1.0 & 0.39 & 1.0 & -3.7 & & & 21.7 & 1.9 \\
\hline 146 & $053845.29-690536.8$ & 84.688725 & -69.093558 & 0.2 & 0.1 & 4.3 & 2.8 & 0.7 & 0.9 & 0.90 & 1.3 & -3.0 & $\mathrm{~g} \ldots$ & & 15.7 & 1.2 \\
\hline 149 & $\begin{array}{l}053845.76-685759.8 \\
038346.48-690522.5\end{array}$ & $\begin{array}{l}84.690689 \\
84693691\end{array}$ & $\begin{array}{l}-68.966618 \\
-69089594\end{array}$ & 1.0 & 7.7 & 12.2 & 4.9 & 6.8 & 5.2 & 0.90 & 2.2 & -4.1 & $\ldots$ & $\mathrm{a}$ & 19.6 & 1.7 \\
\hline $\begin{array}{l}150 \\
152 \\
152-2\end{array}$ & $\begin{array}{l}033846.48-690022.5 \\
05385179-690908.5\end{array}$ & $\begin{array}{l}84.693691 \\
84.715827\end{array}$ & $\begin{array}{l}-69.089594 \\
-69.152366\end{array}$ & $\begin{array}{l}0.4 \\
0.2\end{array}-1$ & $\begin{array}{l}0.4 \\
3.5\end{array}$ & $\begin{array}{r}2.7 \\
15.8\end{array}$ & $\begin{array}{l}2.3 \\
4.9\end{array}$ & $\begin{array}{l}0.3 \\
3.2\end{array}$ & $\begin{array}{l}0.0 \\
-7.8\end{array}$ & $\begin{array}{l}0.90 \\
0.89\end{array}$ & 0.9 & -2.7 & $\mathrm{~g} \ldots$ & $\cdots$ & 8.4 & 1.4 \\
\hline 152 & $05853.19-6909080.50$ & $\begin{array}{l}84.15027 \\
8472049\end{array}$ & $\begin{array}{l}-69.153000 \\
-6903351\end{array}$ & 0.2 & $\begin{array}{l}3.5 \\
3 .\end{array}$ & 15.8 & 4.9 & 3.2 & 0.8 & 0.89 & 2.9 & $\begin{array}{ll}-5 \\
<-5\end{array}$ & $\ldots$ & $\mathrm{a}$ & $\begin{array}{l}21.5 \\
87\end{array}$ & 1.0 \\
\hline 155 & 0 & 84.734474 & 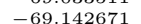 & 0.4 & $\begin{array}{l}3.0 \\
3.0\end{array}$ & 5.9 & $\begin{array}{ll}3.1 \\
3.2\end{array}$ & 1.0 & $\begin{array}{ll}0.3 \\
0.0\end{array}$ & 0.89 & 1.6 & $\begin{array}{lll}-3.9 & \\
-3 & 0\end{array}$ & $g \ldots$ & a & 21.6 & 1.0 \\
\hline 156 & $053857.07-690605.5$ & 84.737795 & -69.101544 & 0.1 & 1.1 & 11.1 & $\begin{array}{l}.2 \\
4.0\end{array}$ & 0.9 & 6.9 & 0.90 & 2.4 & $<-5$ & $\ldots$. & a & 21.9 & 2.5 \\
\hline 159 & $053902.74-690452.8$ & 84.761453 & -69.081350 & 0.4 & 1.8 & 3.6 & 2.5 & 0.4 & 0.0 & 0.90 & 1.1 & -3.0 & $\ldots$ & $\mathrm{a}$ & 21.5 & 0.9 \\
\hline 160 & $053903.15-690703.8$ & 84.763141 & -69.117738 & 0.3 & 2.1 & 6.4 & 3.2 & 0.6 & 5.9 & 0.89 & 1.7 & $<-5$ & $\ldots$. & $\mathrm{a}$ & 21.8 & 3.7 \\
\hline 163 & $053908.49-685959.1$ & 84.785386 & -68.999761 & 0.4 & 6.1 & 34.0 & 6.8 & 6.0 & 19.0 & 0.91 & 4.6 & $<-5$ & $\ldots$. & $\mathrm{a}$ & 20.0 & 2.4 \\
\hline 164 & $053909.46-690429.8$ & 84.789434 & -69.074945 & 0.3 & 2.5 & 9.5 & 3.7 & 0.5 & 8.9 & 0.89 & 2.2 & $<-5$ & & $\mathrm{a}$ & 21.3 & 3.6 \\
\hline $\begin{array}{l}165 \\
166\end{array}$ & $\begin{array}{l}053913.05-691110.2 \\
05391406-685729\end{array}$ & $\begin{array}{l}84.804384 \\
84.808616\end{array}$ & $\begin{array}{l}-69.186193 \\
-68.958086\end{array}$ & $\begin{array}{l}0.6 \\
0.8\end{array}$ & $\begin{array}{l}6.0 \\
86\end{array}$ & $\begin{array}{r}5.9 \\
20.8\end{array}$ & $\begin{array}{l}3.4 \\
7.4\end{array}$ & $\begin{array}{r}2.1 \\
25.2\end{array}$ & $\begin{array}{l}4.3 \\
7.3\end{array}$ & $\begin{array}{l}0.90 \\
0.90\end{array}$ & $\begin{array}{l}1.5 \\
2.6\end{array}$ & $\begin{array}{l}-2.9 \\
-3.9\end{array}$ & & $\mathrm{a}$ & $\begin{array}{l}18.6 \\
190\end{array}$ & $\begin{array}{l}3.8 \\
1.6\end{array}$ \\
\hline 160 & $0591585-685525$ & $\begin{array}{l}04.800010 \\
848071\end{array}$ & $\begin{array}{l}-0.9030000 \\
-68\end{array}$ & 0.0 & $\begin{array}{l}0.0 \\
8.3\end{array}$ & 162 & 62 & 158 & 101 & 0.900 & 2.0 & $\begin{array}{l}-3.9 \\
-36\end{array}$ & & $a$ & 190 & 1.00 \\
\hline 168 & $053919.43-6903302$ & 84.830990 & -69.058413 & 0.4 & 3.8 & 4.4 & 28 & 0.6 & 1.8 & 0.90 & 1.3 & -3.5 & $\ldots$ & a & 200 & 1.8 \\
\hline 170 & $053939.44-690029.9$ & 84.914354 & -69.008314 & 0.4 & $\begin{array}{l}.0 \\
7.2\end{array}$ & 39.8 & 7.1 & 3.2 & 17.5 & 0.89 & 5.2 & $<-5$ & $\ldots$. & $\begin{array}{l}a \\
\mathrm{a}\end{array}$ & 19.8 & 1.8 \\
\hline 171 & $053943.92-6$ & 84.933033 & -69.160589 & 0.6 & 6.6 & 7.6 & 3.7 & 2.4 & 2.8 & 0.89 & 1.8 & -3.7 & $\ldots$ & $\mathrm{a}$ & 20.7 & 1.8 \\
\hline 172 & $053946.16-690842.1$ & 84.942335 & -69.145047 & 0.7 & 6.2 & 9.7 & 4.3 & 4.3 & 0.0 & 0.90 & 2.0 & -3.8 & .... & $\mathrm{a}$ & 20.7 & 1.1 \\
\hline 174 & $053951.73-690815.0$ & 84.965569 & -69.137500 & 0.7 & 6.5 & 9.8 & 4.7 & 7.2 & 0.8 & 0.89 & 1.9 & -2.9 & $\cdots$ & $\mathrm{a}$ & 20.5 & 1.3 \\
\hline 175 & $053954.14-690106.9$ & 84.975604 & -69.018590 & 1.0 & 7.7 & 7.1 & 3.9 & 3.9 & 2.2 & 0.89 & 1.6 & -2.6 & & $\mathrm{a}$ & 19.6 & 1.8 \\
\hline 176 & $\begin{array}{l}053958.59-690610.1 \\
\end{array}$ & 84.994166 & -69.102825 & 0.5 & 6.6 & 17.4 & 5.2 & 4.6 & 10.9 & 0.90 & $\begin{array}{l}3.0 \\
2.7\end{array}$ & $<-5$ & & $\mathrm{a}$ & 18.2 & 2.5 \\
\hline 178 & $\begin{array}{l}054001.87-690018.7 \\
05400614-60152\end{array}$ & $\begin{array}{l}85.007811 \\
85.025606\end{array}$ & $\begin{array}{l}-69.105207 \\
-69.031244\end{array}$ & 0.9 & $\begin{array}{r}6.9 \\
8.2\end{array}$ & 16.0 & $\begin{array}{l}5.3 \\
6.2\end{array}$ & $\begin{array}{l}7.0 \\
6.7\end{array}$ & $\begin{array}{r}3.9 \\
142\end{array}$ & $\begin{array}{l}0.90 \\
0.90\end{array}$ & $\begin{array}{l}2.7 \\
3.8\end{array}$ & $\begin{array}{l}<-5 \\
<-5\end{array}$ & $\ldots$ & $\therefore$ & $\begin{array}{l}19.3 \\
18.8\end{array}$ & 27 \\
\hline 179 & $054008.59-690202.4$ & $\begin{array}{l}85.035829 \\
8529\end{array}$ & $\begin{array}{l}-69.034423 \\
-6923\end{array}$ & 0.7 & 8.3 & 26.2 & 6.3 & 6.8 & 15.4 & 0.90 & 3.8 & $<-5$ & $8 \ldots$ & $\mathrm{a}$ & 19.5 & 2.3 \\
\hline 180 & $054022.50-690736.8$ & 85.093770 & -69.126895 & 1.1 & 8.9 & 13.4 & 5.2 & 8.6 & 5.3 & 0.90 & 2.3 & -4.0 & ge.. & $\cdots$ & 13.1 & 1.9 \\
\hline
\end{tabular}

${ }^{\mathrm{a}}$ Full band $=0.5-8 \mathrm{keV}$; hard band $=2-8 \mathrm{keV}$.

$\mathrm{b}_{\text {Off-axis angle }}$

${ }^{c^{c}} P_{B}=$ probability that extracted counts (full band) are solely from background.

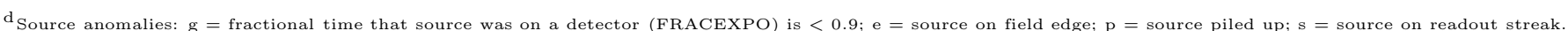

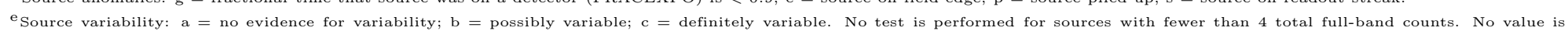


reported for sources in chip gaps or on field edges

NoTE.-See $\S 3$ for a detailed description of the columns. Note that a reduced PSF fraction (significantly below 90\%) indicates that the source is in a crowded region 
TABLE 2

Tentative Sources: Basic Properties

\begin{tabular}{|c|c|c|c|c|c|c|c|c|c|c|c|c|c|c|c|c|}
\hline \multirow{2}{*}{\multicolumn{2}{|c|}{$\begin{array}{c}\text { Source } \\
\text { CXOU J } \\
(2)\end{array}$}} & \multicolumn{4}{|c|}{ Position } & \multicolumn{5}{|c|}{ Extracted Counts $\mathrm{a}^{\mathrm{a}}$} & \multicolumn{6}{|c|}{ Characteristics } \\
\hline & & $\begin{array}{c}\alpha_{\mathrm{J} 2000} \\
\text { (deg) } \\
(3)\end{array}$ & $\begin{array}{c}\delta_{\text {J J2000 }} \\
\text { (deg) } \\
(4)\end{array}$ & $\begin{array}{l}\text { Err } \\
(\text { (I) } \\
(5) \\
\end{array}$ & $\begin{array}{l}\theta^{\mathrm{b}} \\
\left(^{\prime}\right. \\
(6) \\
\end{array}$ & $\begin{array}{l}\text { Net } \\
\text { Full } \\
(7) \\
\end{array}$ & $\begin{array}{l}\Delta \mathrm{Net} \\
\text { Full } \\
(8) \\
\end{array}$ & $\begin{array}{c}\text { Bkgd } \\
\text { Full } \\
(9) \\
\end{array}$ & $\begin{array}{c}\text { Net } \\
\text { Hard } \\
(10) \\
\end{array}$ & $\begin{array}{l}\text { PSF } \\
\text { Frac } \\
(11) \\
\end{array}$ & $\begin{array}{l}\text { Signif } \\
(12) \\
\end{array}$ & $\begin{array}{c}\log P_{B}{ }^{c} \\
\text { (13) }\end{array}$ & $\begin{array}{l}\text { Anom }^{\mathrm{d}} \\
(14)\end{array}$ & $\begin{array}{l}\operatorname{Var}^{\mathrm{e}} \\
\text { (15) }\end{array}$ & $\begin{array}{c}\text { EffExp } \\
(\mathrm{ks}) \\
(16)\end{array}$ & $\begin{array}{c}\text { Med E } \\
(\mathrm{keV}) \\
(17)\end{array}$ \\
\hline 16 & $053754.49-690545.5$ & 84.477048 & -69.095997 & 0.5 & 4.5 & 5.6 & 3.4 & 2.4 & 1.3 & 0.89 & 1.4 & -2.5 & ... & $\mathrm{a}$ & 20.4 & 1.3 \\
\hline 20 & $053811.10-690523.7$ & 84.546286 & -69.089943 & 0.4 & 3.0 & 4.4 & 3.0 & 1.6 & 0.7 & 0.90 & 1.2 & -2.2 & & $\mathrm{a}$ & 19.4 & 1.4 \\
\hline 31 & $053835.99-690600.3$ & 84.649982 & -69.100092 & 0.4 & 0.8 & 3.4 & 2.5 & 0.6 & 0.0 & 0.90 & 1.1 & -2.5 & & $\mathrm{a}$ & 21.5 & 1.0 \\
\hline 32 & $053836.52-685726.9$ & 84.652170 & -68.957477 & 1.2 & 8.3 & 7.4 & 4.3 & 6.6 & 1.1 & 0.90 & 1.5 & -2.1 & & $\mathrm{a}$ & 19.3 & 1.4 \\
\hline 35 & $053839.57-690559.8$ & 84.664915 & -69.099960 & 0.2 & 0.5 & 3.3 & 2.5 & 0.7 & 0.9 & 0.90 & 1.1 & -2.3 & & $\mathrm{a}$ & 21.6 & 1.8 \\
\hline 38 & $053840.36-690532.3$ & 84.668203 & -69.092306 & 0.4 & 0.4 & 2.6 & 2.3 & 0.4 & 0.0 & 0.90 & 0.9 & -2.0 & $\mathrm{~g} \ldots$ & & 13.4 & 1.0 \\
\hline $\begin{array}{l}39 \\
40\end{array}$ & $\begin{array}{l}053840.51-690600.8 \\
038440.57-690556.8\end{array}$ & $\begin{array}{l}84.668795 \\
84.669048\end{array}$ & $\begin{array}{l}-69.100227 \\
-69099107\end{array}$ & $\begin{array}{l}0.6 \\
0.2\end{array}-2$ & $\begin{array}{l}0.5 \\
0.4\end{array}$ & $\begin{array}{l}1.8 \\
1.9\end{array}$ & $\begin{array}{l}2.0 \\
2.0\end{array}$ & $\begin{array}{l}0.2 \\
0.1\end{array}$ & $\begin{array}{l}0.9 \\
0.0\end{array}$ & $\begin{array}{l}0.64 \\
0.39\end{array}$ & $\begin{array}{l}0.7 \\
0.7\end{array}$ & $\begin{array}{l}-1.6 \\
-2.4\end{array}$ & 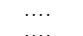 & & $\begin{array}{l}21.6 \\
21.6\end{array}$ & $\begin{array}{l}2.4 \\
1.4\end{array}$ \\
\hline $\begin{array}{l}40 \\
42\end{array}$ & $053841.17-690600.9$ & $\begin{array}{l}84.669048 \\
84.671552\end{array}$ & $\begin{array}{l}-69.099107 \\
-69.100274\end{array}$ & $\begin{array}{l}0.2 \\
0.1\end{array}$ & $\begin{array}{l}0.4 \\
0.4\end{array}$ & $\begin{array}{l}1.9 \\
2.5\end{array}$ & $\begin{array}{l}2.0 \\
2.3\end{array}$ & $\begin{array}{l}0.1 \\
0.5\end{array}$ & 0.8 & $\begin{array}{l}0.39 \\
0.80\end{array}$ & $\begin{array}{l}0.7 \\
0.9\end{array}$ & $\begin{array}{l}-2.4 \\
-1.9\end{array}$ & $\ldots$. & & $\begin{array}{l}21.6 \\
21.6\end{array}$ & $\begin{array}{l}1.4 \\
1.2\end{array}$ \\
\hline 44 & & & -69.098949 & 0.1 & & 1.9 & & 0.1 & 0.0 & 0.39 & 0.7 & & $\cdots$ & & 21.6 & 1.5 \\
\hline 48 & $053841.54-690601.3$ & 84.673084 & $\begin{array}{l}-69.100388 \\
-\end{array}$ & 0.3 & 0.4 & 1.9 & 2.0 & 0.1 & 0.0 & 0.39 & 0.7 & -2.1 & $\ldots .$. & & 21.6 & $\begin{array}{l}1.0 \\
1.6\end{array}$ \\
\hline 52 & $053841.61-690602.9$ & 84.673388 & -69.100826 & 0.4 & 0.4 & 1.9 & 2.0 & 0.1 & 1.0 & 0.39 & 0.7 & -2.1 & $\cdots$ & $\ldots$ & 21.6 & 2.0 \\
\hline 53 & $053841.68-690624.8$ & 84.673705 & -69.106890 & 0.2 & 0.7 & 3.3 & 2.5 & 0.7 & 0.8 & 0.90 & 1.0 & -2.2 & & $\mathrm{a}$ & 21.6 & 0.9 \\
\hline 54 & $053841.70-690613.1$ & 84.673784 & -69.103644 & 0.3 & 0.6 & 2.1 & 2.3 & 0.9 & 0.0 & 0.90 & 0.7 & -1.2 & & & 21.6 & 1.0 \\
\hline 55 & $053841.70-690602.1$ & 84.673786 & -69.100593 & 0.3 & 0.4 & 1.8 & 2.0 & 0.2 & 1.9 & 0.46 & 0.7 & -1.9 & & & 21.6 & 5.0 \\
\hline 56 & $\begin{array}{l}053841.72-690606.9 \\
053841.72-690555.4\end{array}$ & $\begin{array}{l}84.673854 \\
84.673867\end{array}$ & $\begin{array}{l}-69.101919 \\
-69.098726\end{array}$ & 0.3 & 0.5 & 2.7 & 2.3 & 0.3 & 0.0 & 0.64 & 0.9 & -2.5 & $\cdots$ & & 21.6 & 1.7 \\
\hline 58 & $053841.75-690608.1$ & $\begin{array}{l}84.673972 \\
84.6739\end{array}$ & $\begin{array}{l}-69.098120 \\
-69.102276\end{array}$ & $\begin{array}{l}0.5 \\
0.5\end{array}$ & $\begin{array}{l}0.3 \\
0.5\end{array}$ & $\begin{array}{l}2.6 \\
1.8\end{array}$ & $\begin{array}{l}2.3 \\
2.0\end{array}$ & $\begin{array}{l}0.4 \\
0.2\end{array}$ & $\begin{array}{l}1.9 \\
0.9\end{array}$ & $\begin{array}{l}0.75 \\
0.55\end{array}$ & $\begin{array}{l}0.9 \\
0.7\end{array}$ & $\begin{array}{l}-2.2 \\
-1.7\end{array}$ & $\cdots$ & & $\begin{array}{l}21.6 \\
21.6\end{array}$ & $\begin{array}{l}3.9 \\
2.6\end{array}$ \\
\hline 60 & $053841.90-690551.9$ & 84.674611 & -69.097770 & 0.4 & 0.3 & $\begin{array}{l}2.0 \\
2.1\end{array}$ & 2.0 & $\begin{array}{l}0.2 \\
0.9\end{array}$ & $\begin{array}{l}0.9 \\
0.0\end{array}-0$ & $\begin{array}{l}0.55 \\
0.90\end{array}$ & $\begin{array}{l}0.7 \\
0.7\end{array}$ & $\begin{array}{l}-1.7 \\
-1.2\end{array}$ & $\cdots$ & & $\begin{array}{l}21.6 \\
21.6\end{array}$ & $\begin{array}{l}2.6 \\
1.4\end{array}$ \\
\hline 61 & $053841.92-690602.8$ & 84.674676 & -69.100802 & 0.1 & 0.4 & 1.8 & 2.0 & $\begin{array}{l}0.9 \\
0.2\end{array}$ & 0.0 & 0.46 & 0.7 & -1.9 & $\ldots$. & & $\begin{array}{l}21.0 \\
21.6\end{array}$ & $\begin{array}{l}1.4 \\
1.5\end{array}$ \\
\hline 62 & $053841.94-690607.6$ & 84.674764 & -69.102132 & 0.2 & 0.5 & 1.8 & 2.0 & 0.2 & 0.0 & 0.55 & 0.7 & -1.7 & $\because$ & & 21.6 & 0.8 \\
\hline 69 & $053842.06-690600.0$ & 84.675260 & -69.100020 & 0.4 & 0.4 & 1.8 & 2.0 & 0.2 & 0.0 & 0.50 & 0.7 & -1.8 & & & 21.6 & 1.0 \\
\hline 70 & $053842.09-690608.7$ & 84.675381 & -69.102437 & 0.3 & 0.5 & 1.7 & 2.0 & 0.3 & 0.0 & 0.60 & 0.7 & -1.5 & & & 21.6 & 1.3 \\
\hline 71 & $053842.11-690548.3$ & 84.675480 & -69.096751 & 0.1 & 0.3 & 1.8 & 2.0 & 0.2 & 0.0 & 0.46 & 0.7 & -2.0 & & & 21.6 & 1.0 \\
\hline 72 & $\begin{array}{l}053842.15-690549.2 \\
053842.16-690605.9\end{array}$ & $\begin{array}{l}84.675632 \\
84.675674\end{array}$ & $\begin{array}{l}-69.097008 \\
-69.101663\end{array}$ & $\begin{array}{r}0.5 \\
0.3\end{array}$ & 0.3 & 1.8 & 2.0 & 0.2 & 1.0 & 0.46 & 0.7 & -2.0 & & & 21.6 & 2.8 \\
\hline $\begin{aligned} 74 \\
75\end{aligned}$ & $\begin{array}{l}053842.16-690005.9 \\
053842.22-690609.7\end{array}$ & $\begin{array}{l}84.675074 \\
84.675934\end{array}$ & $\begin{array}{l}-69.101603 \\
-69.102711\end{array}$ & $\begin{array}{l}0.3 \\
0.6\end{array}$ & 0.5 & 1.9 & 2.0 & $\begin{array}{l}0.1 \\
0.3\end{array}$ & $\begin{array}{l}0.0 \\
0.0\end{array}$ & $\begin{array}{l}.39 \\
0.60\end{array}$ & $\begin{array}{l}0.1 \\
0.7\end{array}$ & $\begin{array}{l}-2.1 \\
-1.5\end{array}$ & $\cdots$ & & $\begin{array}{l}21.6 \\
21.6\end{array}$ & 1.2 \\
\hline 76 & $053842.22-690613.8$ & 84.675946 & -69.103847 & 0.5 & 0.6 & 2.1 & $\begin{array}{l}2.0 \\
2.3\end{array}$ & $\begin{array}{l}0.3 \\
0.9\end{array}$ & $\begin{array}{l}0.0 \\
0.7\end{array}$ & $\begin{array}{l}0.60 \\
0.90\end{array}$ & $\begin{array}{l}0.7 \\
0.7\end{array}$ & $\begin{array}{l}-1.5 \\
-1.2\end{array}$ & $\ldots$ & & $\begin{array}{l}21.6 \\
21.6\end{array}$ & $\begin{array}{l}1.5 \\
1.6\end{array}$ \\
\hline 77 & $053842.26-690611.3$ & 84.676084 & -69.103143 & 0.5 & 0.5 & 1.8 & 2.0 & 0.2 & 0.0 & 0.55 & 0.7 & -1.7 & $\therefore$ & & 21.6 & 1.1 \\
\hline 81 & $053842.29-690559.3$ & 84.676212 & -69.099819 & 0.0 & 0.3 & 1.9 & 2.0 & 0.1 & 1.0 & 0.39 & 0.7 & -2.1 & $\ldots$ & $\ldots$ & 21.6 & 4.4 \\
\hline 84 & $053842.41-690610.4$ & 84.676721 & -69.102915 & 0.4 & 0.5 & 1.8 & 2.0 & 0.2 & 0.0 & 0.55 & 0.7 & -1.6 &.. & & 21.6 & 1.4 \\
\hline 85 & $053842.42-690559.6$ & 84.67 & -69.099892 & 0.3 & 0.3 & 1.9 & 2.0 & 0.1 & 0.0 & 0.39 & 0.7 & -2.1 & .. & $\cdots$ & 21.6 & 1.6 \\
\hline 91 & $053842.62-690624.5$ & 84.677622 & -69.106831 & 0.7 & 0.7 & 1.3 & 2.0 & 0.7 & 0.0 & 0.90 & 0.5 & -0.8 & & & 21.6 & 1.0 \\
\hline $\begin{array}{l}95 \\
97\end{array}$ & $\begin{array}{l}053842.65-690600.7 \\
0\end{array}$ & $\begin{array}{l}84.677747 \\
84.678183\end{array}$ & $\begin{array}{l}-69.100220 \\
-69.099045\end{array}$ & 0.2 & 0.3 & 1.9 & 2.0 & 0.1 & 0.0 & $\begin{array}{l}0.39 \\
0.39\end{array}$ & 0.7 & -2.1 & & & 21.6 & 1.4 \\
\hline $\begin{array}{l}97 \\
98\end{array}$ & $\begin{array}{l}053842.76-690565.5 \\
053842.76-690606.8\end{array}$ & $\begin{array}{l}84.678183 \\
84.678189\end{array}$ & $\begin{array}{l}-69.099045 \\
-69.101914\end{array}$ & $\begin{array}{l}0.4 \\
0.2\end{array}-1$ & $\begin{array}{l}0.3 \\
0.4\end{array}$ & $\begin{array}{l}1.9 \\
3.4\end{array}$ & $\begin{array}{l}2.0 \\
2.5\end{array}$ & $\begin{array}{l}0.1 \\
0.6\end{array}$ & $\begin{array}{l}1.0 \\
1.8\end{array}$ & $\begin{array}{l}0.39 \\
0.80\end{array}$ & $\begin{array}{l}0.7 \\
1.1\end{array}$ & $\begin{array}{l}-2.1 \\
-2.5\end{array}$ & $\cdots$ & $\cdots$ & $\begin{array}{l}21.6 \\
21.6\end{array}$ & $\begin{array}{l}2.0 \\
2.0\end{array}$ \\
\hline 100 & $053842.78-690545.2$ & 84.678252 & $\begin{array}{l}-69.095909 \\
\end{array}$ & 0.3 & 0.2 & 2.0 & $\begin{array}{l}2.5 \\
2.3\end{array}$ & $\begin{array}{l}0.6 \\
1.0\end{array}$ & $\begin{array}{l}1.8 \\
1.8\end{array}$ & $\begin{array}{l}0.80 \\
0.90\end{array}$ & $\begin{array}{l}1.1 \\
0.7\end{array}$ & $\begin{array}{l}-2.5 \\
-1.1\end{array}$ & $\ldots$ & ... & $\begin{array}{l}21.6 \\
21.6\end{array}$ & $\begin{array}{l}2.0 \\
2.4\end{array}$ \\
\hline 103 & $053842.90-690610.0$ & 84.678764 & -69.102802 & 0.0 & 0.5 & 1.8 & 2.0 & 0.2 & 0.0 & 0.56 & 0.7 & -1.6 & $\ldots$ & & 21.6 & 1.2 \\
\hline 107 & $053843.02-690559.0$ & 84.679268 & -69.099741 & 0.3 & 0.3 & 3.3 & 2.5 & 0.7 & 0.8 & 0.84 & 1.0 & -2.3 & $\ldots$ & $\mathrm{a}$ & 21.6 & 1.6 \\
\hline 109 & $053843.07-690628.2$ & 84.679464 & $\begin{array}{l}-69.107856 \\
-695\end{array}$ & 0.3 & 0.8 & 3.3 & 2.5 & 0.7 & 0.0 & 0.90 & 1.1 & -2.3 & $\ldots$ & a & 21.6 & 1.3 \\
\hline 117 & $053843.33-69$ & 84.68 & -69.16 & 0.4 & 0.4 & 1.9 & 2.0 & 0.1 & 0.0 & & 0.7 & -2.1 & & $x^{2}+2+2$ & .6 & 1.0 \\
\hline 119 & $053843.39-690542.3$ & 84.680826 & -69.095102 & 0.3 & 0.1 & 3.0 & 2.5 & 1.0 & 0.0 & 0.90 & 1.0 & -1.8 & & & 21.6 & 0.8 \\
\hline 121 & $\begin{array}{l}053843.46-690644.3 \\
05384350-690744.6\end{array}$ & $\begin{array}{l}84.681087 \\
84.681257\end{array}$ & $\begin{array}{l}-69.112307 \\
-69.129060\end{array}$ & $\begin{array}{l}0.3 \\
0.2\end{array}$ & $\begin{array}{l}1.0 \\
20\end{array}$ & $\begin{array}{l}3.3 \\
40\end{array}$ & $\begin{array}{l}2.5 \\
2.8\end{array}$ & $\begin{array}{l}0.7 \\
1.0\end{array}$ & $\begin{array}{l}0.9 \\
0.0\end{array}-2$ & $\begin{array}{l}0.90 \\
0.89\end{array}$ & $\begin{array}{l}1.0 \\
1.2\end{array}$ & $\begin{array}{l}-2.3 \\
-2.4\end{array}$ & & $\stackrel{a}{a}$ & $\begin{array}{l}21.7 \\
21.7\end{array}$ & $\begin{array}{l}1.2 \\
1.0\end{array}$ \\
\hline 124 & $\begin{array}{r}0538433.50-69074.6 \\
05384365-690604.9\end{array}$ & $\begin{array}{l}84.681257 \\
84.681889\end{array}$ & $\begin{array}{l}-69.129060 \\
-69.101388\end{array}$ & $\begin{array}{l}0.2 \\
0.3\end{array}-1$ & $\begin{array}{l}2.0 \\
0.4\end{array}$ & $\begin{array}{l}4.0 \\
1.8\end{array}$ & $\begin{array}{l}2.8 \\
2.0\end{array}$ & $\begin{array}{l}1.0 \\
0.2\end{array}$ & $\begin{array}{l}0.0 \\
0.0\end{array}-0$ & $\begin{array}{l}0.89 \\
0.55\end{array}$ & $\begin{array}{l}1.2 \\
0.7\end{array}$ & $\begin{array}{l}-2.4 \\
-1.7\end{array}$ & & $\ldots$ & $\begin{array}{l}21.7 \\
21.6\end{array}$ & $\begin{array}{l}1.0 \\
1.6\end{array}$ \\
\hline 127 & $053843.86-690615.7$ & 84.682785 & -69.104373 & 0.3 & 0.5 & 2.4 & 2.3 & 0.6 & 0.9 & & 0. & -1.7 & $\ldots$. & & 21.6 & 0.9 \\
\hline 128 & $053843.90-69$ & 84.682957 & -69.0 & 0.4 & 0.2 & 2.5 & 2.3 & 0.5 & 0.0 & & 0 & -1.7 & g. & & 11.8 & 1. \\
\hline 130 & $053844.08-690558.2$ & 84.683673 & -69.099520 & 0.3 & 0.3 & 2.6 & 2.3 & 0.4 & 0.0 & 0.75 & 0.9 & -2.1 & $\therefore$ & & 21.6 & 1.5 \\
\hline 134 & $053844.34-69060$ & 84.684757 & -69.102277 & 0.4 & 0.4 & 1.8 & 2.0 & 0.2 & 0.0 & & 0.7 & -1.8 & $\ldots$. & & 21.6 & 0.9 \\
\hline 136 & & 84.685 & -69.098307 & 0.3 & 0.2 & 1.8 & 2.0 & 0.2 & 1.0 & & 0.7 & -1.9 & & $\cdots$ & 21.7 & 2.3 \\
\hline 138 & $053844.47-690530.1$ & $\begin{array}{ll}84.685329 \\
84686232\end{array}$ & -69.091712 & 0.5 & 0.2 & 2.6 & 2.3 & 0.4 & 0.0 & 0.90 & 0.9 & -2.1 & $g \ldots$ & & 9.9 & 1.4 \\
\hline $\begin{array}{l}141 \\
142\end{array}$ & $\begin{array}{l}055844.69-690611.3 \\
053844.72-690606.8\end{array}$ & $\begin{array}{l}84.686232 \\
84.686360\end{array}$ & $\begin{array}{l}-69.103143 \\
-69.101891\end{array}$ & $\begin{array}{l}0.4 \\
0.3\end{array}$ & $\begin{array}{l}0.5 \\
0.4\end{array}$ & $\begin{array}{l}3.2 \\
1.9\end{array}$ & $\begin{array}{l}2.5 \\
2.0\end{array}$ & $\begin{array}{l}0.8 \\
0.1\end{array}$ & $\begin{array}{l}3.8 \\
0.0\end{array}-10$ & $\begin{array}{l}0.90 \\
0.50\end{array}$ & $\begin{array}{l}1.0 \\
0.7\end{array}$ & $\begin{array}{l}-2.0 \\
-2.0\end{array}$ & 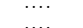 & $\ldots$ & $\begin{array}{l}21.6 \\
21.7\end{array}$ & $\begin{array}{l}3.1 \\
1.8\end{array}$ \\
\hline 145 & 601.7 & 84.687829 & $\begin{array}{l}-09.101091 \\
-69.100482\end{array}$ & $\begin{array}{l}0.3 \\
0.6\end{array}$ & $\begin{array}{l}0.4 \\
0.3\end{array}$ & 1.9 & $\begin{array}{l}2.0 \\
2.0\end{array}$ & $\begin{array}{l}0.1 \\
0.1\end{array}$ & $\begin{array}{l}0.0 \\
0.0\end{array}$ & & 0. & $\begin{array}{l}-2.0 \\
-2.3\end{array}$ & & & 21.7 & $\begin{array}{l}1.8 \\
1.3\end{array}$ \\
\hline 147 & & 84.689080 & -69.094445 & 0.1 & 0.1 & 3.1 & 2.5 & 0.9 & 0.9 & & 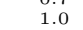 & -1.8 & $\cdots$ & & 0 & 0 \\
\hline 148 & 05 & 690398 & -69.106217 & 0.3 & 0.6 & 3.3 & 2.5 & 0.7 & 0.9 & & 1 & -2.2 & 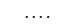 & $\mathrm{a}$ & & 1.4 \\
\hline 151 & 053 & 694851 & -69.1 & 0.3 & 0.7 & 2.4 & 2.3 & 0.6 & 0.0 & & 0 & -1.7 & g.. & & 17.4 & 1.1 \\
\hline 153 & $053852.47-6 \mathrm{~s}$ & 84.718639 & -69.1 & 0.2 & 0.8 & 3.2 & 2.5 & 0.8 & 0.0 & 0. & 1. & -2.0 & & & 21.9 & 1.1 \\
\hline 157 & $053857.66-69$ & 84.740266 & -69.096488 & 0.1 & 1.1 & 4.0 & 2.8 & 1.0 & 0.0 & & 1. & -2.5 & $\cdots$ & $\mathrm{a}$ & 21.9 & 1.2 \\
\hline 158 & $\begin{array}{l}053857.87-691012.3 \\
\end{array}$ & 84.741137 & -69.170105 & 0.4 & 4.6 & 5.3 & 3.5 & 3.7 & 1.6 & 0.90 & 1.3 & -1.9 & & $\mathrm{a}$ & 年1.1 & 1.7 \\
\hline 162 & $\begin{array}{r}053903.57-68748.9 \\
05394.69-690452.3\end{array}$ & $\begin{array}{l}84.764896 \\
84.769563\end{array}$ & $\begin{array}{l}-68.963586 \\
-69.081217\end{array}$ & $\begin{array}{l}0.8 \\
0.1\end{array}$ & $\begin{array}{l}8.1 \\
2.0\end{array}$ & 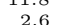 & $\begin{array}{l}6.3 \\
2.3\end{array}$ & $\begin{aligned} 20.2 \\
0.4\end{aligned}$ & 0.0 & $\begin{array}{lll}0.09 \\
0.89\end{array}$ & $\begin{array}{l}1.1 \\
0.9\end{array}$ & -2.0 & $\ldots$ & a & 1.2. & $\begin{array}{l}1.1 \\
0.9\end{array}$ \\
\hline 162 & & & -69.081217 & & & & & & & & & & & & 21.5 & 0.9 \\
\hline
\end{tabular}


TABLE 2-Continued

\begin{tabular}{|c|c|c|c|c|c|c|c|c|c|c|c|c|c|c|c|c|}
\hline \multicolumn{2}{|r|}{ Source } & \multicolumn{4}{|c|}{ Position } & \multicolumn{5}{|c|}{ Extracted Counts ${ }^{\mathrm{a}}$} & \multicolumn{6}{|c|}{ Characteristics } \\
\hline $\begin{array}{l}\text { Seq } \\
\# \\
\text { (1) }\end{array}$ & $\begin{array}{c}\text { CXOU J } \\
\text { (2) }\end{array}$ & $\begin{array}{c}\alpha_{\text {J2000 }} \\
\text { (deg) } \\
(3)\end{array}$ & 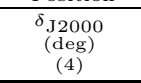 & $\begin{array}{l}\text { Err } \\
\left({ }^{\prime \prime}\right) \\
(5) \\
\end{array}$ & $\begin{array}{c}\theta^{\mathrm{b}} \\
\left(^{\prime}\right) \\
(6) \\
\end{array}$ & $\begin{array}{l}\text { Net } \\
\text { Full } \\
(7)\end{array}$ & $\begin{array}{l}\Delta \text { Net } \\
\text { Full } \\
(8)\end{array}$ & $\begin{array}{l}\text { Bkgd } \\
\text { Full } \\
(9)\end{array}$ & $\begin{array}{l}\text { Net } \\
\text { Hard } \\
(10) \\
\end{array}$ & $\begin{array}{l}\text { PSF } \\
\text { Frac } \\
(11)\end{array}$ & $\begin{array}{l}\text { Signif } \\
(12) \\
\end{array}$ & $\begin{array}{l}\log P_{B}{ }^{\mathrm{C}} \\
(13)\end{array}$ & $\begin{array}{l}\text { Anom }^{\mathrm{d}} \\
(14)\end{array}$ & $\begin{array}{l}\operatorname{Var}^{\mathrm{e}} \\
(15)\end{array}$ & $\begin{array}{c}\text { EffExp } \\
(\mathrm{ks}) \\
(16) \\
\end{array}$ & $\begin{array}{c}\begin{array}{c}\text { Med E } \\
(\mathrm{keV}) \\
(17)\end{array} \\
\end{array}$ \\
\hline $\begin{array}{l}169 \\
173\end{array}$ & $\begin{array}{l}053933.97-690529.9 \\
053950.74-691047.3\end{array}$ & $\begin{array}{l}84.891553 \\
84.961420\end{array}$ & $\begin{array}{l}-69.091649 \\
-69.179823\end{array}$ & $\begin{array}{l}0.5 \\
0.8\end{array}$ & $\begin{array}{l}4.4 \\
7.7\end{array}$ & $\begin{array}{l}5.9 \\
6.1\end{array}$ & $\begin{array}{l}3.5 \\
3.9\end{array}$ & $\begin{array}{l}3.1 \\
4.9\end{array}$ & $\begin{array}{l}0.0 \\
6.8\end{array}$ & $\begin{array}{l}0.91 \\
0.90\end{array}$ & $\begin{array}{l}1.4 \\
1.4\end{array}$ & $\begin{array}{l}-2.4 \\
-1.9\end{array}$ & $\ldots$ & $\begin{array}{l}\mathrm{a} \\
\mathrm{a}\end{array}$ & $\begin{array}{l}20.9 \\
20.1\end{array}$ & $\begin{array}{l}1.0 \\
4.0\end{array}$ \\
\hline
\end{tabular}

${ }^{a_{F}}$ Full band $=0.5-8 \mathrm{keV} ;$ hard band $=2-8 \mathrm{keV}$.

$\mathrm{b}_{\text {Off-axis angle. }}$

${ }^{\mathrm{C}} P_{B}=$ probability that extracted counts (full band) are solely from background.

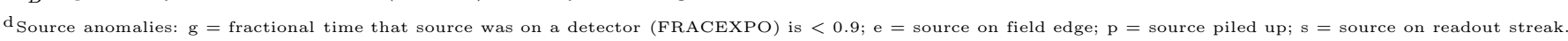
e Source variability: $a=$ no evidence for variability; $\mathrm{b}=$ possibly variable; $\mathrm{c}=$ definitely variable. No test is performed for sources with fewer than 4 total full-band counts. No value is
reported for sources in chip gaps or on field edges.

NoтE.-See $\S 3$ for a detailed description of the columns. Note that a reduced PSF fraction (significantly below $90 \%$ ) indicates that the source is in a crowded region. 
TABLE 3

X-ray Spectroscopy for Photometrically Selected Sources: Thermal Plasma Fits

\begin{tabular}{|c|c|c|c|c|c|c|c|c|c|c|c|c|}
\hline \multicolumn{4}{|c|}{ Source } & \multicolumn{3}{|c|}{ Spectral Fit ${ }^{\mathrm{a}}$} & \multicolumn{5}{|c|}{ X-ray Luminosities ${ }^{b}$} & \multirow{2}{*}{$\begin{array}{c}\text { Notes }^{c} \\
(13)\end{array}$} \\
\hline $\begin{array}{c}\text { Seq } \\
\# \\
(1)\end{array}$ & $\begin{array}{c}\text { CXOU J } \\
(2)\end{array}$ & $\begin{array}{c}\text { Net } \\
\text { Counts } \\
(3)\end{array}$ & $\begin{array}{c}\text { Signif } \\
(4)\end{array}$ & $\begin{array}{c}\log N_{H} \\
\left(\mathrm{~cm}^{-2}\right) \\
(5)\end{array}$ & $\begin{array}{c}k T \\
(\mathrm{keV}) \\
(6)\end{array}$ & $\begin{array}{c}\log E M \\
\left(\mathrm{~cm}^{-3}\right) \\
(7)\end{array}$ & $\begin{array}{c}\log L_{s} \\
(8)\end{array}$ & $\begin{array}{c}\log L_{h} \\
(9)\end{array}$ & $\begin{array}{c}\log L_{h, c} \\
\left(\mathrm{ergs} \mathrm{s}^{-1}\right) \\
(10)\end{array}$ & $\begin{array}{c}\log L_{t} \\
(11)\end{array}$ & $\begin{array}{c}\log L_{t, c} \\
(12)\end{array}$ & \\
\hline 1 & $053707.64-691243.4$ & 20.3 & 3.1 & 22.3 & 1.6 & 57.7 & 33.33 & 33.95 & 34.11 & 34.04 & 34.65 & $\cdots$ \\
\hline 3 & $053728.90-690457.9$ & 11.2 & 2.3 & $20.8+0.9$ & 2.5 & $56.3+0.3$ & 32.99 & 32.94 & 32.94 & 33.27 & 33.32 & $\mathrm{H}$ \\
\hline 5 & $053742.64-690958.2$ & 53.8 & 3.6 & 21.5 & 1.4 & 57.1 & 33.64 & 33.40 & 33.43 & 33.84 & 34.07 & $\ldots$ \\
\hline 6 & $053743.45-690901.8$ & 11.8 & 2.2 & 21.5 & 1.7 & 56.5 & 32.92 & 32.88 & 32.90 & 33.20 & 33.41 & $\cdots$ \\
\hline 10 & $053749.11-690508.7$ & 9.4 & 2.1 & 21.5 & 2.4 & 56.5 & 32.93 & 33.08 & 33.10 & 33.31 & 33.48 & R130 \\
\hline 11 & $053750.21-690424.0$ & 10.7 & 2.1 & 20.7 & $-0.20 .4+0.4$ & $-0.356 .2+0.4$ & 32.98 & 31.09 & 31.10 & 32.98 & 33.07 & $\mathrm{R} 103 \mathrm{f}^{\mathrm{d}}$ \\
\hline 12 & $053751.63-691021.4$ & 99.4 & 7.4 & $20.9+0.6$ & $0.8+0.1$ & $57.0+0.3$ & 33.86 & 32.84 & 32.85 & 33.90 & 34.00 & $\ldots$ \\
\hline 13 & $053752.81-691058.5$ & 16.2 & 2.1 & 21.7 & 0.5 & 57.1 & 33.23 & 32.15 & 32.21 & 33.26 & 33.96 & $\ldots$ \\
\hline 14 & $053753.04-690943.6$ & 15.7 & 2.0 & 21.7 & 0.9 & 56.7 & 33.10 & 32.49 & 32.54 & 33.19 & 33.66 & $\mathrm{H}$ \\
\hline 18 & $053802.71-690259.2$ & 20.3 & 3.5 & $-0.522 .1+0.3$ & -1.22 .3 & $-0.457 .0+0.6$ & 32.98 & 33.49 & 33.57 & 33.61 & 33.97 & \\
\hline 36 & $053840.21-690559.8$ & 65.9 & 7.2 & $21.2+0.4$ & $2.0+2.6$ & $57.3+0.2$ & 33.86 & 33.76 & 33.77 & 34.12 & 34.22 & Mk39 \\
\hline 45 & $053841.48-690557.0$ & 8.9 & 2.2 & 21.7 & 0.5 & 56.9 & 33.09 & 32.09 & 32.15 & 33.13 & 33.81 & O3 V star \\
\hline 49 & $053841.56-690515.4$ & 14.6 & 2.9 & $21.2+0.6$ & 2.5 & $56.6+0.3$ & 33.14 & 33.20 & 33.21 & 33.47 & 33.57 & R140b \\
\hline 51 & $053841.59-690513.4$ & 377.6 & 18.5 & $-0.0921 .9+0.08$ & $-0.110 .9+0.10$ & $-0.0858 .3+0.11$ & 34.51 & 34.18 & 34.25 & 34.68 & 35.25 & R140a1/a2 \\
\hline 67 & $053842.06-690602.2$ & 10.8 & 2.4 & 21.7 & 0.9 & 56.7 & 33.08 & 32.53 & 32.59 & 33.19 & 33.69 & R136 core \\
\hline 78 & $053842.28-690601.4$ & 9.8 & 2.3 & 21.8 & $-0.51 .1+0.6$ & $-0.356 .6+0.3$ & 32.94 & 32.65 & 32.71 & 33.12 & 33.57 & R136 core \\
\hline 79 & $053842.29-690603.4$ & 21.9 & 3.8 & 21.3 & 4.2 & 56.8 & 33.38 & 33.67 & 33.68 & 33.85 & 33.93 & R136a3 \\
\hline 82 & $053842.34-690458.1$ & 15.1 & 3.0 & 21.5 & $-0.91 .8+2.9$ & $-0.256 .4+0.2$ & 32.89 & 32.89 & 32.92 & 33.19 & 33.39 & R139 \\
\hline 83 & $053842.35-690602.8$ & 52.8 & 6.3 & $-0.521 .6+0.3$ & $-0.41 .2+0.4$ & $-0.257 .4+0.3$ & 33.82 & 33.54 & 33.58 & 34.00 & 34.31 & R136a1/a2 \\
\hline 90 & $053842.60-690602.9$ & 10.8 & 2.4 & 21.4 & 2.3 & 56.6 & 33.10 & 33.15 & 33.17 & 33.43 & 33.56 & O3 III star \\
\hline 102 & $053842.89-690604.9$ & 246.8 & 14.7 & $-0.121 .7+0.1$ & $-0.83 .0+1.3$ & $-0.158 .0+0.1$ & 34.34 & 34.69 & 34.72 & 34.85 & 35.04 & $\mathrm{R} 136 \mathrm{c}$ \\
\hline 111 & $053843.08-690605.0$ & 13.9 & 2.9 & 21.7 & 1.4 & 56.8 & 33.22 & 33.09 & 33.13 & 33.46 & 33.77 & $\ldots$ \\
\hline 131 & $053844.13-690556.6$ & 50.6 & 6.2 & 22.0 & 0.6 & 57.7 & 33.55 & 32.95 & 33.06 & 33.65 & 34.63 & $\mathrm{Mk} 33 \mathrm{Sa}$ \\
\hline 132 & $053844.25-690605.9$ & 948.6 & 29.8 & $-0.0821 .6+0.07$ & $-0.73 .9+1.1$ & $-0.0558 .3+0.05$ & 34.69 & 35.08 & 35.11 & 35.23 & 35.38 & Mk34 \\
\hline 133 & $053844.30-690554.6$ & 14.8 & 3.0 & 22.0 & 1.2 & 57.1 & 33.13 & 33.13 & 33.22 & 33.43 & 33.99 & $\mathrm{Mk} 33 \mathrm{Na}$ \\
\hline 139 & $053844.52-690605.1$ & 13.6 & 2.8 & 21.6 & -2.74 .2 & -0.256 .4 & 32.84 & 33.25 & 33.27 & 33.39 & 33.53 & $\ldots$ \\
\hline 149 & $053845.76-685759.8$ & 12.2 & 2.2 & 22.2 & 1.3 & 56.9 & 32.72 & 33.00 & 33.13 & 33.19 & 33.84 & \\
\hline 154 & $053853.38-690200.6$ & 12.0 & 2.5 & 21.0 & $-1.52 .1+6.6$ & $-0.356 .6+0.1$ & 33.20 & 33.08 & 33.08 & 33.44 & 33.51 & $\mathrm{H}, \mathrm{R} 144$ \\
\hline 156 & $053857.07-690605.5$ & 11.1 & 2.4 & 22.5 & $-0.71 .6+2.8$ & $57.1+0.4$ & 32.44 & 33.22 & 33.43 & 33.29 & 33.99 & H, R145 \\
\hline 163 & $053908.49-685959.1$ & 34.0 & 4.6 & $22.4+0.2$ & $1.4+1.6$ & $57.6+0.6$ & 33.05 & 33.70 & 33.91 & 33.79 & 34.54 & $\ldots$ \\
\hline 164 & $053909.46-690429.8$ & 9.5 & 2.2 & 23.0 & 0.8 & 58.4 & & 33.41 & 34.25 & 33.42 & & $\ldots$ \\
\hline 172 & $053946.16-690842.1$ & 9.7 & 2.0 & 21.7 & 0.7 & 56.5 & 32.88 & 32.04 & 32.09 & 32.93 & 33.46 & $\ldots$ \\
\hline 177 & $054001.87-690618.7$ & 16.0 & 2.7 & 21.9 & 1.4 & 56.7 & 32.96 & 32.97 & 33.03 & 33.27 & 33.65 & $\ldots$ \\
\hline
\end{tabular}

${ }^{\text {a }}$ All fits were wabs* $^{*}($ apec $)$ in $X S P E C$, used CSTAT, and assumed $0.3 Z_{\odot}$ abundances.

${ }^{\mathrm{b}} \mathrm{X}$-ray luminosities: $\mathrm{s}=$ soft band $(0.5-2 \mathrm{keV}) ; \mathrm{h}=$ hard band $(2-8 \mathrm{keV}) ; \mathrm{t}=$ total band $(0.5-8 \mathrm{keV})$. Absorption-corrected luminosities are subscripted with a $c$. When $l o g N_{H}>22.5$, $L_{s}$ and $L_{t, c}$ are unreliable and have been omitted. Luminosities were calculated assuming a distance of $50.0 \mathrm{kpc}$.

${ }^{\mathrm{c}} \mathrm{H}$ means the fit was performed by hand, usually because the automated fit yielded non-physical results. Well-known counterparts from Table 5 are listed here for the convenience of the reader. 
${ }^{\mathrm{d}}$ Given luminosities are incorrect for this foreground star. Its flux can be calculated as $\log F=\log L-47.48$.

Nоте.-See $\S 3$ for descriptions of the columns. Quantities in italics were frozen in the spectral fit; results are tentative. Uncertainties represent $90 \%$ confidence intervals. More significant digits are used for uncertainties $<0.1$ in order to avoid large rounding errors; for consistency, the same number of significant digits is used for both lower and upper uncertainties were used only as spline fits to obtain rough estimates of luminosities; actual fit values are unreliable. 
TABLE 4

X-ray Spectroscopy for Photometrically Selected Sources: Power LaW Fits

\begin{tabular}{|c|c|c|c|c|c|c|c|c|c|c|c|c|}
\hline \multicolumn{4}{|c|}{ Source } & \multicolumn{3}{|c|}{ Spectral Fit ${ }^{\mathrm{a}}$} & \multicolumn{5}{|c|}{ X-ray Fluxes ${ }^{b}$} & \multirow[t]{2}{*}{ Notes $^{c}$} \\
\hline $\begin{array}{l}\text { Seq } \\
\# \\
(1)\end{array}$ & $\begin{array}{c}\text { CXOU J } \\
(2)\end{array}$ & $\begin{array}{c}\text { Net } \\
\text { Counts } \\
(3)\end{array}$ & $\begin{array}{c}\text { Signif } \\
(4)\end{array}$ & $\begin{array}{c}\log N_{H} \\
\left(\mathrm{~cm}^{-2}\right) \\
(5)\end{array}$ & $\begin{array}{l}\Gamma \\
(6)\end{array}$ & $\begin{array}{c}\log N_{\Gamma} \\
(7)\end{array}$ & $\begin{array}{c}\log F_{s} \\
(8)\end{array}$ & $\begin{array}{c}\log F_{h} \\
\quad(\mathrm{ph} \\
(9)\end{array}$ & $\begin{array}{c}\log F_{h, c} \\
\text { ons cm } \mathrm{cm}^{-2} \\
(10)\end{array}$ & $\begin{array}{c}\log F_{t} \\
\left.\mathrm{~s}^{-1}\right) \\
(11)\end{array}$ & $\begin{array}{c}\log F_{t, c} \\
(12)\end{array}$ & \\
\hline 4 & $053736.30-690236.8$ & 54.7 & 6.3 & $21.3+0.5$ & $1.0+0.8$ & $-5.3+0.4$ & -14.14 & -13.39 & -13.38 & -13.32 & -13.28 & \\
\hline 7 & $053745.61-691011.1$ & 1574.3 & 31.5 & $-0.0621 .9+0.06$ & $-0.22 .4+0.2$ & $-0.08-3.3+0.09$ & -12.60 & -12.21 & -12.17 & -12.06 & -11.74 & N157B nebula \\
\hline 9 & $053747.41-691019.8$ & 6186.8 & 73.9 & $-0.0321 .8+0.03$ & $-0.072 .0+0.08$ & $-0.04-2.9+0.04$ & -12.04 & -11.54 & -11.51 & -11.42 & -11.21 & PSR J0537-6910 \\
\hline 15 & $053754.39-690222.4$ & 106.5 & 9.3 & $-0.322 .0+0.2$ & $-0.62 .0+0.7$ & $-0.3-4.5+0.4$ & -13.88 & -13.21 & -13.16 & -13.12 & -12.85 & $\ldots$ \\
\hline 19 & $053809.92-685658.3$ & 198.8 & 12.9 & $-0.221 .6+0.2$ & $-0.31 .9+0.5$ & $-0.2-4.4+0.2$ & -13.45 & -13.05 & -13.03 & -12.90 & -12.76 & $\ldots$ \\
\hline 25 & $053826.14-690013.1$ & 58.1 & 6.6 & $-0.621 .5+0.4$ & $-0.61 .8+1.0$ & $-0.3-5.1+0.4$ & -14.03 & -13.63 & -13.61 & -13.48 & -13.36 & $\ldots$ \\
\hline 27 & $053833.46-691158.7$ & 24.1 & 3.6 & 22.1 & 1.7 & -5.2 & -14.56 & -13.70 & -13.65 & -13.64 & -13.42 & $\ldots$ \\
\hline 29 & $053834.79-685917.4$ & 11.4 & 2.3 & 21.9 & 0.6 & -6.1 & -15.10 & -13.86 & -13.84 & -13.84 & -13.78 & $\ldots$ \\
\hline 152 & $053851.79-690908.5$ & 15.8 & 2.9 & 21.6 & 1.4 & -5.8 & -14.71 & -14.07 & -14.06 & -13.98 & -13.90 & $\ldots$ \\
\hline 166 & $053914.06-685729.1$ & 20.8 & 2.6 & 21.5 & 1.6 & -5.4 & -14.33 & -13.82 & -13.80 & -13.70 & -13.61 & $\mathrm{H}$ \\
\hline 167 & $053915.85-685752.5$ & 16.2 & 2.4 & 22.3 & 1.5 & -5.4 & -14.70 & -13.78 & -13.74 & -13.73 & -13.57 & $\mathrm{H}$ \\
\hline 170 & $053939.44-690029.9$ & 39.8 & 5.2 & 20.7 & $-0.40 .8+0.4$ & $-0.2-5.6+0.2$ & -14.28 & -13.49 & -13.49 & -13.43 & -13.42 & $\ldots$ \\
\hline 176 & $053958.59-690610.1$ & 17.4 & 3.0 & 21.0 & 0.5 & -6.1 & -14.72 & -13.77 & -13.77 & -13.73 & -13.72 & $\ldots$ \\
\hline 178 & $054006.14-690152.4$ & 25.3 & 3.8 & 21.7 & 0.7 & -5.7 & -14.61 & -13.52 & -13.50 & -13.48 & -13.43 & $\ldots$ \\
\hline 179 & $054008.59-690202.4$ & 26.2 & 3.8 & 22.2 & 2.1 & -4.9 & -14.52 & -13.70 & -13.63 & -13.64 & -13.30 & $\ldots$ \\
\hline 180 & $054022.50-690736.8$ & 13.4 & 2.3 & 22.1 & 2.3 & -5.0 & -14.58 & -13.97 & -13.90 & -13.87 & -13.48 & $\ldots$ \\
\hline
\end{tabular}

${ }^{a}$ All fits were wabs* $^{*}\left(\right.$ powerlaw) in XSPEC and used CSTAT. $\Gamma$ is the power law photon index and $N_{\Gamma}$ is the power law normalization.

${ }^{b}$ X-ray fluxes: $\mathrm{s}=$ soft band $(0.5-2 \mathrm{keV}) ; \mathrm{h}=$ hard band $(2-8 \mathrm{keV}) ; \mathrm{t}=$ total band $(0.5-8 \mathrm{keV})$. Absorption-corrected fluxes are subscripted with a $c$.

${ }^{\mathrm{c}} \mathrm{H}$ means the fit was performed by hand, usually because the automated fit yielded non-physical results.

NotE.-See $\S 3$ for descriptions of the columns. Quantities in italics were frozen in the spectral fit; results are tentative. Uncertainties represent $90 \%$ confidence intervals. More significant digits are used for uncertainties $<0.1$ in order to avoid large rounding errors; for consistency, the same number of significant digits is used for both lower and upper uncertainties. Uncertainties are missing when XSPEC was unable to compute them or when their values were so large that the parameter is effectively unconstrained. Fits lacking all uncertainties were used only as spline fits to obtain rough estimates of fluxes; actual fit values are unreliable. 
Table 5

X-ray Point Source Counterparts

\begin{tabular}{|c|c|c|c|c|c|c|c|c|c|c|}
\hline \multicolumn{2}{|r|}{ Source } & \multirow{2}{*}{$\begin{array}{l}\operatorname{Sep}^{\prime} \mathrm{n}^{\mathrm{a}} \\
\left({ }^{\prime \prime}\right) \\
(3)\end{array}$} & \multirow{2}{*}{$\begin{array}{l}\text { Spectral Type }{ }^{\mathrm{b}} \\
(4) \\
\end{array}$} & \multirow{2}{*}{$\begin{array}{c}\text { BAT99 } \\
(5) \\
\end{array}$} & \multirow{2}{*}{$\begin{array}{l}\text { P93 } \\
\text { (6) }\end{array}$} & \multirow{2}{*}{$\begin{array}{c}\text { MH94 } \\
(7)\end{array}$} & \multirow{2}{*}{$\begin{array}{l}\text { PPL02 } \\
\text { (8) }\end{array}$} & \multicolumn{2}{|c|}{ 2MASS Coordinates } & \multirow{2}{*}{$\begin{array}{l}\text { Other match or other name; comments } \\
\text { (11) }\end{array}$} \\
\hline $\begin{array}{c}\mathrm{Seq}_{(1)} \\
(1)\end{array}$ & $\begin{array}{c}\text { CXOU J } \\
(2)\end{array}$ & & & & & & & $\begin{array}{l}\alpha_{\mathrm{J} 2000} \\
(9)\end{array}$ & $\begin{array}{c}\delta_{\mathrm{J} 2000} \\
(10)\end{array}$ & \\
\hline 1 & $\begin{array}{l}053707.64-691243.4 \\
05372839-6912170\end{array}$ & 18.5 & $\ldots$ & $\cdots$ & $\cdots$ & $\cdots$ & $\cdots$ & . & & XMM source \#4 from Haberl et al. (2001) (ACIS source clipped) \\
\hline $\begin{array}{l}2 \\
3\end{array}$ & $\begin{array}{l}503728.39-691217.0 \\
053728.90-690457.9\end{array}$ & 4.3 & $\cdots$ & $\ldots$ & $\cdots$ & $\ldots$ & $\cdots$ & 84.373746 & -69.082619 & $\begin{array}{l}X M M \text { source seen in Fig1 of Haberl et al. (2001) } \\
\mathbf{T}^{\mathrm{C}}\end{array}$ \\
\hline 4 & $053736.30-690236.8$ & 4.8 & & & & & & 84.400018 & -69.042328 & $\mathrm{~T}$ \\
\hline 5 & $053742.64-690958.2$ & 3.2 & .. & .. & $\ldots$ & .. & .. & & & 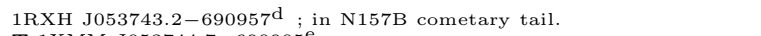 \\
\hline 6 & $053743.45-690901.8$ & 5.4 & .. & .. & $\cdots$ & .. & .. & 84.434784 & -69.149818 & T 1 XMM J053744.7-690905 \\
\hline $\begin{array}{l}7 \\
8\end{array}$ & $\begin{array}{l}053745.61-691011.1 \\
053746.01-690410.6\end{array}$ & $\begin{array}{l}3.2 \\
3.3\end{array}$ & $\cdots$ & $\cdots$ & $\cdots$ & $\cdots$ & $\cdots$ & $\begin{array}{l}84.438465 \\
84.439616\end{array}$ & $\begin{array}{l}-69.170448 \\
-69.070145\end{array}$ & $\begin{array}{l}\text { Main N157B cometary nebula } \\
1 \mathrm{RXH} J 053745.4-690402\end{array}$ \\
\hline 9 & $053747.41-691019.8$ & 0.6 & & ... & $\ldots$ & ... & ... & & & PSR J0537-6910: 1RXH J053747.3-691020, 1XMM J053747.8-691021 \\
\hline 10 & $053749.11-690508.7$ & 0.6 & WN6+B1Ia & 92 & ... & ... & & 84.454298 & -69.085632 & HDE 269891, R130, 1RXS J053803.8-690925 \\
\hline 11 & $053750.21-690424.0$ & 0.2 & & & & & CX19 & 84.459243 & -69.073425 & R103F, foreground M star; LMC 290 (Sasaki et al. 2000) \\
\hline 12 & $053751.63-691021.4$ & 2.3 & .. & .. & .. & .. & & 84.464840 & -69.173256 & T 1RXH J053752.0-691024 \\
\hline 14 & $\begin{array}{l}053753.04-690943.6 \\
003754.39-690222.4\end{array}$ & 2.2 & $\ldots$ & & & & & 84.470616 & -69.162727 & T 1RXH J053752.8-690946 \\
\hline $\begin{array}{l}15 \\
16\end{array}$ & 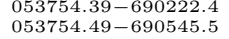 & $\begin{array}{l}2.1 \\
1.4\end{array}$ & $\cdots$ & $\cdots$ & $\cdots$ & $\cdots$ & CX20 & 84.475993 & -69.096123 & \\
\hline 17 & $053758.24-690921.5$ & 5.9 & & & & & & (2.... & & 1RXH J053757.9-690915 \\
\hline 18 & $053802.71-690259.2$ & 1.4 & $\cdots$ & $\cdots$ & & $\cdots$ & CX18 & & & \\
\hline $\begin{array}{l}19 \\
22\end{array}$ & $\begin{array}{l}5038099.92-685658.3 \\
053813.35-690104.3\end{array}$ & $\begin{array}{l}1.6 \\
3.9\end{array}$ & & & & $\ldots$ & $\cdots$ & 84.555015 & -69.016800 & $\begin{array}{l}\text { 1RXH J053810.1-685657, LMC } 291 \text { (Sasaki et al. 2000) } \\
\text { T }\end{array}$ \\
\hline 23 & $053813.97-690747.8$ & 0.1 & ... & ... & $\ldots$ & ... & CX14 & 84.558174 & -69.129936 & \\
\hline 27 & $053833.46-691158.7$ & 0.2 & 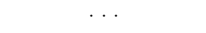 & .. & . & & & 84.639237 & -69.199684 & 1RXH J053832.4-691203 \\
\hline 28 & $053834.73-690533.5$ & 1.6 & .. & $\cdots$ & $\cdots$ & $\cdots$ & $\cdots$ & & & T Parker et al. (1998) \#32563 \\
\hline $\begin{array}{l}32 \\
33\end{array}$ & $\begin{array}{l}053836.52-685726.9 \\
053836.85-690812.2\end{array}$ & $\begin{array}{l}4.7 \\
2.9\end{array}$ & $\cdots$ & $\cdots$ & $\cdots$ & $\cdots$ & $\cdots$ & 84.650190 & -68.956398 & $1 \mathrm{RXH}-1053836.5-690810$ \\
\hline 34 & $\begin{array}{l}\begin{array}{l}5338366.85-690812.2 \\
053838.07-690543.2\end{array} \\
-\end{array}$ & $\begin{array}{l}2.9 \\
0.8\end{array}$ & $04.5: \mathrm{V} \ldots$ & $\cdots$ & 621 & $\cdots$ & $\ldots$ & 84.658047 & -69.095245 & 1RXH J053836.5-690810 \\
\hline 35 & $053839.57-690559.8$ & 1.2 & & & $720^{\mathrm{g}}$ & & & & & \\
\hline $\begin{array}{l}36 \\
39\end{array}$ & $\begin{array}{l}053840.21-690559.8 \\
053840.51-690600.8\end{array}$ & 0.2 & O3If/WN6-A & 99 & 767 & $\begin{array}{l}57 \\
67\end{array}$ & CX8 & & & Melnick 39 \\
\hline 40 & $053840.57-690556.7$ & 0.2 & WN6h & 100 & 786 & 71 & $\mathrm{CX} 6$ & 84.668894 & -69.099213 & R134 \\
\hline 41 & $053840.70-690557.0$ & 0.3 & & & 811 & 81 & ${ }^{2}$ & & & \\
\hline 42 & $053841.17-690600.9$ & 1.0 & $(\mathrm{O} 5 \mathrm{~V})$ & $\cdots$ & 827 & 129 & $\cdots$ & & & $T$ \\
\hline 43 & $\begin{array}{l}053841.19-690258.5 \\
003841.48-6905570\end{array}$ & 0.3 & $07 \mathrm{~V}$ & $\ldots$ & 861 & & $\mathrm{CX}_{3}$ & $\begin{array}{l}84.671778 \\
84672530\end{array}$ & -69.049530 & IRAS $05390-6904$ \\
\hline $\begin{array}{l}45 \\
46\end{array}$ & $\begin{array}{l}5038411.48-690557.0 \\
053841.49-690600.6\end{array}$ & $\begin{array}{l}0.3 \\
0.2\end{array}$ & $\begin{array}{l}\mathrm{O} 3 \mathrm{~V} \\
\mathrm{O} 3 \mathrm{~V}\end{array}$ & $\cdots$ & $\begin{array}{l}860 \\
863\end{array}$ & $\begin{array}{l}201 \\
203\end{array}$ & $\mathrm{CX} 3$ & 84.672530 & -69.099205 & MH 198 and ACIS 44 also nearby. \\
\hline 49 & $053841.56-690515.4$ & 1.8 & wN6 & 103 & 880 & & .. & & & R140b \\
\hline 50 & $053841.56-691015.4$ & 4.5 & & & & & & & & 1RXH J053842.4-691015 \\
\hline $\begin{array}{c}51 \\
52\end{array}$ & $053841.59-690513.4$ & $\begin{array}{l}0.6 \\
0.2\end{array}$ & $\mathrm{WC} 5+\mathrm{O} / \mathrm{WN} 6+\mathrm{O}$ & $101 / 102$ & 877 & $\ldots$ & CX10 & 84.673399 & -69.087212 & HD 269919 , blend of R140a1/a2 \\
\hline 53 & $\begin{array}{l}053841.61-690002.9 \\
05381.68-690624.8\end{array}$ & $\begin{array}{l}0.2 \\
1.1\end{array}$ & O5III & & 885 & 231 & & & & \\
\hline 54 & $053841.70-690613.1$ & 1.0 & O3III (f) & .. & 900 & 290 & .. & 84.674065 & -69.103676 & T; MH 283 also nearby. \\
\hline 62 & $053841.94-690607.6$ & 0.2 & $\mathrm{O} 3 \mathrm{III}(\mathrm{f})+\mathrm{O} 8$ & $\ldots$ & 912 & 320 & & . & & 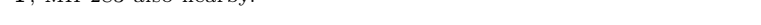 \\
\hline 67 & $053842.06-690602.2$ & 0.2 & $\mathrm{O} 3 \mathrm{~V}+\mathrm{O} 3-5 \mathrm{~V}$ & & & 354 & $\cdots$ & . & & R136 core \\
\hline 68 & $053842.06-690545.3$ & 0.3 & & $\cdots$ & 921 & 365 & .. & & .. & \\
\hline 69 & $\begin{array}{l}053842.06-690600.0 \\
0\end{array}$ & 0.1 & $(\mathrm{O} 5 \mathrm{~V})$ & $\cdots$ & 924 & 351 & $\cdots$ & & $\cdots$ & MH 372 also nearby. \\
\hline $\begin{array}{l}70 \\
73\end{array}$ & $\begin{array}{l}553842.09-690608.7 \\
053842.15-690555.4\end{array}$ & $\begin{array}{l}0.3 \\
0.4\end{array}$ & O3If/WN6-A & 105 & $\begin{array}{l}918 \\
922\end{array}$ & 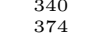 & $\mathrm{CX} 4$ & 84.675539 & -69.098694 & Melnick 42 ; ACIS 64 also nearby. \\
\hline 76 & $053842.22-690613.8$ & 1.2 & O4If + & & 917 & 339 & & 84.675916 & -69.104004 & T Melnick 37Wa \\
\hline 77 & $053842.26-690611.3$ & 0.6 & & & 933 & & & & & \\
\hline 78 & $053842.28-690601.4$ & 0.2 & O3V & & & 486 & $\cdots$ & & $\cdots$ & T R136 core \\
\hline 79 & $\begin{array}{l}053842.29-690603.4 \\
053842.29-690604.8\end{array}$ & $0.2 / 0.1$ & $\mathrm{WN} 5 \mathrm{~h} /(\mathrm{O} 3 \mathrm{~V})^{\mathrm{h}}$ & 106 & 937 & $\begin{array}{l}467 / 454 \\
465\end{array}$ & & & & R136a3/a6 + MH 451; blend in R136 core. \\
\hline 82 & $\begin{array}{l}053842.34-690458.1 \\
05384.29\end{array}$ & 0.1 & O6Iaf/WN & 107 & 952 & & CX11 & 84.676472 & -69.082802 & R139 \\
\hline $\begin{array}{l}83 \\
85\end{array}$ & $\begin{array}{l}053842.35-690602.8 \\
053842.42-690559.6\end{array}$ & $\begin{array}{r}0.1 / 0.2 \\
0.4\end{array}$ & WN5h/WN5h & $108 / 109$ & $\ldots$ & $\begin{array}{l}498 / 511 \\
505\end{array}$ & 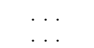 & $\ldots$ & (e & R136a1/a2 + MH 491 + others; blend in R136 core. \\
\hline 86 & $053842.46-690604.0$ & $0.4 / 0.2$ & $(\mathrm{O} 3 \mathrm{~V}) / \mathrm{O} 3 \mathrm{~V}^{\mathrm{h}}$ & $\ldots$ & & $537 / 517$ & $\ldots$ & ... & ... & Blend of these + MH $536+$ MH 559, in R136 core. \\
\hline 87 & $053842.48-690601.0$ & 0.2 & $\mathrm{O} 3 \mathrm{~V}$ & & 950 & 535 & & & & \\
\hline 88 & $053842.53-690605.4$ & 0.3 & & ( & & 548 & .. & & .. & \\
\hline 90 & $053842.60-690602.9$ & 0.0 & O3III(f) & $\cdots$ & & 592 & $\cdots$ & & $\cdots$ & MH 608 also nearby. \\
\hline $\begin{array}{l}93 \\
95\end{array}$ & $\begin{array}{l}053842.65-690556.3 \\
053842.65-609600.7\end{array}$ & $\begin{array}{l}0.2 \\
0.3\end{array}$ & $\begin{array}{l}(\mathrm{O} 5 \mathrm{~V}) \\
\mathrm{O} 7 \mathrm{~V}(\mathrm{f})\end{array}$ & $\cdots$ & 978 & $\begin{array}{l}620 \\
603\end{array}$ & $\cdots$ & & $\cdots$ & ACIS 97 also nearby. \\
\hline 96 & $\begin{array}{l}\begin{array}{l}538342.65-690600.7 \\
053842.71-690601.9\end{array} \\
-1\end{array}$ & 0.4 & O3III(f) & & & 602 & & & & Blend. \\
\hline 98 & $053842.76-690606.8$ & 0.4 & & & & 623 & & $\cdots$ & & \\
\hline
\end{tabular}


TABLE 5-Continued

\begin{tabular}{|c|c|c|c|c|c|c|c|c|c|c|}
\hline \multirow{2}{*}{\multicolumn{2}{|c|}{$\frac{\text { Source }}{\mathrm{CXOU} \mathrm{J}}$}} & \multirow{2}{*}{$\begin{array}{l}\operatorname{Sep}^{\prime} \mathrm{n}^{\mathrm{a}} \\
\left({ }^{\prime \prime}\right) \\
(3)\end{array}$} & \multirow{2}{*}{$\begin{array}{l}\text { Spectral Type }{ }^{\mathrm{b}} \\
\text { (4) }\end{array}$} & \multirow{2}{*}{$\begin{array}{c}\text { BAT99 } \\
(5)\end{array}$} & \multirow{2}{*}{$\begin{array}{c}\text { P93 } \\
(6)\end{array}$} & \multirow{2}{*}{$\begin{array}{c}\text { MH94 } \\
(7)\end{array}$} & \multirow{2}{*}{$\begin{array}{c}\text { PPL02 } \\
(8)\end{array}$} & \multicolumn{2}{|c|}{ 2MASS Coordinates } & \multirow{2}{*}{$\begin{array}{c}\text { Other match or other name; comments } \\
\text { (11) }\end{array}$} \\
\hline & & & & & & & & $\begin{array}{l}\alpha_{\mathrm{J}} 2000 \\
(9)\end{array}$ & $\begin{array}{c}\delta_{\mathrm{J} 2000}(10) \\
(10)\end{array}$ & \\
\hline 99 & $053842.76-690603.3$ & $0.1 / 0.5 / 0.3$ & (O5V)/WN9ha/O3V & 111 & 985 & $657 / 637 / 666$ & & ... & $\cdots$ & R136b; blend in R136 core. \\
\hline 102 & $053842.89-690604.9$ & & WN5h & 112 & 998 & & $\mathrm{CX} 2$ & & & R136c \\
\hline 103 & $053842.90-690610.0$ & 1.4 & $\mathrm{O} 3 \mathrm{III}(\mathrm{f})$ & & 1013 & 716 & & ( & . & T Melnick $35 \mathrm{~N}$ \\
\hline 105 & $053842.98-690601.3$ & 0.3 & 的 & $\cdots$ & 1001 & 711 & & & . & $\pi$ \\
\hline 108 & $053843.04-690603.4$ & 0.7 & O3III (f) & $\cdots$ & 1023 & 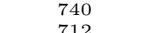 & $\cdots$ & $\cdots$ & . & $\mathbf{T}$ \\
\hline $\begin{array}{l}111 \\
113\end{array}$ & $\begin{array}{l}055843.08-690065.0 \\
053843.16-690601.8\end{array}$ & $\begin{array}{l}0.4 \\
0.2\end{array}-10$ & $\mathrm{O} 3 \mathrm{~V}$ & $\cdots$ & 1026 & $\begin{array}{l}712 \\
744\end{array}$ & & & & \\
\hline 114 & $053843.17-690614.5$ & 0.2 & O3If/WN6-A & 114 & 1029 & 742 & & 84.680012 & -69.104057 & Melnick 35 \\
\hline 115 & $053843.17-690547.0$ & 0.6 & O3If/WN6-A & 113 & 1018 & 728 & $\cdots$ & 84.679650 & -69.096329 & Melnick 30 \\
\hline $\begin{array}{l}119 \\
125\end{array}$ & $\begin{array}{l}053843.39-690542.3 \\
053843.69-690547.7\end{array}$ & $\begin{array}{l}0.9 \\
0.1\end{array}-1$ & $\begin{array}{l}\text { (O5V) } \\
\text { O3V }\end{array}$ & & $\begin{array}{l}1034 \\
1080\end{array}$ & $\begin{array}{l}748 \\
815\end{array}$ & $\cdots$ & & & \\
\hline $\begin{array}{r}125 \\
127\end{array}$ & $\begin{array}{l}055843.69-690547.7 \\
053843.86-690615.7\end{array}$ & $\begin{array}{l}0.1 \\
0.8\end{array}-12$ & $\mathrm{O} 3 \mathrm{~V}$ &. & $\begin{array}{l}1080 \mathrm{~g} \\
1076^{\mathrm{g}}\end{array}$ & 815 & $\cdots$ & . & & $\mathrm{T}$ \\
\hline 131 & $053844.13-690556.6$ & 0.0 & O3III (f) & & 1120 & 870 & $\mathrm{CX} 7$ & 84.684352 & -69.098747 & Melnick $33 \mathrm{Sa}$; $2 \mathrm{MASS}$ source is $\mathrm{Mk} 33 \mathrm{Na}+33 \mathrm{Sa}$. \\
\hline 132 & $053844.25-690605.9$ & 0.0 & WN5h & 116 & 1134 & 880 & CX5 & 84.684357 & -69.101624 & Melnick 34 \\
\hline 133 & $053844.30-690554.6$ & 0.2 & $\begin{array}{l}\text { O3If } \\
\text { BoIa }\end{array}$ & & 1140 & 887 & CX9 & 84.684352 & -69.098747 & Melnick $33 \mathrm{Na}$; $2 \mathrm{MASS}$ source is $\mathrm{Mk} 33 \mathrm{Na}+33 \mathrm{Sa}$. \\
\hline $\begin{array}{l}148 \\
152\end{array}$ & $\begin{array}{l}0358451.69-690622.3 \\
053851.79-69098.5\end{array}$ & $\begin{array}{l}0.2 \\
1.4\end{array}$ & Bora & $\cdots$ & 1257 & $\cdots$ & CX15 & & -69.106178 & $\begin{array}{l}\text { Melnick } 12 \\
\text { 1RXH J053851.7-690907 }\end{array}$ \\
\hline 153 & $053852.47-690611.0$ & 1.7 & & & & & & & & T Parker et al. (1998) \#33218 \\
\hline 154 & $053853.38-690200.6$ & 0.1 & WN6h & 118 & 9037 & $\cdots$ & CX17 & 84.722448 & -69.033546 & HD $38282, \mathrm{R} 144$, ROSAT source $^{\mathrm{i}}$ \\
\hline 156 & $053857.07-690605.5$ & 0.0 & $\mathrm{WN} 6(\mathrm{~h})$ & 119 & 1788 & & $\mathrm{CX} 12$ & 84.737775 & -69.101540 & HD 269928, R145 \\
\hline 167 & $053915.85-685752.5$ & 2.2 & & & & & & & & 1RXH J053915.9-685750 \\
\hline 171 & $053943.92-690938.1$ & 3.2 & & & & & & 84.930560 & -69.160568 & \\
\hline 176 & $053958.59-690610.1$ & 9.0 & & & & & & & & 1XMM J054000.1-690614: ACIS $176+177$ \\
\hline 177 & $054001.87-690618.7$ & 1.4 & $\cdots$ & $\cdots$ & & $\cdots$ & $\cdots$ & & $\cdots$ & MDM $77^{\mathrm{j}}, 1 \mathrm{XMM} J 054000.1-690614:$ ACIS $176+177$ \\
\hline 178 & $054006.14-690152.4$ & 6.7 & ... & $\cdots$ & & .. & .. & & ... & 2RXP J054007.4-690153k : ACIS $178+179$ \\
\hline 179 & $054008.59-690202.4$ & 11.5 & $\cdots$ & . & $\cdots$ & $\cdots$ & $\cdots$ & $\cdots$ & . & 2RXP J054007.4-690153: ACIS $178+179$ \\
\hline
\end{tabular}

aSource separations are with respect to (in order of availability) MH94, 2MASS, or the first entry in the "other match" column.

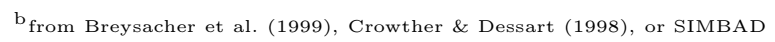

${ }^{\mathrm{c}} \mathbf{T}$ means match is tentative, usually due to counterpart/source separation $>0.5^{\prime \prime}$ for R136 sources or separation at the edge of the $90 \%$ Chandra PSF contour for sources farther off-axis.

d "1RXH" sources are from the ROSAT Source Catalog of Pointed Observations with the High Resolution Imager produced by the ROSAT Science Team in 2000.

e "1XMM" source is from the XMM Serendipitous Source Catalog Version 1.0.1 produced by the XMM-Newton Survey Science Centre Consortium in 2003.

f "1RXS" source is from the ROSAT Bright Source Catalog (Voges et al. 1999).

g From the full catalog Parker (1992); too faint to appear in Parker (1993).

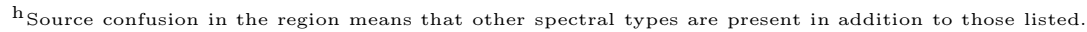

${ }^{\mathrm{i}}$ Position consistent with both 1RXH J053852.8-690158 and 1RXH J053853.4-690204.

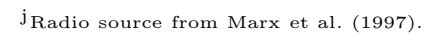

k "2RXP” source is from the Second ROSAT (PSPC) Source Catalog of Pointed Observations, produced by the ROSAT Consortium in 2000. NotE.- "BAT99" = Breysacher et al. (1999); "P93" = Parker (1993); "MH94" = Malumuth \& Heap (1994); "PPL02" = Portegies Zwart et al. (2002). Sequence numbers for tentative ACIS sources (from Table 2)
are shown in italics. Counterparts have been omitted where source confusion made it difficult to assign a one-to-one match between an ACIS source and a counterpart. This is particularly true in the R136 core -
Parker (1993) and 2MASS counterparts are generally omitted in this region. Parker (1993) and MASS counterparts are generally omitted in this region. 